\title{
GAMMA-RAY SCANNING TECHNIQUES FOR FAST BREEDER REACTOR SAFETY STUDIES
}

\author{
L. A. Beach and A. G. Pieper \\ Nuclear Reactions Branch \\ Radiation Division \\ and \\ M. P. Young \\ Nuclear Instrumentation Branch \\ Radiation Division
}

July 12,1961

\section{U. S. NAVAL RESEARCH LABORATORY \\ Washington, D.C.}




\section{DISCLAIMER}

This report was prepared as an account of work sponsored by an agency of the United States Government. Neither the United States Government nor any agency Thereof, nor any of their employees, makes any warranty, express or implied, or assumes any legal liability or responsibility for the accuracy, completeness, or usefulness of any information, apparatus, product, or process disclosed, or represents that its use would not infringe privately owned rights. Reference herein to any specific commercial product, process, or service by trade name, trademark, manufacturer, or otherwise does not necessarily constitute or imply its endorsement, recommendation, or favoring by the United States Government or any agency thereof. The views and opinions of authors expressed herein do not necessarily state or reflect those of the United States Government or any agency thereof. 


\section{DISCLAIMER}

Portions of this document may be illegible in electronic image products. Images are produced from the best available original document. 


\section{CONTENTS}

Abstract

Problem Status

iii

Authorization

iii

STATEMENT OF THE PROBLEM

PRESENT APPRAISAL OF THE ORIGINAL OBJECTIVES

SUMMARY OF THE PROJECT 2

TREAT REACTOR CHARACTERISTICS 4

GAMMA-RAY PINHOLE CAMERA

TRANSITION FROM PINHOLE CAMERA TO RADIATION SCANNING DEVICE

RADIATION SCANNING DEVICE

Drum

Detectors

Amplifiers

Oscilloscopes

Sweep and Frame Trigger Circuits

Scope Display

Cameras

System Check-Out and Alignment Procedures 20

Control System and Operating Procedure $\quad 22$

MEASUREMENTS WITH THE DRUM AT THE NRL REACTOR 24

Transmission Measurements $\quad 24$

Space Resolution $\quad 26$

Horizontal Slits $\quad 28$

MEASUREMENTS AT TREAT WITH THE MARK I SYSTEM 28

TEST MEASUREMENTS, EARLY 1960

PREDICTIONS AND RECOMMENDATION FOR A

MARK II SYSTEM

MEASUREMENTS, AUGUST 1960

Shield Modifications $\quad 37$

$\begin{array}{ll}\text { Static Tests } & 39\end{array}$

Transient Tests 48 
PREDICTIONS OF MARK II SYSTEM

VALUE OF DATA OBTAINED WITH THE MARK II SYSTEM

CONCLUSIONS

56

ACKNOWLEDGMENTS 56

APPENDIX A - Design and Fabrication of Mark I Drum 57

APPENDIX B - Optimum Drum Design 58

APPENDIX C - Statistical Criteria 62

APPENDIX D - Signal Intensity Calculation 67

APPENDIX E - Calculation of the Ratio of the Pin-in-Container Signal to the Container Signal

69 


\begin{abstract}
A Radiation Scanning Device was constructed to observe meltdown of fast breeder reactor fuel elements in the TREAT reactor by means of self gamma emission. Although the original desired specification had been to view natural uranium pins with a space resolution of $0.1 \mathrm{in}$. and a time resolution of 1 millisecond, the system had been designed to give the above space resolution, but the time resolution would be 5 milliseconds or longer depending on the signal intensity. The system failed to give satisfactory pictures because of low signal strength which gave poor contrast against high-strength background from the container required for safety reasons. Measurements indicated that a Mark II system could be constructed to view enriched pins in the standard container with a space resolution of 0.15 in. horizontally and 0.75 in. vertically with a time resolution of 5 milliseconds.
\end{abstract}

\title{
PROBLEM STATUS
}

This is the final report on the problem, which has been closed.

\section{AUTHORIZATION}

NRL Problem H04-19

Contract No. AT(11-1)-607

Manuscript submitted April 5, 1961. 


\section{GAMMA-RAY SCANNING TECHNIQUES \\ FOR FAST BREEDER REACTOR SAFETY STUDIES}

\section{STATEMENT OF THE PROBLEM}

In 1957 Argonne National Laboratory, as part of the Atomic Energy Commission program in the safety of fast breeder reactors, was planning the construction of a thermal reactor (TREAT or Transient Reactor Test Facility) at the National Reactor Test Site in Idaho. This reactor was to be capable of melting in a test chamber fuel elements of the type appropriate for fast reactors (except for enrichment). Initial studies were planned on the meltdown of dry pins with optical observations and post visual inspection. Later studies were to include immersion of the pins in liquid sodium, a typical coolant for fast breeder reactors. Since the initial presence of sodium would preclude any visual observations, considerations were given to observations of the fuel flow by means of nuclear radiation emanating from the fuel itself. It was proposed that, in principle, this radiation can be made to display the motion of the fuel using a pinhole camera technique.*

Preliminary discussions between personnel of ANL and NRL established the following desirable specifications of a system to observe the fuel motion. The system was to observe the melting of fuel pins approximately $16 \mathrm{in}$. long contained in a 4 in. by $4 \mathrm{in}$. test chamber in the center of the TREAT core, viewing a cross-sectional area 4 in. wide by $16 \mathrm{in}$. high through a $4 \mathrm{in}$. wide by $24 \mathrm{in}$. high slot in the core and reflector. Since it was planned to melt fuel pins of approximately 0.15 in. diameter which are normally spaced closely together, the space resolution was set as 0.1 in. or less. Since coolant flows may be up to $10 \mathrm{ft} / \mathrm{sec}$ and in view of the above space resolution, the time resolution was specified as 1 millisecond, if possible. The melting of fuel pins was to be affected by a reactor transient with a power rise following a period of as short as 5 milliseconds. However, slower transients were anticipated, depending on the needs of the program. Initial measurements were to be with single pins or a few placed in a row across the width of the test chamber but the eventual desire was to view a complete cluster of tightly packed fuel elements (approximately 90 elements).

Based upon these discussions, ANL requested NRL to submit a proposal for the development of a single gamma-ray pinhole camera for use in connection with TREAT. NRL submitted a proposalf for such a development program which resulted in Contract No. AT(11-1)-607 between the Chicago Operations Office of the AEC and NRL.

\section{PRESENT APPRAISAL OF THE ORIGINAL OBJECTIVES}

It is now clear that the original objectives for a gamma-ray device to observe fuel motion are unattainable with any reasonable system under the operating procedures of the meltdown experiments at the TREAT reactor. The proposed attainment of these objectives was based upon the assumption that an adequate intelligence could be obtained

\footnotetext{
*A preliminary discussion of this technique for this application is contained in a letter. from Bob Watt, Los Alamos Scientific Laboratory, to David Okrent, dated April 2, 1957. TLetter from G. A. Freund, ANI, to NRL dated June 6, 1957. $\ddagger$ NRL Proposal 7400-82:CVS:dh, dated July 11, 1957.
} 
from the fuel in strong contrast with signals from all background sources. Since this assumption is not valid, the effect of the actual conditions on the objectives and specifications of a gamma-ray device will be discussed.

In the letter giving a preliminary discussion of a pinhole camera, Bob Watt considered the fuel was heated to melting by a power surge which was then cut off completely. Then he computed the gamma-ray brightness of the fuel from fission product decay, neglecting all other gamma sources, although he admitted some may be useful. He also did not discuss any background effects except to mention that certain neutron effects could prove serious. He also assumed that the test chamber would be backed by a material black to gamma rays, such as lead or bismuth, to eliminate background signals from fuel behind the test chamber. He concluded that a gamma-ray pinhole camera could give pictures of television quality and frame rates, and further, that there were no serious problems in pushing the frame rate up to 1000 frames/sec except in low signal cases where statistical fluctuations in the signal may reduce the resolution attainable. His conclusions are acceptable under the limitation that the power surge is completely cut off and all observations are made after the reactor flux, particularly neutron flux, has gone to zero.

It was pointed out in the NRL proposal that with a transient of $5-\mathrm{ms}$ period, the amount of negative reactivity $(10 \%)$ to be inserted to terminate the transient would only reduce the power by a factor of 10 before the power curve would level off into one with an $80-\mathrm{sec}^{*}$ period due to delayed neutrons. It was therefore assumed that, in general, meltdown would occur (and observation start) before the signal from prompt fission gammas decreased to the level of decay product gamma rays. We now know that almost any material placed in the high neutron and gamma flux of a reactor core has a high gamma-ray brightness. Therefore, the test chamber cannot be backed by a material such as lead or bismuth and the system must not be able to view any part of the main core. The slot must extend entirely through the core and reflector, not just to the test chamber. Collimation must be placed between the system and the core so the system will not view any core material on the sides of the slot beyond the test section, consequently reducing the viewed width at the test section to about $2.5 \mathrm{in}$. In addition, the container required to insure no contamination of TREAT cannot be considered as only attenuating the pin signal but as a background of comparable strength. Therefore, the specified arrangement of natural uranium pins within a standard container provides essentially no contrast, whereas $6 \%$ enriched pins appear brighter than the container by no more than a factor of 2 . Also, as constructed, due to a change in the control rod drive mechanism, TREAT cannot provide transients with periods as short as $5 \mathrm{~ms}$. Normal operation results in periods of 200 to $300 \mathrm{~ms}$, and transients are temperature limited through the negative temperature coefficient of graphite. Thus a lower level of intelligence flow is obtained from the pin than anticipated, which coupled with the poor contrast of signal to background requires a drastic reduction in obtainable space and time resolutions.

\section{SUMMARY OF THE PROJECT}

The original proposal was for the development of a single gamma-ray pinhole camera and its use in connection with meltdown measurements at TREAT. Gamma rays passing through a pinhole would form an image of the test chamber on the sodium iodide screen. Fluorescent light from the screen would be focused by a fast lens on the cathode of an image orthicon tube. A low noise television chain with appropriate recording equipment was to record on film a reproduction of the optical image on the sodium iodide screen. Predictions based on gamma-ray considerations gave a space resolution of 0.10 to 0.15 in. With the image orthicons available at that time, the intensity of radiation from the pin

*The 80-sec period corresponds to the 55-sec half-life of the longest period in the

delayed neutrons. 
indicated enough light from the scintillation to give satisfactory pictures at 30 frames/ sec. If the new RCA intensifier image orthicon became available, it was expected that $180 \mathrm{frames} / \mathrm{sec}$ could be obtained. Since the dynamic range of an image orthicon is 20 (and probably considerably less when set for maximum resolution), a single system could only cover a portion of the intensity range of a transient. A second image orthicon and TV system would be required for complete coverage.

By the time contract negotiations had been completed in early 1958 , it appeared that a radiation scanning device might come closer to meeting the original specifications than a pinhole camera. Trial measurements with gamma-ray sources indicated that predictable space resolutions could be obtained with long collimating holes extending through a rotating drum scanning across a source. (Appendix A discusses design of a drum used in what was designated the Mark I system.) The space resolution of a scanning-type system is a function of the diameter of collimating hole, the diameter of the drum, and the distance from drum to object. (The effect of these three parameters on an optimum drum design is calculated in Appendix B.) Indications were that a scanning device could be constructed with a large number of collimating holes scanning across the test chamber that would have a space resolution of $0.15 \mathrm{in}$., a time resolution of 4 to $5 \mathrm{~ms}$, and a dynamic range of 50. In practice, the difficulty of fabricating these collimating holes through a highly attenuating medium was greater than expected. Measurements with the constructed device at the NRL Reactor indicated that spatial resolution was as predicted, but that the transmission of the collimating holes was low and nonuniform. When installed at TREAT, certain background terms, particularly those from fast neutron effects, were more important than estimated. This high background coupled with the lower signal from the slower transients, the poor transmission of collimating holes, and the low contrast of pin to container resulted in the system's failure to see a fuel pin even at peak power levels. Neutron shielding was added to the system and collimation was placed between the system and core so the system did not view the sides of the slot in the core. When this modified system still could not distinguish a pin from background, larger test collimating holes milled from solid brass plates (for greater neutron attenuation) were tried in place of holes through a drum and were able to see a $6 \%$ enriched pin above the high container signal under low-level steady-state operation. Observations were then made on plates of iron, zircaloy, graphite, and aluminum placed in the sample position to determine the sources of the large amount of container signal. Analysis of the data showed that the gamma rays from the container were largely due to thermal neutron capture, inelastic scattering of fast neutrons, and compton scattering of gamma rays.

It is shown in Appendix $C$ that to distinguish a pin signal from the container signal, taking into account the statistical fluctuations, the following criterion must be satisfied:

$$
\left[\left(\frac{\bar{N}_{s}^{\prime}}{N_{c}}\right)_{N_{s}^{\prime}}\right]^{1 / 2} \geq k U
$$

where $\bar{N}_{s}^{\prime}$ is the average number of gamma rays detected from the pin-in-container in the time to scan a horizontal resolution element, $\overline{\mathrm{N}}_{\mathrm{c}}$ is the average number of counts per view time when scanning across the container, $U$ is a constant dependent on the pulse-height spectra of the pin signal and container signal, and $\mathrm{k}$ is a statistical parameter which, if equal to 2, will insure that during $98 \%$ of the scans the pin signal will be discernible above the container signal. This equation clearly demonstrates that for low pin-to-container signal ratios, it is essential to have the magnitude of the pin signal $\left(\overline{\mathrm{N}}_{\mathrm{s}}^{\prime}\right)$ large.

An expression is derived in Appendix D which shows how the magnitude of a signal obtained through a collimating hole is directly proportional to the framing time and to the cube of both the horizontal and vertical space resolutions. Since the time resolution of the system could not be relinquished because of the contemplated fast transients 
and high flow rates, the space resolution had to be relaxed. Horizontal space resolution was at its maximum value because it was equal to the diameter of the pin. Therefore, a Mark II system with a vertical space resolution of twice the horizontal space resolution of 0.15 in. was proposed. When viewing a pin in the standard container, the container attenuates the pin signal and the pin attenuates the container signal which originates from behind the pin. The ratio of pin-in-container to container is derived in Appendix $\mathrm{E}$ and is given by

$$
\frac{\mathrm{N}_{\mathrm{s}}^{\prime}}{\mathrm{N}}=\frac{1}{a} \frac{\mathrm{N}_{\mathrm{s}}}{\mathrm{N}_{\mathrm{c}}}-\frac{(\beta-1)}{\beta(a+1)}
$$

The ratio $\mathrm{N}_{\mathrm{s}} / \mathrm{N}_{\mathrm{c}}$ is the true pin signal to container ratio; $x$ and $\beta$ are respectively the attenuation factors of the pin signal by the container and of the container signal by the pin. It can be seen that for small ratios of $\mathrm{N}_{\mathrm{s}} / \mathrm{N}_{\mathrm{c}}$ the effect of the attenuation factors $a$ and $\beta$ on $\mathrm{N}_{\mathrm{s}} / \mathrm{N}_{\mathrm{c}}$ can be very serious. Therefore, it was proposed to increase $\mathrm{N}_{\mathrm{s}}$ by using enriched $\mathrm{U}^{235}$ fuel pins and reduce a by removing the graphite liner in the container and replacing the stainless capsule with a zircaloy capsule.

These results were incorporated in the design of a Mark II system. With a drum fabricated by milling slots in brass plates, it was predicted that natural uranium pins could be viewed for a factor of 5 down from the peak with a horizontal resolution of $0.15 \mathrm{in}$., a vertical resolution of $0.30 \mathrm{in.}$, and a time resolution of $5 \mathrm{~ms}$, provided that most of the graphite were removed from the test element and the stainless steel capsule surrounding the pin were replaced by one of zircaloy. When ANL rejected these proposed changes in the test chamber for safety reasons, they requested consideration of a Mark II system of the above horizontal and time resolution but with increased vertical resolution (0.5 to $1.0 \mathrm{in}$.). Test measurements at TREAT in August 1960 indicated that such a Mark II system would be able to see 3 to $6 \%$ enriched pins with 0.75 -in. vertical space resolutions. However, with the reduced usefulness of the data obtainable and a tight budget, it was decided to terminate the project.

\section{TREAT REACTOR CHARACTERISTICS}

The TREAT Reactor was constructed at the National Reactor Test Site during 1958 and became critical early in 1959. It is a thermal reactor fueled with a homogeneous mixture of enriched $\mathrm{UO}_{2}$ and graphite clad with zircaloy. Fuel stringers 4 in. by 4 in. in cross section contain $4 \mathrm{ft}$ of this fuel-graphite mixture plus $2 \mathrm{ft}$ of graphite on either end. Although the maximum core dimensions are $6 \mathrm{ft} 4$ in. $\mathrm{x} 6 \mathrm{ft} 4 \mathrm{in}$., a normal loading for transient operation (with a 4 in. wide by 24 in. high slot) is approximately $5 \mathrm{ft}$ in diameter. The central element is replaced by the test chamber and the remainder of the outer fuel positions are filled with graphite stringers (removable reflector). A permanent reflector of $2 \mathrm{ft}$ of stacked graphite surrounds the core. Biological protection to approximately $100 \mathrm{kw}$ steady-state operation is provided by a $5 \mathrm{-ft}$ shield of magnetite concrete. Transients are initiated (and may be terminated) by pneumatically driven (compressed air) control rods. Transients rise with a period of 100 to $200 \mathrm{~ms}$ or longer and are normally allowed to be temperature limited (negative temperature coefficient of graphite). Peak powers of greater than $1000 \mathrm{Mw}$ may be obtained with integrated power of $1000 \mathrm{Mw}$ sec. These correspond to a peak flux of $7 \times 10^{15} \mathrm{n} / \mathrm{cm}^{2}-\mathrm{sec}$ and an integrated flux of $4 \times 10^{15} \mathrm{n} / \mathrm{cm}^{2}$.

\section{GAMMA-RAY PINHOLE CAMERA}

The originally proposed system incorporated a gamma-ray pinhole 0.05 in. in diameter 2 meters from the test section and a 1-in. -thick sodium iodide screen 2 meters from 
the pinhole. Gamma rays from the test chamber would, after passing through the pinhole, form an image of the test chamber on the sodium iodide screen with unit magnification. The gamma rays incident upon the screen would cause it to fluoresce and this light would be focussed by a fast lens ( $f / 0.75)$ on the cathode of an image orthicon television pickup tube. A low-noise (Bendix-Friez) television chain and appropriate recording equipment would record a reproduction of the image of the test chamber for subsequent detailed study and analysis.

Calculations of predicted signal strength for the above system (given in Table 1) were made under the assumption that the meltdown was caused by a transient in which reactor power increased with a 5-ms period and the transient was shut down by insertion of $10 \%$ negative reactivity. It was assumed that meltdown occurred near the peak or shortly thereafter; therefore, the most important source of gamma radiation during the time of interest would be prompt fission gammas. It was estimated that with the insertion of $10 \%$ negative reactivity, the power would only decrease by a factor of 10 before leveling off into an $80-\mathrm{sec}$ period caused by delayed neutrons. It was also estimated that the power level would have to decrease another factor of 10 before the decay gammas from fission products would equal the prompt gammas; consequently, they would not be important until very late times. It was estimated by comparison with a somewhat similar arrangement then in operation at NRL that a gamma-ray brightness of approximately the level furnished by the decay gammas was necessary to achieve the desired spatial resolution, even with only $30 \mathrm{frames} / \mathrm{sec}$. The spatial resolution possible with this system was considered to be limited by three considerations: (a) pinhole characteristics, (b) geometrical optics at the sodium iodide screen, and (c) characteristics of the image orthicon tube.

The pinhole design and consequently its characteristics are the results of several compromises. For high intensity a large hole is desirable, but good space resolution requires a small hole. Therefore, it was assumed that the pinhole would be $0.05 \mathrm{in}$. in diameter (or square). A long collimating hole nearly eliminates radiation penetrating the material forming the pinhole but to avoid limiting the desired field of view, 4 in. $x$ $16 \mathrm{in.}$ at the test chamber, the pinhole was assumed to be made of two rectangular pyramid shaped voids with the sides of their bases in the ratio of 4 to 16 and their vertices placed together. Table 2a shows computed values of the intensity at the screen from a point source of gamma rays for pinholes formed by lead and tungsten alloy. Since the width at half intensity across the horizontal field of view is much narrower than the veritcal, the image formed by such a pinhole would be astigmatic. It was proposed to construct an insert forming the pinhole from a high-density metal, preferably tungsten alloy. Even considering the effect of neutrons, a tungsten alloy would still be the most effective material for the insert (as shown in Table 2b), but the resolution in a combined neutron and gamma field would probably be 0.15 to $0.30 \mathrm{in}$. In addition, the edges of the pinhole would probably have exhibited a high gamma-ray brightness from the combined gamma-ray and neutron flux which would have raised the general background irradiation of the screen.

The space resolution is further degraded for points away from the axis of the system by geometrical optics in the sodium iodide. Light going to the image orthicon makes an angle with the direction of the gamma ray creating the light; thus with a 1 -in. sodium iodide screen and a mirror on the side toward the pinhole, this effect would produce a maximum smearing of $0.05 \mathrm{in}$. for points $2 \mathrm{in}$. off the axis and $0.2 \mathrm{in}$. for points $8 \mathrm{in}$. off the axis. This effect is most troublesome when viewing points at the top and bottom of the test section.

An image orthicon tube has the characteristics of showing poor space resolution at low incident light levels. Insight into possible resolution utilizing a television chain looking at a NaI screen was obtained by taking radiographic pictures with the arrangement at NRL. Single objects $1 / 8 \mathrm{in}$. in diameter (either lead rods $3 / 4 \mathrm{in.}$ long or holes in a $3 / 4 \mathrm{in}$. lead plate) were recorded in a single frame $(1 / 30 \mathrm{sec})$ with a $\mathrm{Co}^{60}$ source providing a 
Table 1

Results of Intensity Calculation for a 5-Millisecond Period Viewed Through a Pinhole Camera

\begin{tabular}{|c|c|}
\hline Heat to melt uranium & $60 \mathrm{cal} / \mathrm{g}$ \\
\hline $\begin{array}{l}\text { Number of fissions to melt } \\
\text { uranium }\end{array}$ & $10^{13}$ fissions $/ \mathrm{g}$ \\
\hline Peak fission rate assumed ${ }^{*}$ & $10^{15}$ fissions $/ g-s e c$ \\
\hline $\begin{array}{l}\text { Peak gamma-ray source } \\
\text { strength in fuel }\end{array}$ & $10^{17} \mathrm{Mev}$ of $\gamma^{\prime} \mathrm{s} / \mathrm{cm}^{3}-\mathrm{sec}$ \\
\hline $\begin{array}{l}\text { Peak gamma-ray source } \\
\text { strength in sodium }\end{array}$ & $6 \times 10^{14} \mathrm{Mev}$ of $y^{\prime} \mathrm{s} / \mathrm{cm}^{3}-\mathrm{sec}$ \\
\hline $\begin{array}{l}\text { Peak gamma-ray source } \\
\text { strength in graphite reactor }\end{array}$ & $5 \times 10^{15} \mathrm{Mev}$ of $\gamma^{\prime} \mathrm{s} / \mathrm{cm}^{3}-\mathrm{sec}$ \\
\hline Peak Brightness of fuel pin & $\begin{array}{l}4 \times 10^{16} \mathrm{Mev} \text { of } \gamma^{\prime} \mathrm{s} / \mathrm{cm}^{2}-\mathrm{sec} \text { or } \\
3 \times 10^{15} \mathrm{Mev} \text { of } \gamma^{\prime} \mathrm{s} / \mathrm{cm}^{2}-\mathrm{sec}-\mathrm{sr}\end{array}$ \\
\hline $\begin{array}{l}\text { Brightness of sodium } 1 \mathrm{~cm} \\
\text { thick }\end{array}$ & $6 \times 10^{14} \mathrm{Mev}$ of $\gamma^{\prime} \mathrm{s} / \mathrm{cm}^{2}-\mathrm{sec}$ \\
\hline $\begin{array}{l}\text { Brightness of graphite reactor } \\
\text { behind test section }\end{array}$ & $10^{17} \mathrm{Mev}$ of $\gamma^{\prime} \mathrm{s} / \mathrm{cm}^{2}-\mathrm{sec}$ \\
\hline $\begin{array}{l}\text { Peak brightness of NaI screen } \\
\text { through } 0.05 \text {-in.-diameter } \\
\text { pinhole with screen } 4 \text { meters } \\
\text { from test section }\end{array}$ & $10^{9} \mathrm{Mev}$ of $\gamma^{\prime} \mathrm{s} / \mathrm{cm}^{2}-\mathrm{sec}$ \\
\hline $\begin{array}{l}\text { Brightness of fuel pin from } \\
\text { decay gamma rays from } \\
\text { fission products }\end{array}$ & $3.7 \times 10^{14} \mathrm{Mev}$ of $\gamma^{\prime} \mathrm{s} / \mathrm{cm}^{2}-\mathrm{sec}$ \\
\hline $\begin{array}{l}\text { Screen brightness from decay } \\
\text { gammas }\end{array}$ & $10^{7} \mathrm{Mev}$ of $\gamma^{\prime} \mathrm{s} / \mathrm{cm}^{2}-\mathrm{sec}$ \\
\hline
\end{tabular}

gamma-ray intensity at the screen of approximately $10^{7} \mathrm{Mev}$ of $\gamma^{\prime} \mathrm{s} / \mathrm{cm}^{2}$-sec. When pairs of $1 / 8$-in. holes in a 3/4-in. plate were viewed, they were resolved when the center to center distance was $5 / 16$ in. Since the NRL arrangement had a field of view of 24 in. compared to the proposed $16 \mathrm{in}$. for the pinhole camera, it was predicted that resolved distances could be decreased by the ratio 16 to 24 or to approximately $0.1 \mathrm{in}$. in diameter and $1 / 4$ in. center to center separation with this gamma level $\left(10^{7} \gamma / \mathrm{cm}^{2}-\mathrm{sec}\right.$ at screen) and time resolution $(1 / 30 \mathrm{sec})$.

It was predicted, therefore, that a pinhole camera system might give a spatial resolution of approximately $0.1 \mathrm{in}$. in the horizontal plane and somewhat worse in the vertical plane. The limits were determined by the amount of gamma radiation penetrating through the edge of the pinhole independent of intensity, and the poorer resolution possible if the intensity was too low because of effects from the image orthicon tube. It can now be stated that because data is desired when the neutron flux is still high, the best spatial resolution with a pinhole formed by a tungsten alloy would probably be 0.15 in. to $0.30 \mathrm{in}$.

The time resolution obtainable with the camera was limited by the intensity of radiation reaching the screen to $1 / 30 \mathrm{sec}$, at least with the image orthicons then available. 
Table 2

Computed Width of Intensity Pattern for a Pinhole Camera from a Point Source

\begin{tabular}{|c|c|c|c|c|c|c|}
\hline \multirow{2}{*}{$\begin{array}{c}\text { Percent of } \\
\text { Maximum } \\
\text { Intensity }\end{array}$} & \multicolumn{5}{|c|}{ Horizontal } & \multicolumn{4}{c|}{ Vertical } \\
\cline { 2 - 8 } & Lead & $\begin{array}{c}\text { Tungsten } \\
\text { Alloy }\end{array}$ & Brass & Lead & $\begin{array}{c}\text { Tungsten } \\
\text { Alloy }\end{array}$ & Brass \\
\hline \multicolumn{6}{|c|}{ a. Gamma Rays } \\
\hline 100 & 0.100 & 0.100 & 0.100 & 0.100 & 0.100 & 0.100 \\
50 & 0.132 & 0.124 & 0.146 & 0.225 & 0.190 & 0.290 \\
10 & 0.200 & 0.170 & 0.260 & 0.510 & 0.390 & 0.760 \\
5 & 0.230 & 0.194 & 0.310 & 0.630 & 0.480 & 0.960 \\
\hline \multicolumn{6}{|c|}{ b. Neutrons } \\
\hline 100 & 0.100 & 0.100 & 0.100 & 0.100 & 0.100 & 0.100 \\
50 & 0.220 & 0.170 & 0.180 & 0.600 & 0.380 & 0.435 \\
5 & 0.500 & 0.330 & 0.370 & 1.80 & 1.04 & 1.220 \\
\hline 10 & 0.640 & 0.395 & 0.450 & 2.30 & 1.32 & 1.560 \\
\hline
\end{tabular}

It was understood that if the intensifier image orthicon then being developed by RCA became available, scanning rates could be increased to $180 \mathrm{frames} / \mathrm{sec}$ with development of scanning and recording mechanisms.

The dynamic range of the image orthicon tubes were rather restricted (probably 4 to 20) and nearer the lower limit when set for maximum space resolution. It would not be possible, therefore, for a single image orthicon tube to follow the peak signal and the low intensity after the peak during which meltdown and flow would occur. Unless the light from the peak of the transient were stopped from reaching the image orthicon, it would not recover in time to record the low-level signals of most interest. Therefore, it was proposed to arrange a shutter to open quickly after the light level has fallen to a value which the image orthicon could record. A second image orthicon and television chain with an attenuator would have been required to view the screen if it were desired to see the test chamber during the peak of the transient.

\section{TRANSITION FROM PINHOLE CAMERA TO RADIATION SCANNING DEVICE}

Although the proposed pinhole camera with TV chain appeared capable of obtaining certain objectives, it had several limitations and disadvantages. The spatial resolution was predicted as a nominal 0.1 to 0.15 in. on axis, with the limitations of poorer resolution vertically than horizontally (astigmatic image from shape of pinhole) and additional smearing of resolution when viewing the top and bottom of the test chamber (from geometric optics in sodium iodide screen). The time resolution appeared limited by the intensity available and the current image orthicons to that obtainable with $30 \mathrm{frames} / \mathrm{sec}$, with the possibility of $180 \mathrm{frames} / \mathrm{sec}$ if the new RCA intensifier image orthicon tubes became available but requiring considerable development of recording apparatus. The dynamic range of the system seemed to be severely limited, particularly when the TV chain was adjusted for maximum space resolution. (Radiograph pictures obtained with 
the NRL arrangement showed that $1 \mathrm{in}$. of lead in a $\mathrm{CO}^{60}$ radiation field intense enough for optimum general illumination of the screen showed up as completely dark in the TV picture even though this amount of lead should only attenuate $\mathrm{Co}^{60}$ radiation in broad-beam geometry by a factor of 4 to 5 .) It had been estimated that the construction and installation of the pinhole and associated heavy shielding, the purchase of equipment (sodium iodide screen, lenses, image orthicons, TV chain, and recording apparatus) should cost approximately $\$ 125,000$ with an additional $\$ 50,000$ required for a second lens system, $\mathrm{TV}$ chain, and recording to increase the dynamic range covered.

By the time the contract for NRL to participate in the TREAT Program was completed early in 1958, an alternative system (Radiation Scanning System) had partially evolved that appeared capable of obtaining more of the stated objectives of the project than the pinhole camera. The analogy of the flying spot scanner of early television had started discussions which led to the new system. The development was supported by an intuitive feeling that long collimating holes in a good shielding block would give better space resolution than a pinhole arrangement. This alternative system proposed a rotating drum containing a large number of collimating holes to scan the test section. Gamma rays from the fuel pin that pass through these collimating holes would impinge on several NaI(TI) crystals. Signals from photomultipliers viewing these NaI crystals would, after amplification, intensity-modulate the $z$-axis of multigun oscilloscopes. Sweep traces from these oscilloscopes were to be recorded by a continuously moving film camera for later study and analysis. This system was estimated to be capable of a space resolution of $0.10 \mathrm{in}$. (uniform over entire test section), $250 \mathrm{frames} / \mathrm{sec}$, and a dynamic range of approximately 50 . The recognized limitations were the unknown method of fabricating a suitable drum with small collimating holes and the possible lack of intensity of signal from the fuel pin to give a statistically significant response with the above space and time resolution. The cost of constructing this scanning system was estimated as $\$ 50,000$ in comparison with the estimate of $\$ 125,000$ for the previous system, although it was clearly recognized that difficulties in fabrication of the drum could reduce the cost difference between the two systems.

Experimental checks were made that demonstrated predictable resolutions were obtainable with small collimating holes in a lead block. A 1300 -curie $\mathrm{Co}^{60}$ source was moved in a line perpendicular to the axis of a 0.033 -in. hole in a 14-in. -thick lead block. This source was composed of slugs $1 / 2 \mathrm{in}$. in diameter and was located $10 \mathrm{ft}$ from the block. The measured width of curves in traversing each slug of 0.67 in. could be accounted for by straight geometric optics of the arrangement, taking into account the diameter of the source and a reduction of hole length by one mean free path to compensate for gammarays penetrating the lip of the hole. Other runs with different distances from source to block and different hole sizes also gave predictable results. Therefore, it was apparent that a scanning device could be constructed if a suitable fabrication of a drum could be obtained.

The following design criteria were established for the radiation scanning device:

1. That the entire mechanical arrangement should be assembled on a cart that inserted into the north access hole of the TREAT Reactor.

2. Space resolution of approximately $0.1 \mathrm{in}$. which could be achieved with a collimating hole 15 mils in diameter and $23.5 \mathrm{in.}$ long, nearly the maximum allowable according to criterion 1.

3. Time resolution of 4 to $5 \mathrm{~ms}$, which required drum rotation of at least $1000 \mathrm{rpm}$ with 16 frames per revolution. This rotation required a mechanical strength and rigidity to withstand the centrifugal forces that limited fabrication techniques.

4. Attenuation of the drum for uncollimated radiation should be $10^{8}$ to $10^{9}$ to give a signal-to-noise ratio of at least a factor of 10 . 


\section{RADIATION SCANNING DEVICE}

On the basis of the previously described considerations, a Radiation Scanning Device was to be capable of observing meltdown and subsequent flow of fast breeder reactor type fuel pins during transient bursts of the TREAT reactor. Gamma rays from these fuel pins in the test section of the TREAT reactor were to pass through collimating holes in a rotating drum; signals from scintillation detectors behind the drum intensitymodulated two multigun oscilloscopes. The display of these signals on a raster pattern whose sweeps were triggered by signals picked up magnetically from the rotating drum were to be recorded on continuously moving film.

A block diagram of the gamma collimating system is shown in Fig. 1 and more detailed design drawings are shown in Fig. 2. The collimating holes in the rotating drum scan the gamma-ray picture emitted from the fuel test element similar to the way the flying-spot scanner does in a TV camera. However, to increase time response, the picture is divided into eight sections which are scanned simultaneously and there are eight parallel recording channels (one channel for each section). Trigger pulses which synchronize the eight rasters on the two four-gun oscilloscopes with the pattern made by the collimating holes as they scan the picture are taken from a magnetic pick-off system attached directly to the drum. Directly behind each section of collimating holes is a detector, consisting of a scintillating crystal attached to the face of a photomultiplier tube, which converts the gamma signal to light and then electrical pulses. These electrical pulses, at a rate proportional to the gamma intensity as the collimating hole sweeps the picture, are amplified and used to intensity-modulate the beam of its corresponding oscilloscope. The changing pattern is photographed by a high-speed continuous-strip movie camera. The controls of the system are such that it is manually started and checked except for the cameras, which are started remotely just prior to firing the reactor transient so that the picture is filmed only to cover the transient. Appropriate monitoring and fast go-no-go circuits are also used.

\section{Drum}

The collimating drum described in Appendix A scans the gamma radiation picture being emitted from the fuel element in the following manner. The 16-in,-high, 4-in.-wide gamma picture is divided into eight sections $2 \mathrm{in.} \mathrm{high} \mathrm{and} 4 \mathrm{in}$. wide. The eight sections are scanned simultaneously and each recorded individually on one of the eight recording channels. Each 2-in.-high section is described by ten evenly spaced horizontal lines that are scanned sequentially as the drum rotates to draw one frame of the picture. Therefore, for.each 2-in.-high section, there are ten holes with a vertical displacement of $0.2 \mathrm{in}$. from each other. There is an angular displacement between each of the collimating holes of 2.1 degrees to allow the sweep lines to be in time sequence as the drum rotates. Due to the ratio of the drum periphery and the horizontal viewing width, it is necessary to have eight groups of holes around the drum such that there will not be a long dead time between successive frames. Since each collimating hole views the picture twice for each drum revolution (once in each direction), there will be 16 frames of pictures for each drum revolution. An additional 1.35-degree angular spacing is placed after every tenth hole to provide identification spacing between frames. The arrangement of the collimating holes can be seen in the photograph of the drum in Fig. 3. There are eight vertical groups of ten holes each and eight angularly spaced groups for a total of 640 holes. The gear teeth milled in the base plate of the drum (see Fig. 3) which were used to position it angularly on the boring machine to initially bore the holes, are used to position the drum to record the sweep triggers, and are used to position the drum statically for tests where known angular position is required.

The drum is rotated on its vertical axis by a hydraulic motor as shown with its belt drive coupling in Fig. 3. The electric motor and hydraulic pump which powers the motor is located away from the drum cart with approximately $25 \mathrm{ft}$ of flexible hydraulic lines 

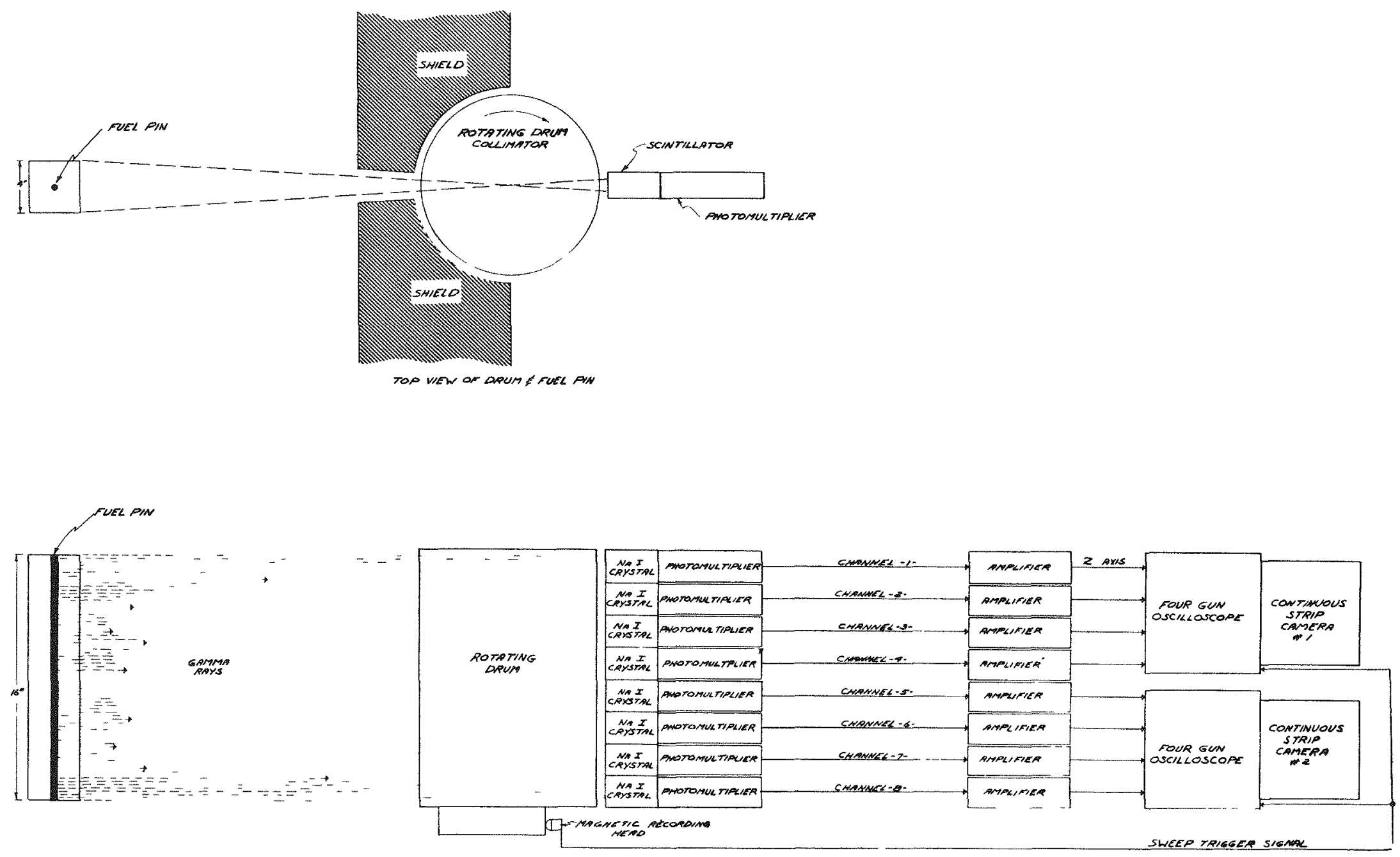

Fig. 1 - Schematic drawing of the Radiation Scanning Device 


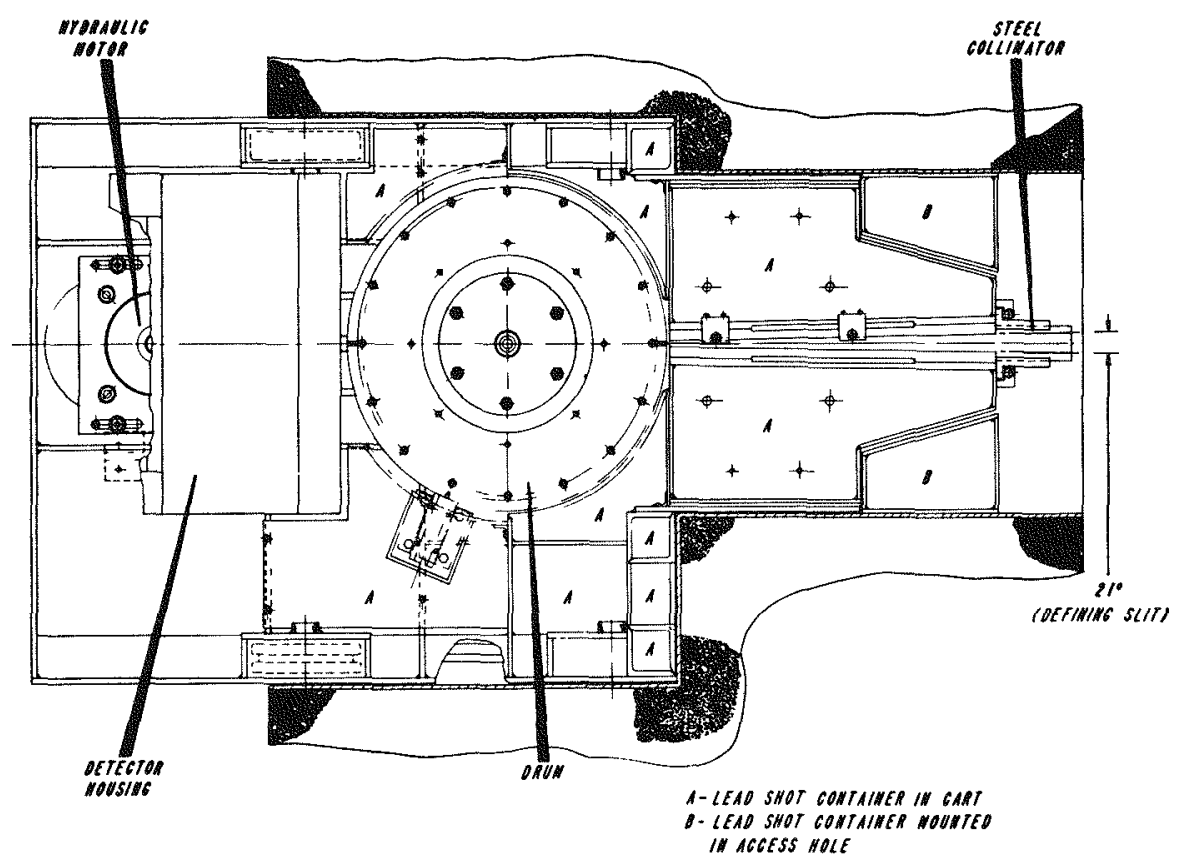

(a) Top view

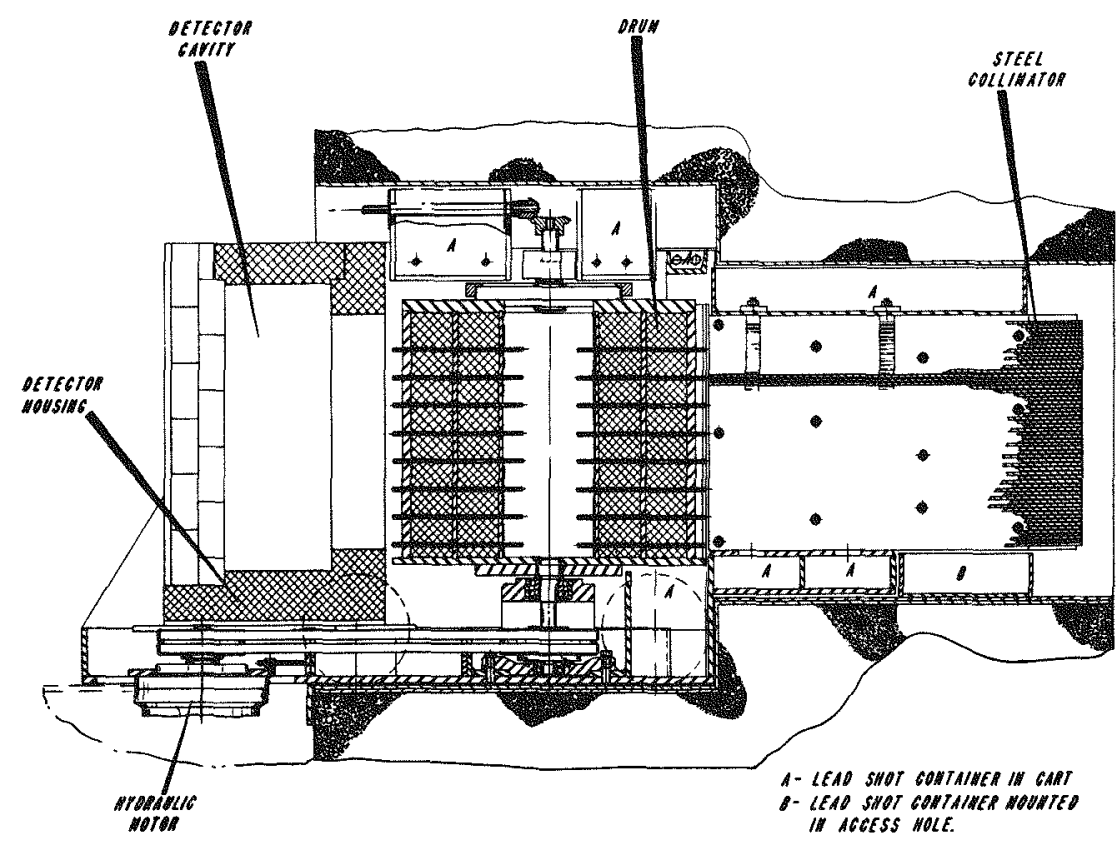

(b) Side view

Fig. 2 - Cart containing Radiation Scanning Device shown inserted into the TREAT reactor shield 


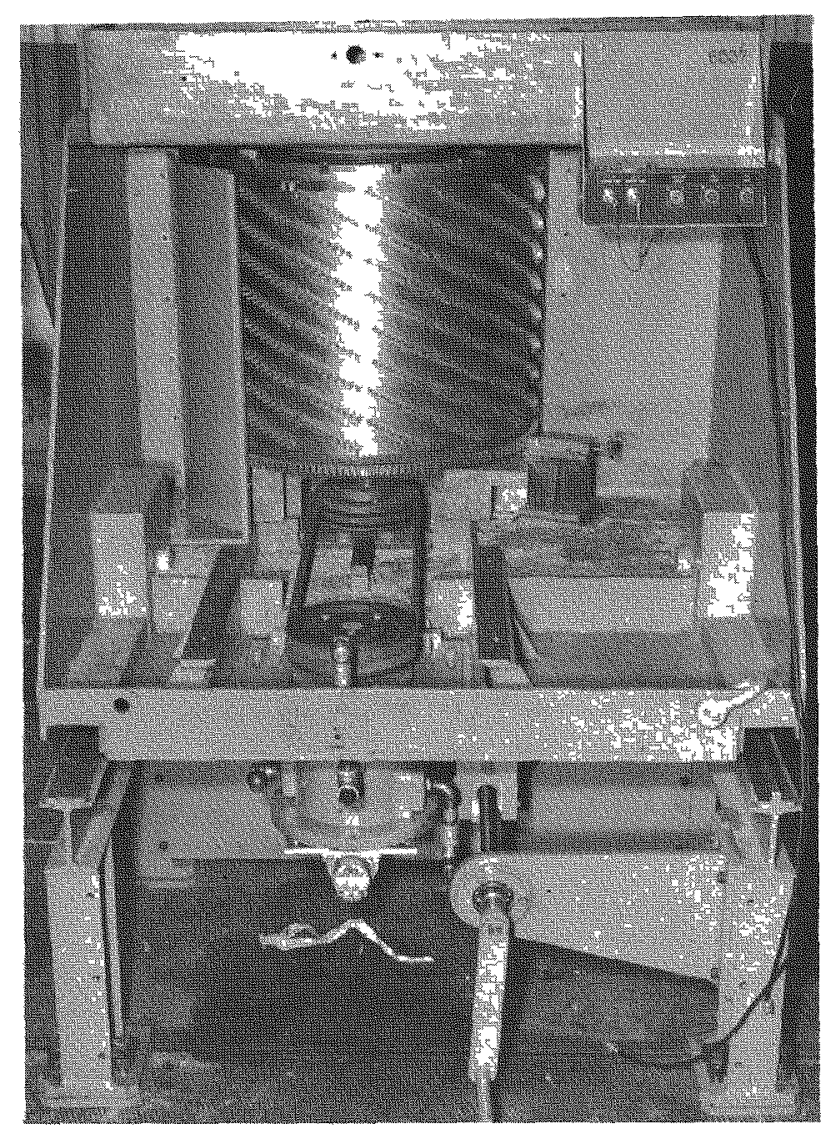

Fig. 3 - Rear view of cart showing arrangement of collimating holes

connecting them. This unit is shown in Fig. 4. The controls for this pump allow a continuously variable drum speed up to about $1400 \mathrm{rpm}$. The pump also has adjustable forced braking for the drum motor. The on-off control, with a preset speed, is wired for either local or remote control. A dc tachometer is attached to the drum motor shaft to provide both local and remote drum speed indication.

\section{Detectors}

The scintillating crystals are cemented to photomultiplier tubes to form the detectors which convert the gamma rays first to light and then to electrical signals. Harshaw NaI(Tl) crystals 1 in. $x 2$ in. $x 2$ in. and 3 -in. DuMont type 6363 photomultiplier tubes are used. Each of the eight crystals are placed in the collimated gamma beams such that each drum hole horizontally sweeps across the 1 -in. dimension, seeing a crystal depth of 2 in. The $2-\mathrm{in}$. height of the crystal matches a corresponding 2 -in. section of the fuel element. A cathode follower is included in each of the detectors to drive the approximately $150 \mathrm{ft}$ of coaxial signal cable which couples the detector in the reactor building to its amplifier located in the instrument trailer just outside the building. The assembled detectors including their Mumetal shields and cathode followers are shown in Fig. 5. AC coupling is used to connect the photomultiplier cathode follower and amplifiers. A $1.25-\mathrm{Mev}$ gamma ray will give rise to a pulse from the cathode follower of about $3 / 4$ volt amplitude and $1 \mu$ sec duration. The bleeder current for the photomultiplier high-voltage dividers is furnished by two Hamner Model N101 high-voltage power supplies capable of 10 ma output 


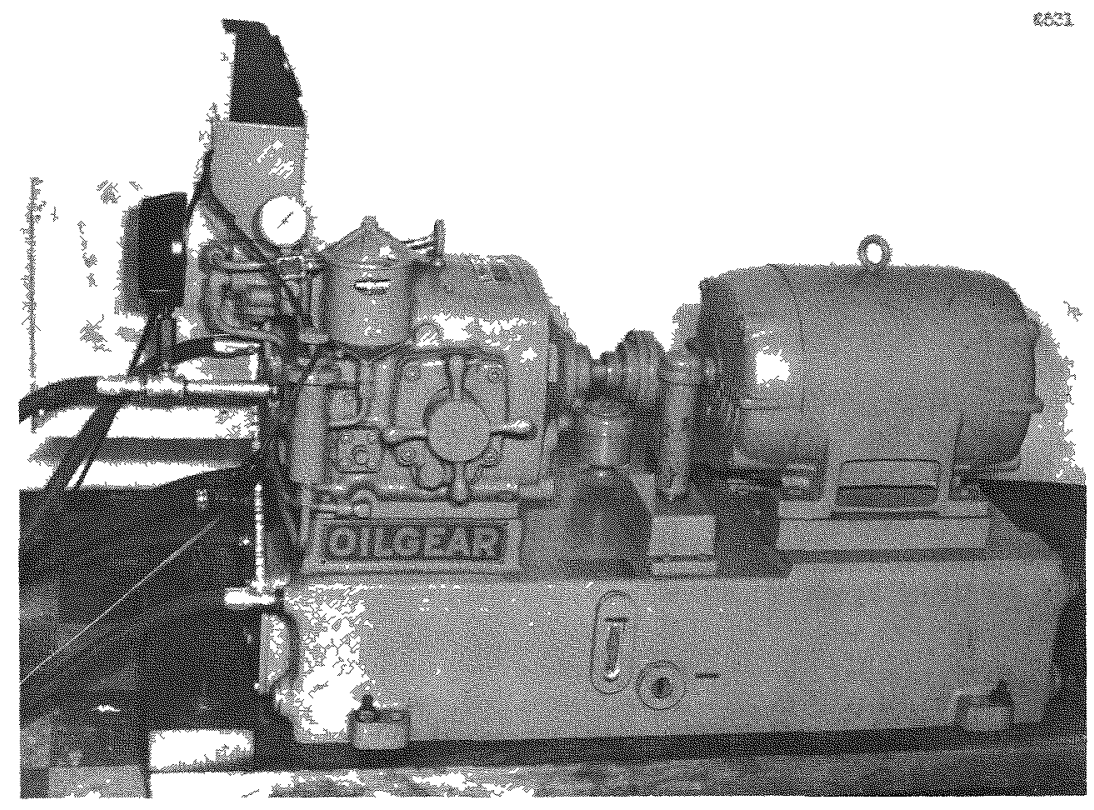

Fig 4 - Motor-pump set to drive the hydraulic motor shown in Fig 3

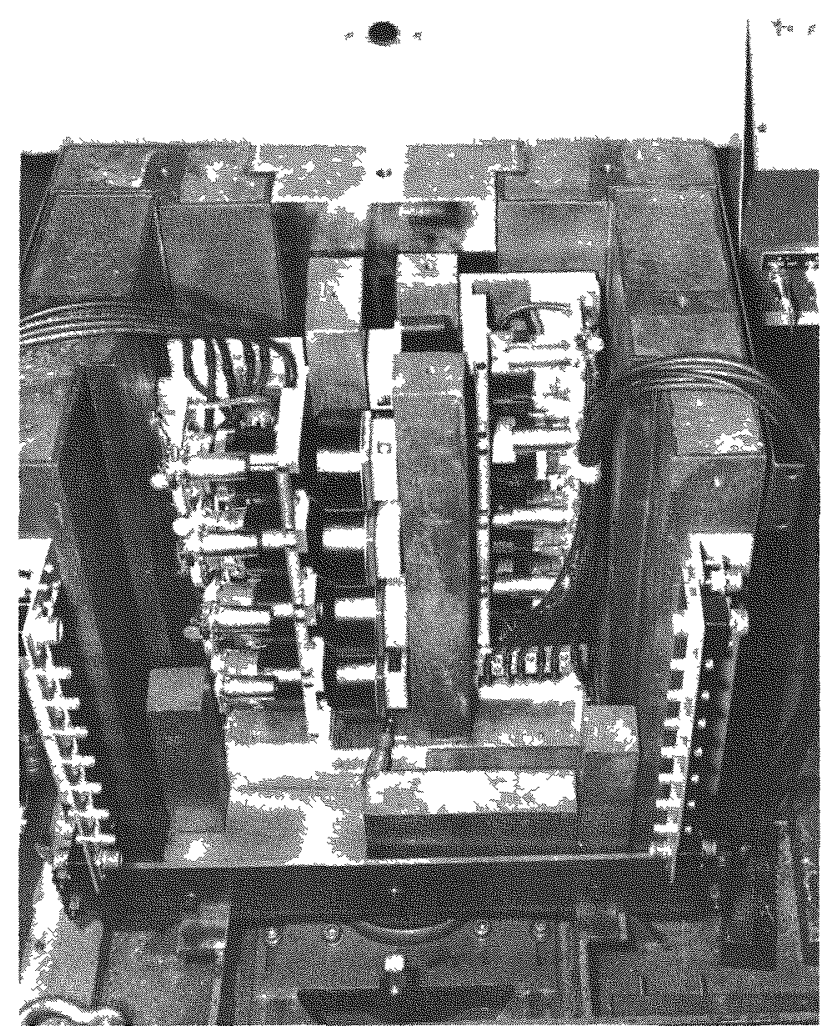

F1g. 5 - Rear view of detector cavity showing the interlocking lead slabs 
each. The high-voltage cabling is such that each supply furnished $4 \mathrm{ma}$ ( $1 \mathrm{ma}$ for each of four dividers). In this way the supply which would normally be the spare is used, but in emergency cases one supply could carry the full $8 \mathrm{ma}$. The same cabling arrangement is used for the cathode follower B+ using two Kepco type KR2-MC power supplies which supply $32 \mathrm{ma}$ each at $+250 \mathrm{v}$ dc. These supplies also furnish $\mathrm{B}+$ power to the go-no-go system.

\section{Amplifiers}

The eight amplifiers used (one for each detector) are the standard plug-in units of the oscilloscopes normally used for vertical amplification of the scope beam. These ac-dc amplifiers can be seen in Fig. 6. In this system the amplifiers are switched in the ac position, which has a response from $10 \mathrm{cps}$ to $100 \mathrm{kc}$. The gains of the amplifiers are individually set such that a single pulse from the detector caused by a $2.0=\mathrm{Mev}$ gamma will be sufficient to fully intensify the scope beam. The individual adjustment of the amplifiers also allows for the variation in gains of the photomultipliers and efficiencies of the crystals. The circuitry in the amplifiers has been modified to include pulse clippers in order to keep the gain high enough to include pulses arising for lower energy gammas and yet not give such a large output for the higher energy gamma signals that the scope would bloom or be difficult to keep in focus.

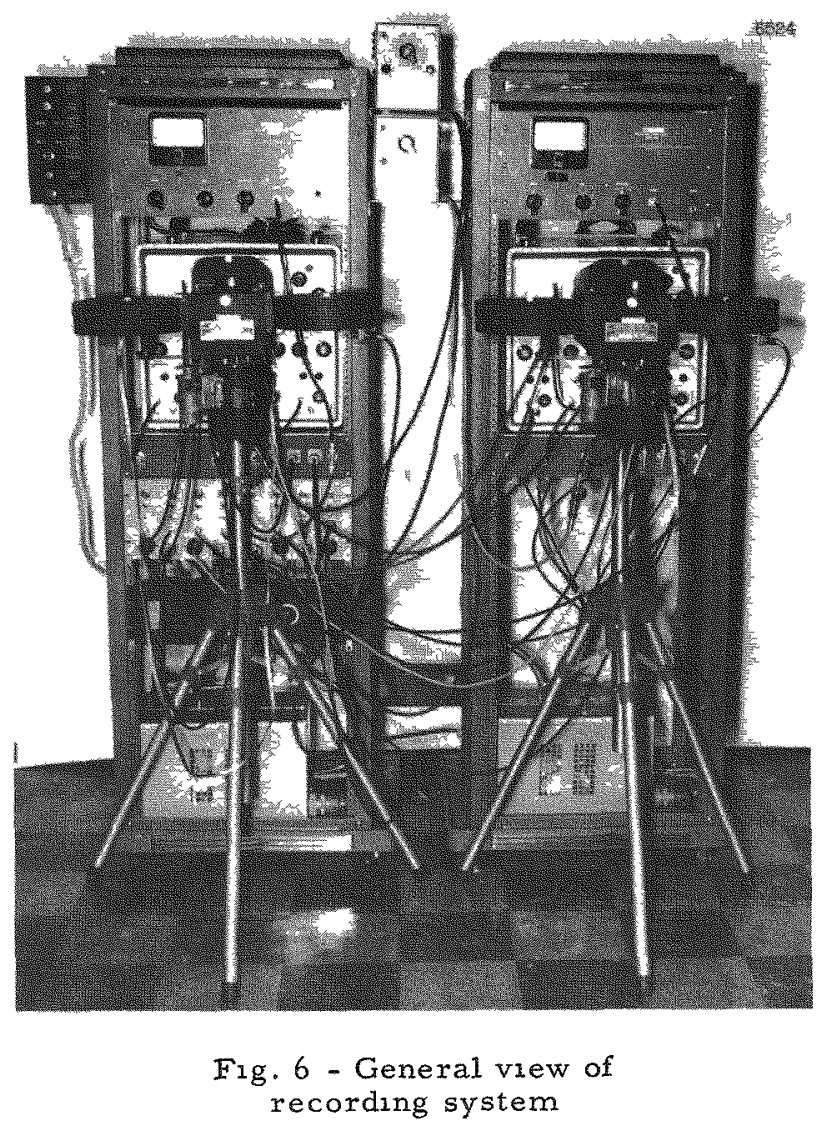




\section{Oscilloscopes}

Two Electronic Tube Corporation Model K-470 four-channel oscilloscopes are used to provide the display for photographing of the eight simultaneously operating channels. The vertical and horizontal sweep circuits of the oscilloscope have been modified to produce a two-dimension raster. The raster is synchronized with the gamma picture as swept by the collimating drum by triggering the horizontal and vertical sweeps from two magnetic pick-offs taken directly from the drum. The gamma detector signal intensity modulates the oscilloscope beam as it sweeps out the raster to form a picture for photographing. A multislope raster is generated for the oscilloscope display to facilitate the assembly of the separate picture sections on each scope onto a single film. This display is described under a separate heading. These sweep circuits were built on plug-in chassis of the oscilloscopes which are shown in Fig. 6. The slope, position, and amplitude controls of the sweeps are brought out on the sides of the oscilloscope because of the density of control knobs already on the front panel. The power supplies for the oscilloscopes are in the bottom of the instrument racks and can also be seen in Fig. 6 .

\section{Sweep and Frame Trigger Circuits}

The triggers for the frame and line-sweep circuits are obtained from the rotating drum by two magnetic reading heads shown in Fig. 7. The reading heads will give a satisfactory signal with a gap between the head and the magnetic dispersion coating on the drum of between 1 and 3.5 mils. The gap width can be easily adjusted by an Allen-head screw and feeler gage as shown in Fig. 8. However, with the degree of balance obtained for the drum, there is practically no need for readjustment after the initial setting. Figure 9 shows the two heads and amplifiers mounted between two shielding boxes which will be filled with lead shot. Figure 10 is a close-up of a transistor amplifier used to amplify the signal from the reading heads to a satisfactory level to trigger the sweep circuits. Figure 11 shows the power supply for these amplifiers.

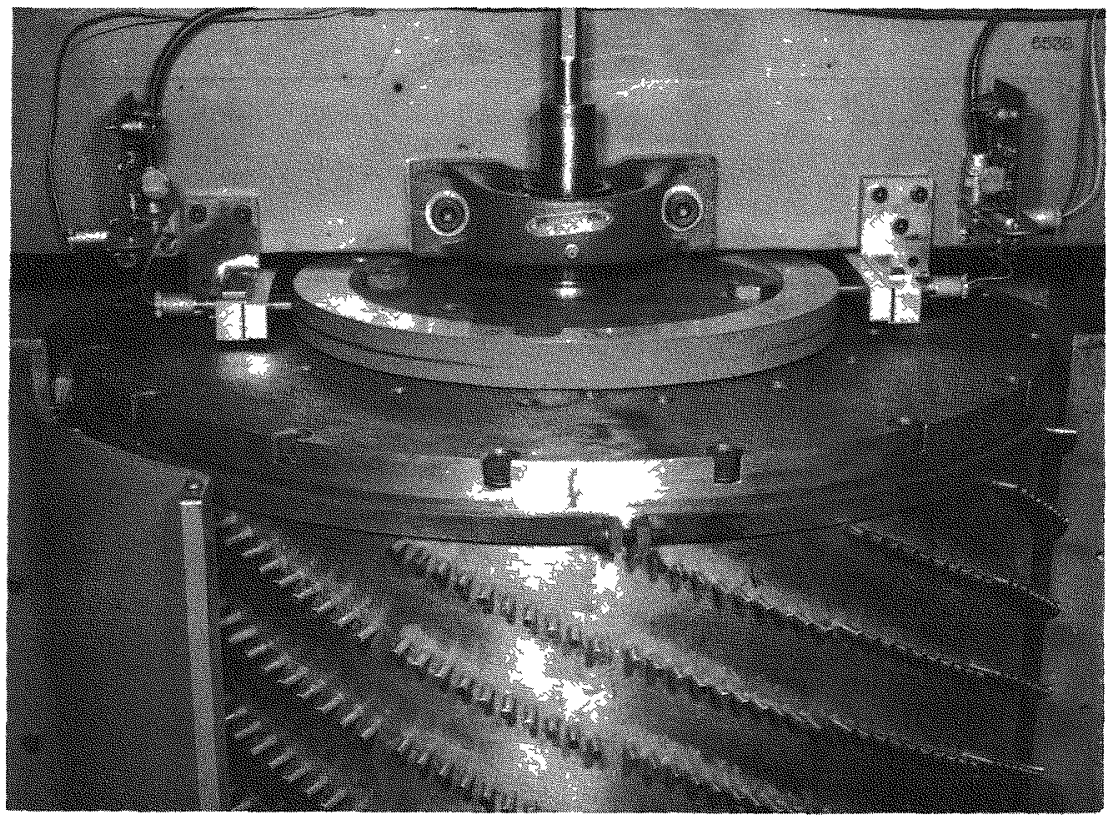

Fig. 7 - View of top of drum showing magnetic reading heads 


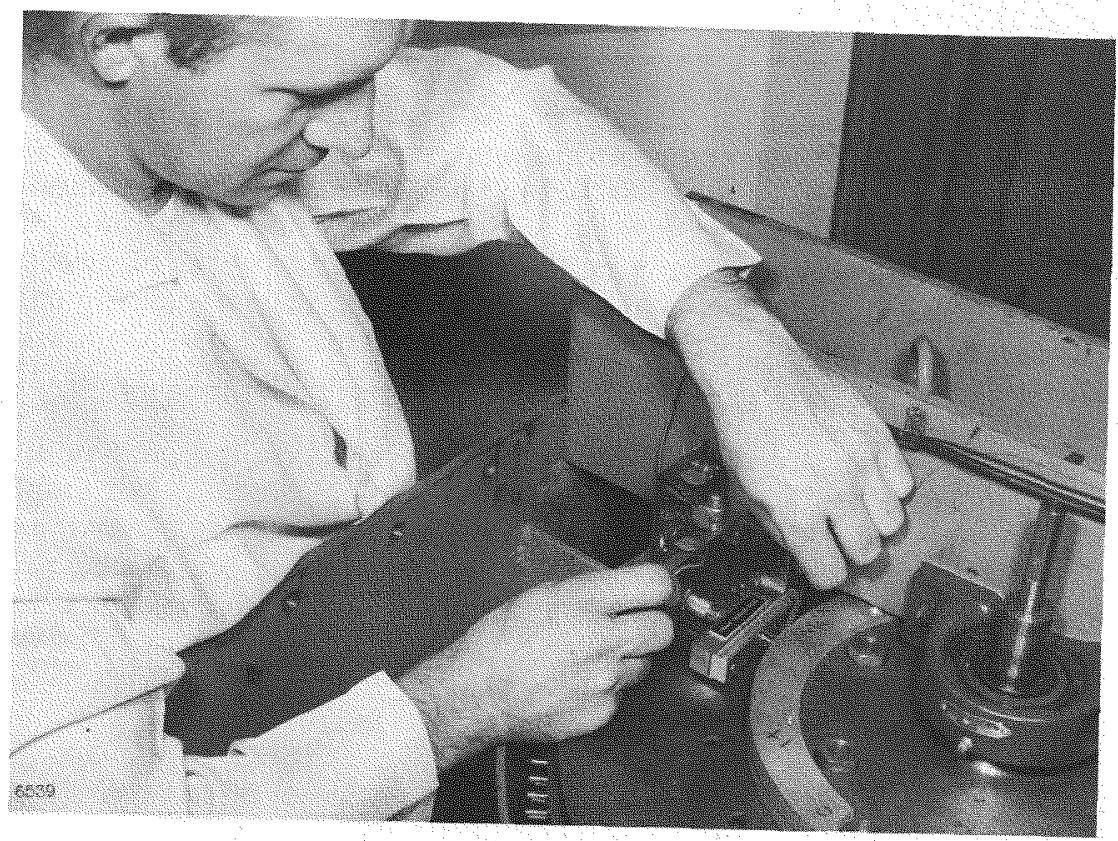

Fig. 8 - Adjustment of the frame trigger head

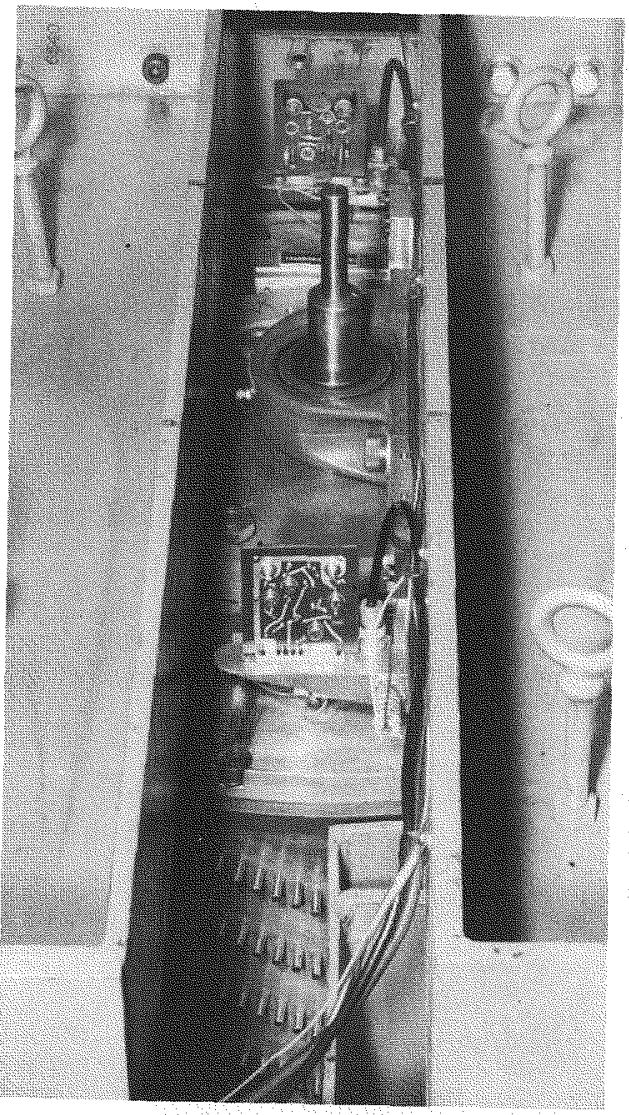

Fig. 9 - The two reading heads and their amplifiers 


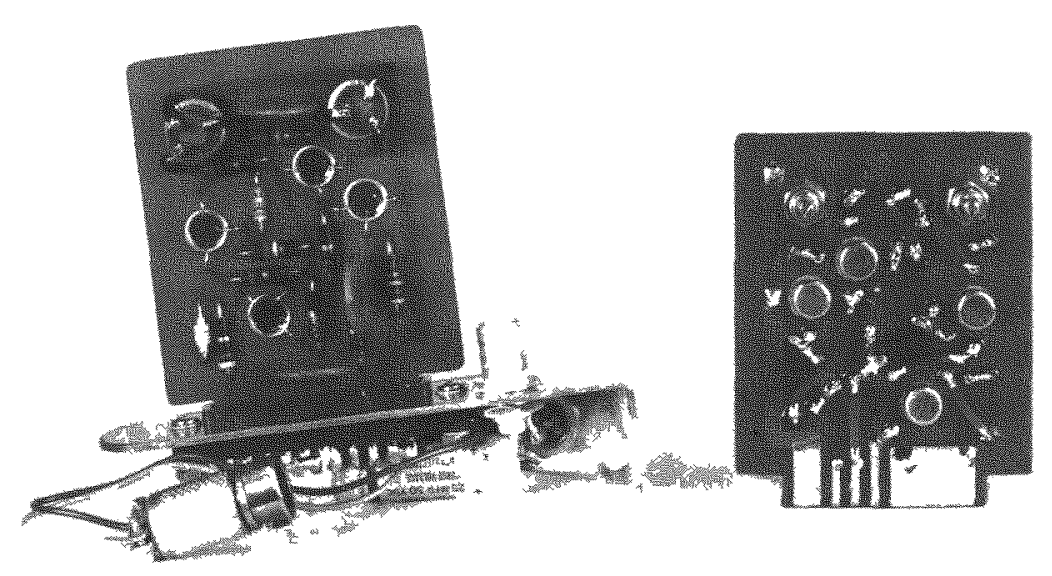

Fig. 10 - Mount and plug-in amplifiers for the reading heads

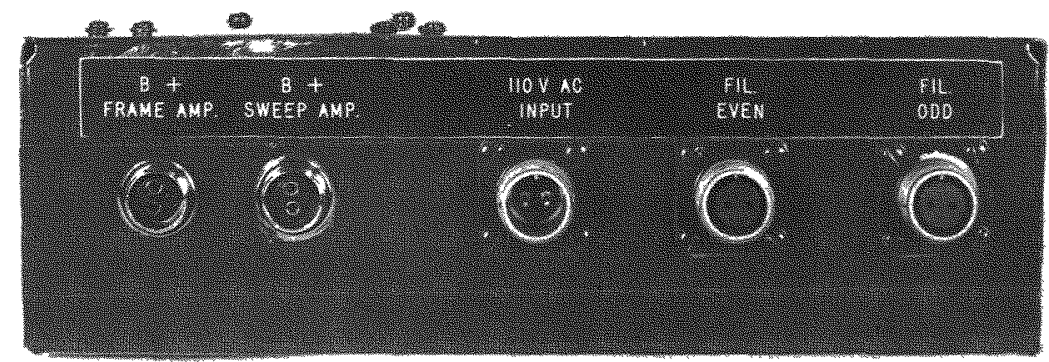

Fig. 11 - Power supply for the reading heads and amplifiers

Figure 12 shows the drum being positioned accurately to record statically a marker on the magnetic dispersion coating. With each vertical series of collimating holes centered in the forward shielding slits and the drum locked in position, the sweep line trigger head was pulsed. When the tenth vertical series of holes in each frame was centered in the slit, the frame trigger head was also pulsed. Shims machined to closely calculated thickness were then placed behind the mounts of the reading heads so that the triggers would start the frame and line sweeps just as the holes rotate into the vertical defining slit. Since the drum rotates clockwise, the shim behind the line trigger head advances it around the drum so that the trigger signal is simultaneous with the appearance of the corresponding holes in the defining slit. Similarly the shim behind the frame trigger head delays it so that the frame trigger signal occurs $50 \mu \mathrm{sec}$ (time interval for the frame sweep to get started) before the first vertical series of holes appears in the slit.

The frame and line sweeps have been set arbitrarily at 4000 and $400 \mu \mathrm{sec}$, respectively, which determines the drum rotation and film speed required for synchronization. A drum speed of $875 \mathrm{rpm}$ will give a 21 -degree rotation for each frame during the required $4000 \mu \mathrm{sec}$. The blanking time between frames (rotation of 1.5 degrees) is approximately 286 $\mu$ sec. The plug-in sweep circult furnished with the oscilloscopes was modified to furnish 


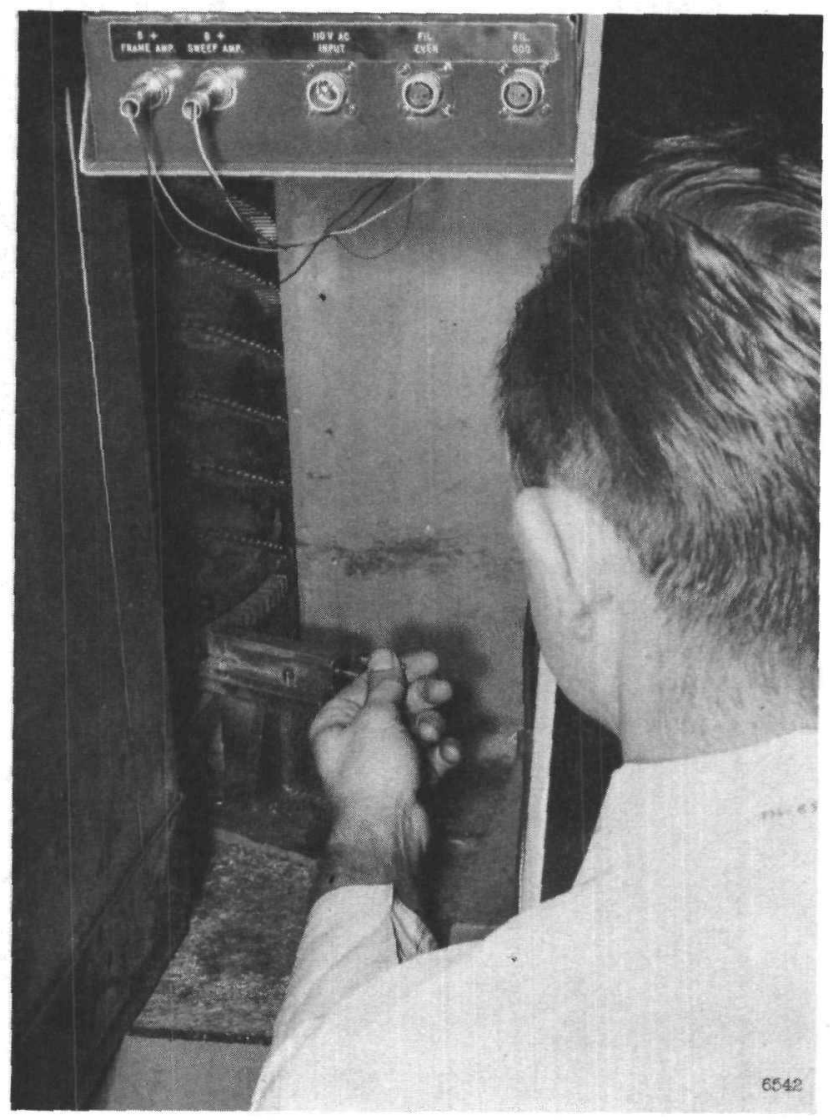

Fig. 12 - Positioning the drum to record statically the markers on the magnetic dispersion coating

the 400- $\mu$ sec line sweeps. A $4000-\mu$ sec sweep circuit was built on a plug-in chassis where a timing circuit normally plugs in, and the oscilloscope cabling was changed to connect this to the vertical deflection plate amplifiers.

\section{Scope Display}

Each camera will record transverse to the film motion an image of half the test section, i.e., corresponding to an area of 4 in. $x 8$ in. (four channels 2 in. high each). To achieve this image in the proper perspective on the film the following display is required on the oscilloscope. Only one hole per crystal views the test section at any time through the slit system and each line on the oscilloscope corresponds to a single hole scanning across the test section. Therefore, as the first vertical series of eight holes of a frame scans the test section, there will appear on each of the scopes four line sweeps $400 \mu \mathrm{sec}$ in duration, $5 \mathrm{~cm}$ in length, one above the other with vertical separations of $2.5 \mathrm{~cm}$. A frame sweep $4000 \mu \mathrm{sec}$ in duration and $2.5-\mathrm{cm}$ beam deflection is applied to the vertical deflection plates. An additional frame sweep of $4000 \mu \mathrm{sec}$ in duration will be modulated with the regular horizontal sweep so that the starting point of each succeeding line sweep has been moved vertically by $0.25 \mathrm{~cm}$ and horizontally by $0.5 \mathrm{~cm}$. The vertical movement gives line spacing and the horizontal movement compensates for film motion. Thus each gun has a raster $2.5 \mathrm{~cm}$ high and $5 \mathrm{~cm}$ long (corresponding to a $2 \mathrm{in}$. high and $4 \mathrm{in}$. wide section of the test chamber), but sloped over by approximately 26.5 degrees. The scopes 
sweep from left to right, but as the camera lens inverts up to down and right to left (essentially a 180-degree rotation of the image) film motion is from right to left. The reduction by the lens is about a factor of $1 / 4$, so the image size of half the test section is approximately $2.5 \mathrm{~cm} \times 1.25 \mathrm{~cm}$. The $25-\mathrm{mm}$ dimension of the image is transverse to the film, leaving adequate room for timing markers and sprocket holes in $35-\mathrm{mm}$ film. This display, therefore, gives a picture on the film of four vertical sections, one on top of the other.

\section{Cameras}

Two $35-\mathrm{mm}$ cameras are used to photograph the signals displayed in picture form on the two four-gun oscilloscopes. The Electronic Tube Corporation Model SM-100 cameras shown in Fig. 6 have a continuously variable control unit which will allow film speed movements up to $12,000 \mathrm{in} . / \mathrm{min}$. The film magazines have a film capacity of $400 \mathrm{ft}$; however, $100-\mathrm{ft}$ rolls used in the same magazines have sufficient recording time to cover the transients. The cameras reach full speed in less than $50 \mathrm{ft}$ of film run after start and maintain constant speed until the end when the drag on the takeup spool reduces the speed. Figure 13 shows the bottom of a $400-\mathrm{ft}$ magazine with the indicator for the amount of film used. The film indicator has a switch which sends a signal to the go-no-go circuits after $50 \mathrm{ft}$ of film are used. The film must move in one frame time $(4000 \mu \mathrm{sec})$ the image width, $1.25 \mathrm{~cm}$, which corresponds to $6380 \mathrm{in.} / \mathrm{min}$ (including the image reduction of $1 / 4$ ). The blanking space between frames on the film will be $0.9 \mathrm{~mm}$ and there will be 233 frames/sec. With a $50-\mathrm{ft}$ loss at beginning and end of a $400-\mathrm{ft}$ roll of film, data can be recorded at constant film speed for approximately $30 \mathrm{sec}$. Timing lights triggered either internally or externally can place markers on the film as desired. Satisfactory exposures of normal raster patterns are obtained on Radar Tri X film with the desired film speeds. The automatic film developer shown in Figs. 14 and 15 will develop and dry a 400-ft roll of film in approximately two hours.

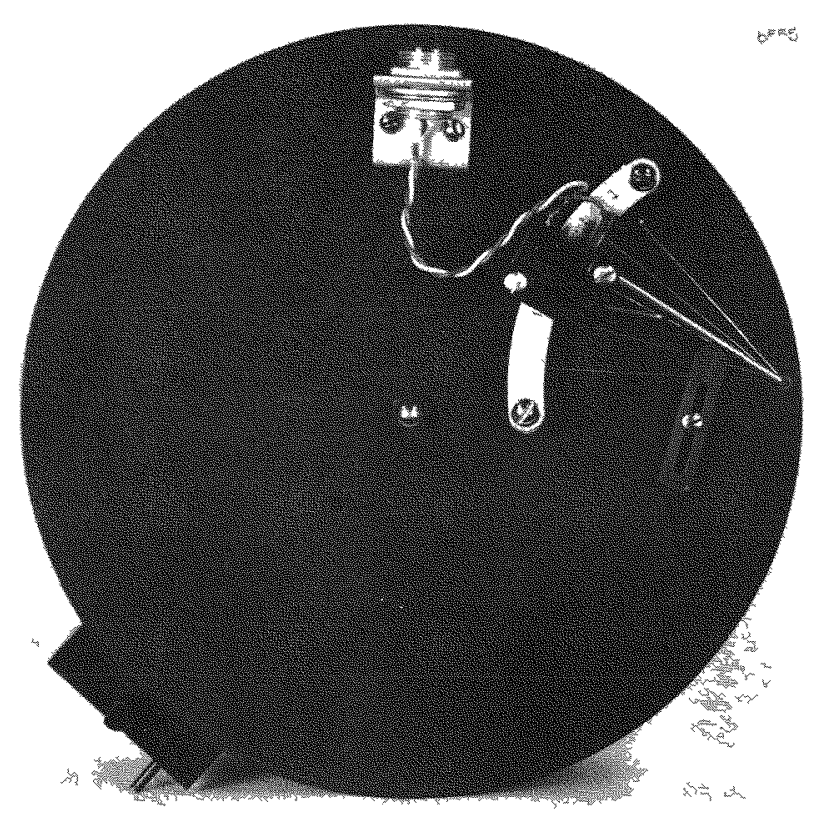

Fig. 13 - Film magazine 


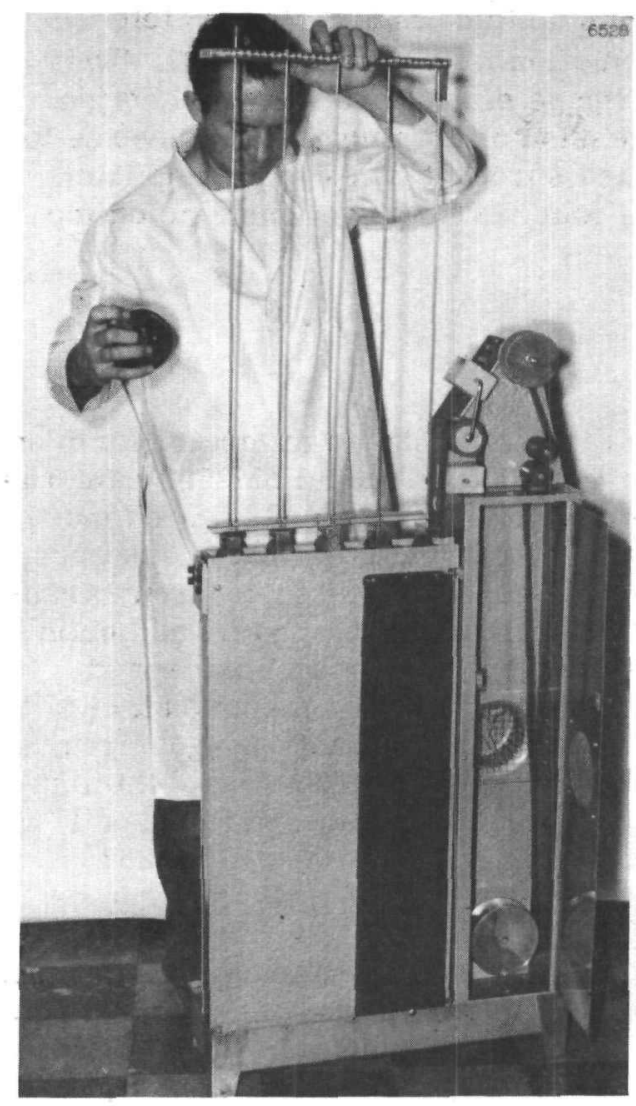

Fig. 14 - Automatic

film developer

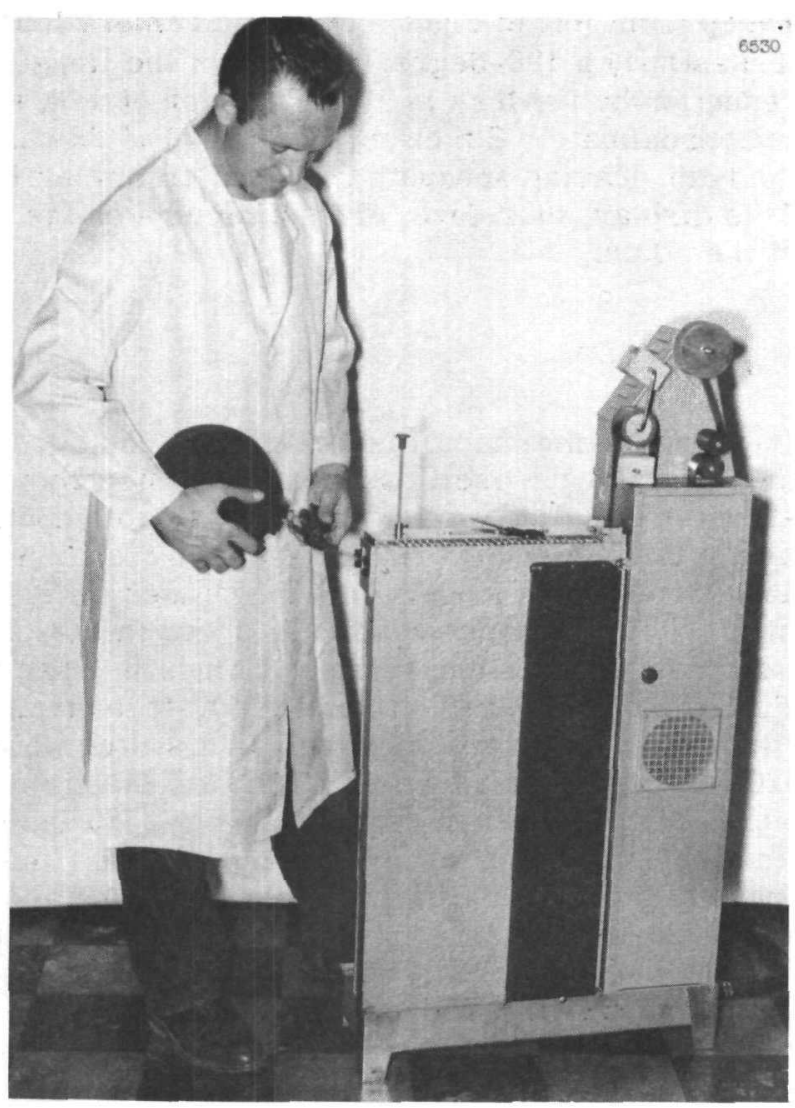

Fig. 15 - Attaching a magazine of film to the automatic developer

System Check-Out and Alignment Procedures

The following simple field tests will indicate that the system equipment is functioning properly. With the drum rotating and all the other electronic equipment on and no signal from the detectors, the intensified pips at the beginning and end of each $400-\mu$ sec sweep, which define individual frames on the film, will form a pattern on the oscilloscope faces. If a template with the correct pattern on it will overlay this pattern on the scope faces, all the oscilloscope and trigger circuits as well as the magnetic pickup system including proper drum rotation must be in order. Individual vertical and horizontal positioning controls for each gun are located on the front of each oscilloscope. The adjustments for both the horizontal and vertical sweep voltage amplitudes which change the heights, widths, and slopes of the rasters are brought out on the sides of the oscilloscopes. The detectors can then be checked by running a small $\mathrm{Co}^{60}$ source mounted on the end of a rod down through a hole in the top plate of the detector cavity past the crystals (see Fig. 16) and observing the oscilloscopes. Random intensified spots should appear on the raster of the channel which corresponds to the crystal which the source is near. The amplifier gain and the beam focus is adjusted by observing the intensified spots on the oscilloscope coming from this source. Figure 17 shows the random intensified spots arising from a source placed next to the detectors and also the intensified pips which define the frames of four channels. 


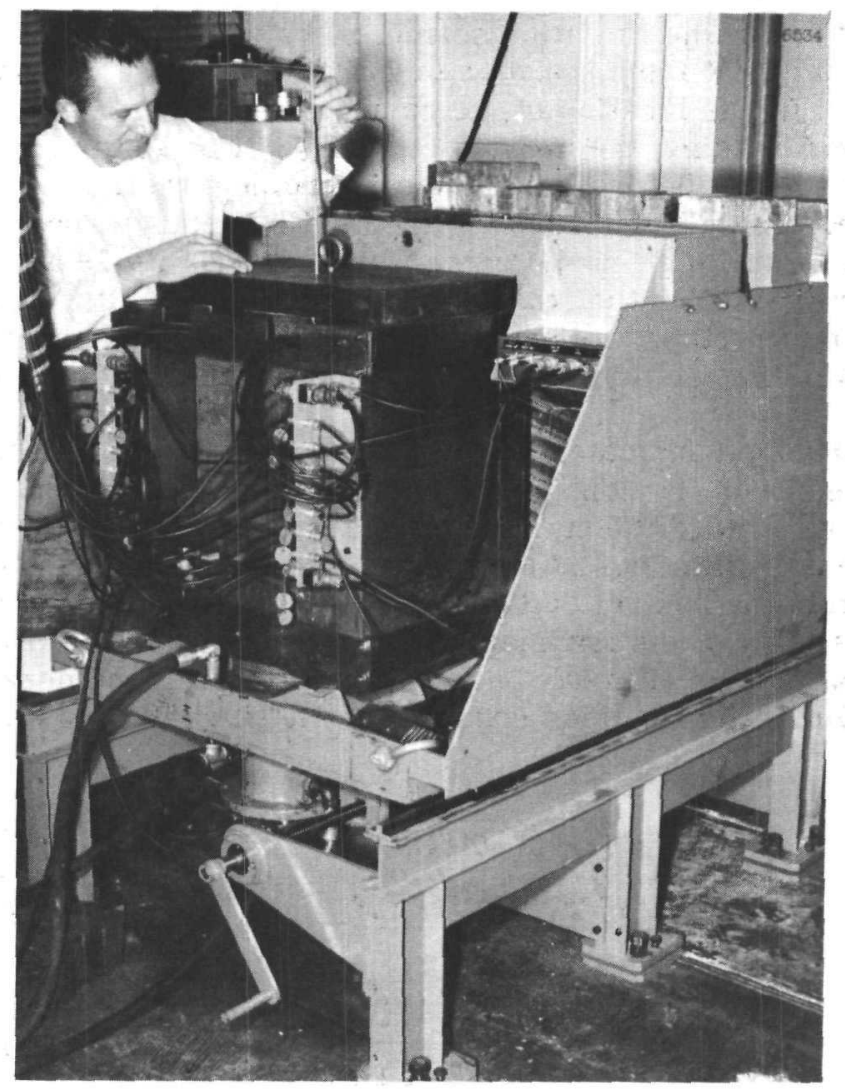

Fig. 16 - Inserting calibration source into detector cavity

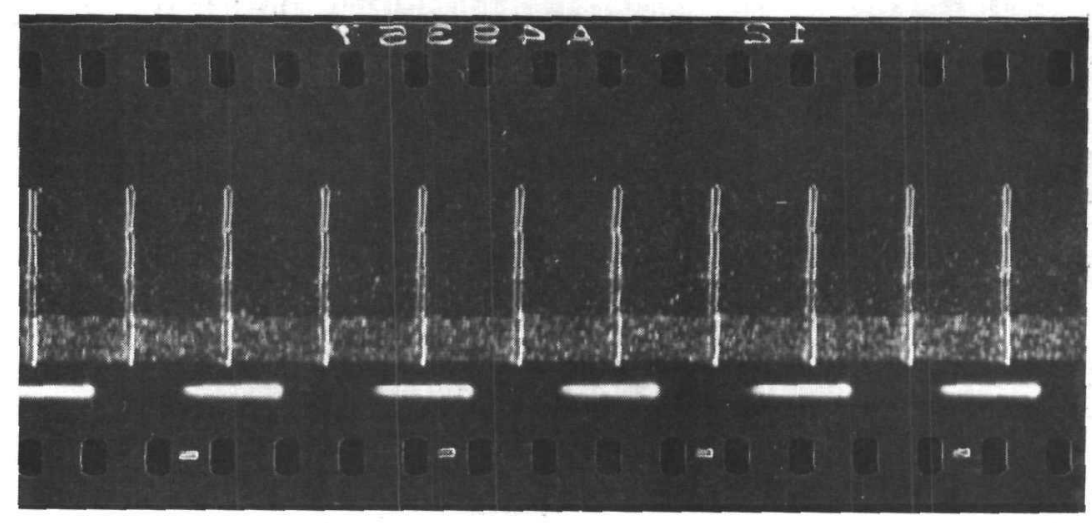

Fig. 17 - Example of display with random intensified spots 
Control System and Operating Procedure

During transient tests, the radiation scanning system will be operated from the remote control station one-half mile from the reactor building. Figure 18 shows a block diagram of the controls indicating the location of the components and connecting cables. Prior to evacuating the reactor building, the hydraulic motor will be started and the rotating drum brought up to preset speed. Before leaving the instrument trailer, the $\mathrm{B}+$ and high-voltage supplies for the detectors will be turned on, the oscilloscopes turned on and checked, and the cameras loaded. A static go-no-go circuit pictured in Fig. 19 and shown in block diagram in Fig. 20 will monitor the frame and line sweep circuits, high voltage for the detectors, and $\mathrm{B}+$ for the cathode followers. The sweep circuits will not work unless the drum is rotating and the magnetic pickup circuits are operating properly.

If the master pilot light indicates the electronics is operating properly, the camera motors will be started from the control station by remote-controlled relay switches at approximately 1 minute before the start of the transient. Speeds of both camera motors will be monitored by dc voltmeters at the control station. At $-5 \mathrm{sec}$, solenoid-operated clutches activated from the control station will start the film movement. A fast go-no-go circuit will allow the start of the transient if microswitches on the film indicators of the magazines signal that $50 \mathrm{ft}$ of film has been pulled through the cameras, earlier tests having shown that film speed becomes constant by the time $50 \mathrm{ft}$ has been drawn through the cameras.

CONTROL DIAGRAM

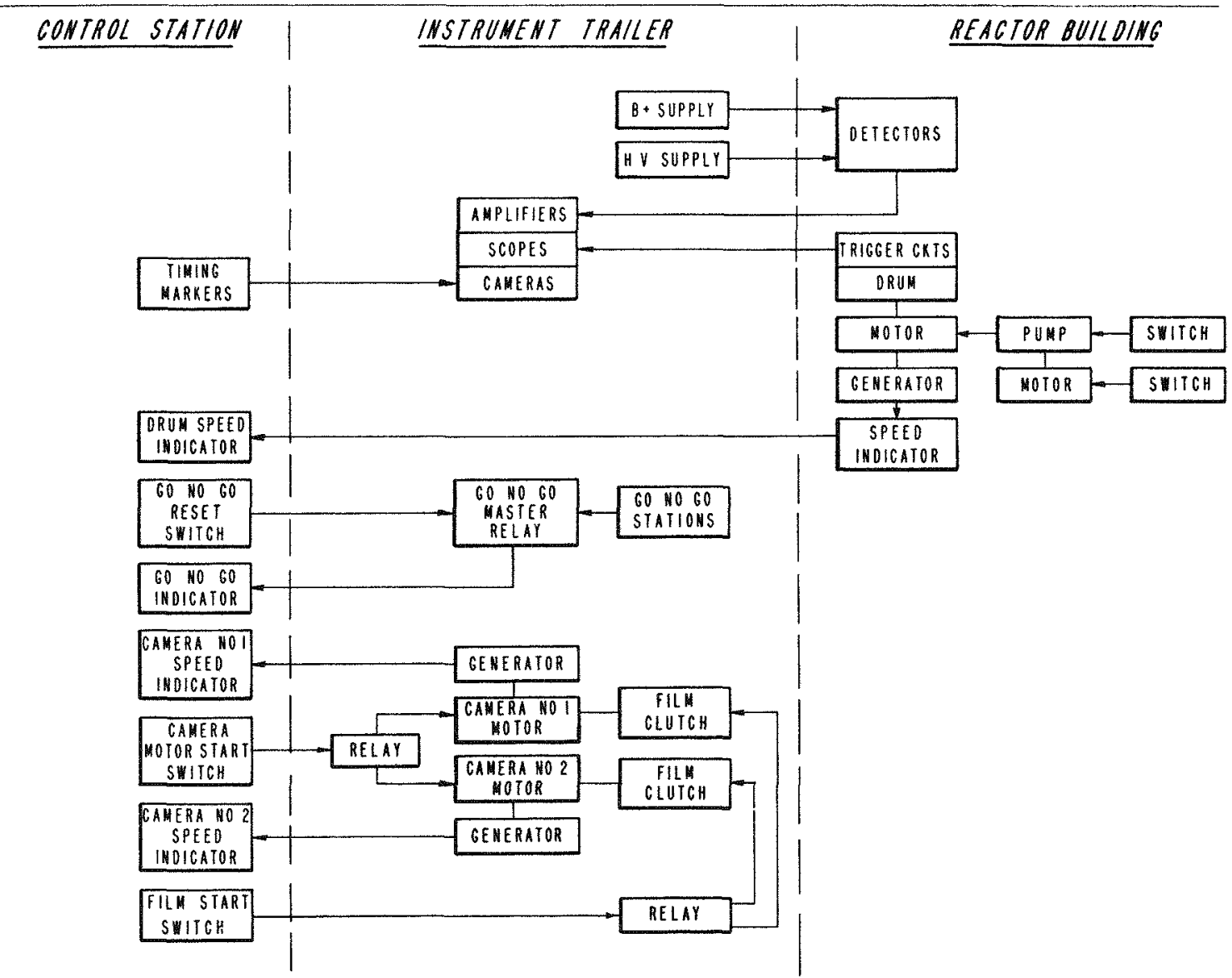

Fig. 18 - Control circuits 


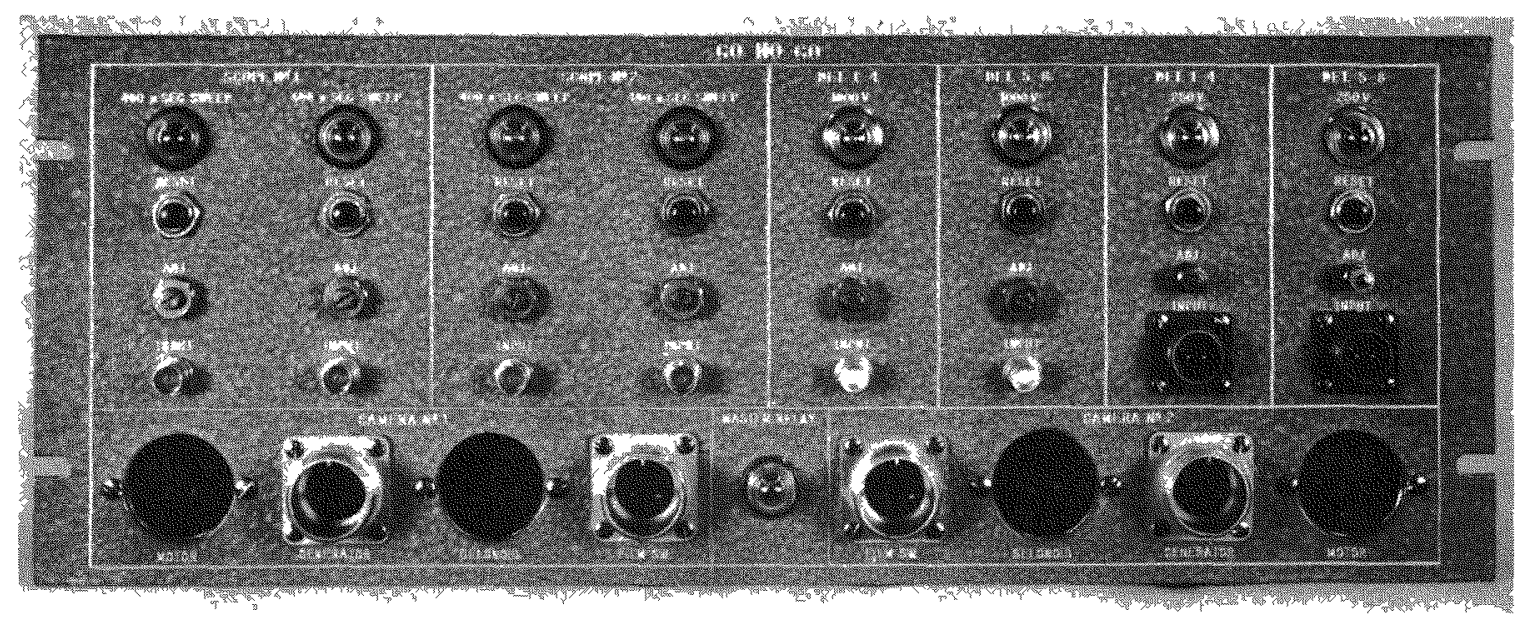

Fig. 19 - Go-no-go c1rcuit

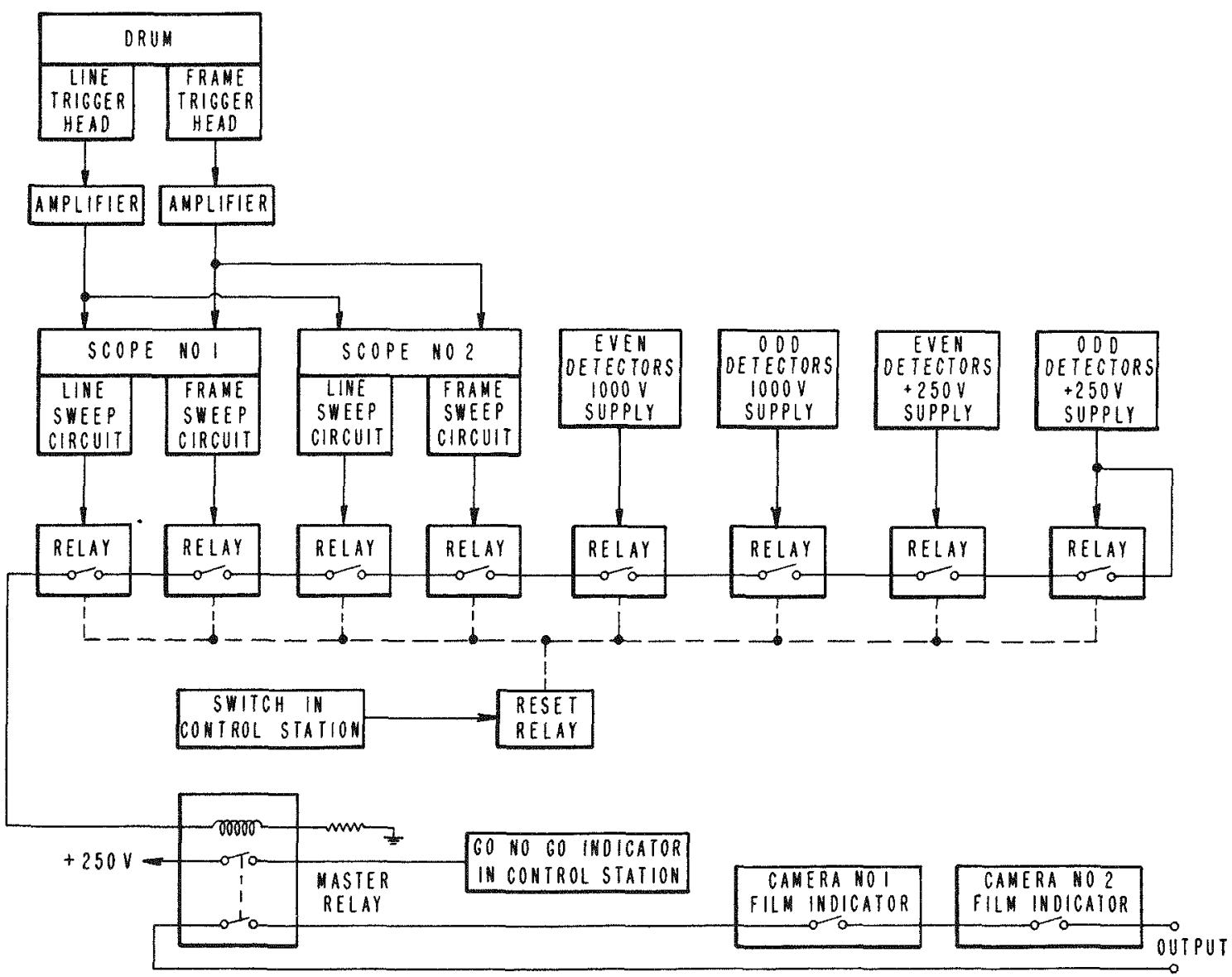

Fig. 20 - Go-no-go circuit 


\section{MEASUREMENTS WITH THE DRUM AT \\ THE NRL REACTOR}

Prior to shipment to Idaho, measurements were made at the NRL Reactor to check the capabilities of the radiation scanning device, particularly of the rotating drum. The cart was positioned before a square beam port 10 in. $\times 10$ in. through 9 feet of concrete shield viewing the core surface where the gamma-ray flux was estimated to be $10^{13} \gamma^{\prime} \mathrm{s} /$ $\mathrm{cm}^{2}-\mathrm{sec}$. Measurements were made of the gamma-ray transmission and space resolution of the collimating holes using this gamma-ray flux with its associated neutrons.

The experimental arrangement (see Fig. 21) was as follows: A T-slot with $1 / 4$ in. $x 4$ in. vertical and horizontal bars was placed in the $1-\mathrm{ft}$ carbon reflector and 4-in. lead shield in the beam port adjacent to the core. A 5-ft water shutter permitted changes in the experimental arrangement during reactor operation. A lead section inserted into the outer end of the water shutter contained another $T$-slot with $1 / 8$ in. $x 4$ in. bars. Paraffin was stacked around the cart for neutron shielding for personnel protection and against interference with other experiments. Due to the collimated beam, considerable care was required to align the cart with respect to the beam before satisfactory measurements could be made. The cart was raised and lowered in front of this collimated beam by means of jackscrews.

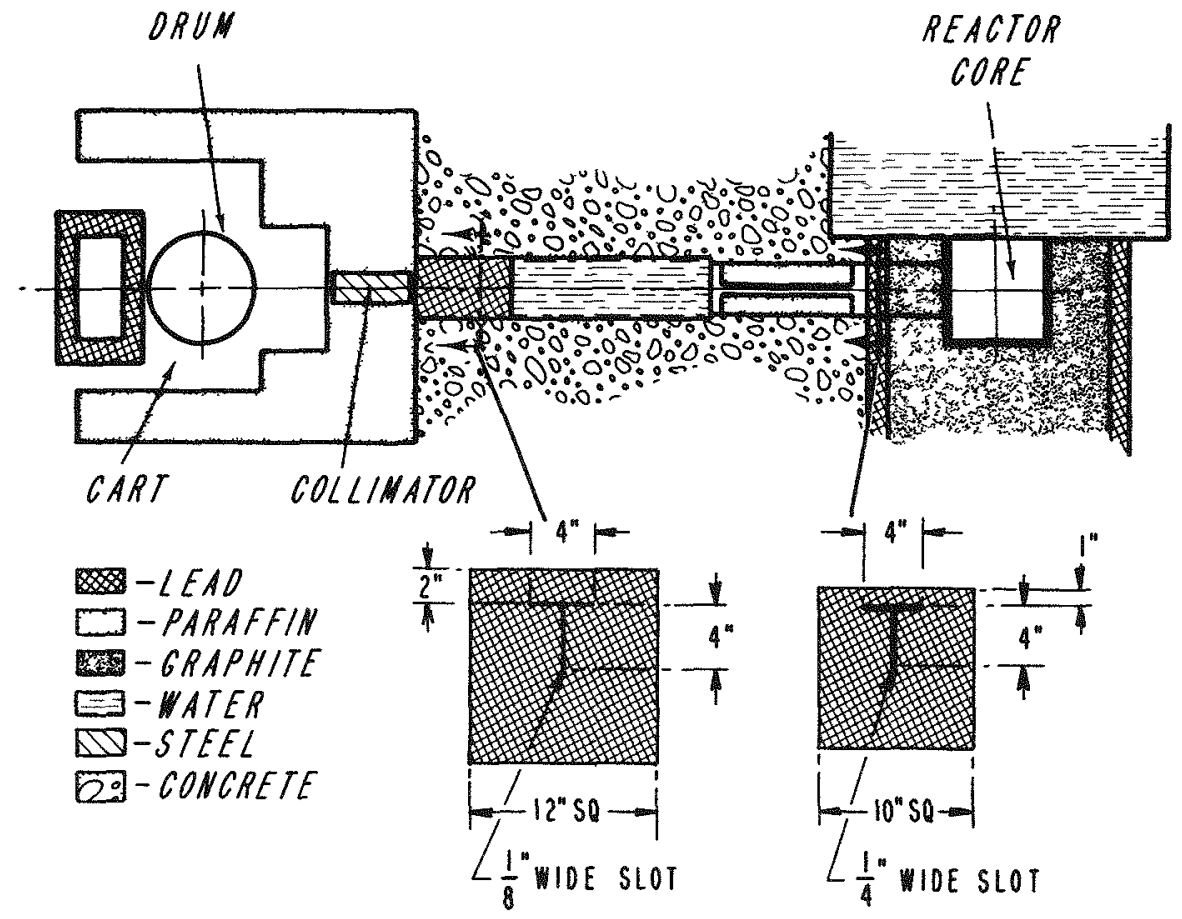

Fig. 21 - Schematic arrangement for measurements with the drum in front of a beam port at the NRI Reactor

\section{Transmission Measurements}

The measurement of the gamma-ray transmission of the collimating holes was a static determination because of the low-intensity source. The predicted counting rate in a 2 in. $x 2$ in. $x 1$ in. NaI(Tl) scintillation detector behind a collimating hole viewing the reactor core through the T-slots was obtained as follows: The 15-mil collimating hole located $165 \mathrm{in}$. from the core surface was effectively viewing a source area of $0.05 \mathrm{~cm}^{2}$ 
with a flux of $10^{13} \gamma^{\prime} \mathrm{s} / \mathrm{cm}^{2}$-sec. Therefore, the source strength is $5 \times 10^{11} \mathrm{y}$ 's $/ \mathrm{sec}$. Since the collimating hole subtends a solid angle of $5 \times 10^{-10}, 250$ gammas per second strike the crystal. The efficiency of the detector for pulses above the discriminator level used in the recording equipment was estimated at $40 \%$. Therefore, for a perfectly aligned hole, a signal of approximately $100 \mathrm{c} / \mathrm{sec}$ above background should be observed, which is in good agreement with the maximum values observed.

A summary of the data on the gamma-ray transmission of all holes is given in Table 3 . It is to be noted that the distribution of all transmission values appears to be gaussian with a mean value of $39 \mathrm{c} / \mathrm{sec}$ with a standard deviation of $20 \mathrm{c} / \mathrm{sec}$. The average deviation in repeated measurements on the holes was approximately 8 counts per sec. Since the predicted counting rate was $100 \mathrm{c} / \mathrm{sec}$, the average measured transmission is only approximately $40 \%$ of the predicted value.

Table 3

Summary of Data on Transmission of Holes

\begin{tabular}{|c|r|r|r|r|r|r|r|r|r|r|r|r|}
\hline \begin{tabular}{c} 
Transmission $\begin{array}{c}\text { Nalues } \\
\text { (c/sec) }\end{array}$ \\
\cline { 2 - 9 }
\end{tabular} & \multicolumn{6}{|c|}{ Number of Holes Giving Signals in Each Range } & \multirow{2}{*}{ Total } & $\begin{array}{c}\text { Accum. } \\
\text { Total }\end{array}$ \\
\hline $0-10^{*}$ & 8 & 0 & 0 & 0 & 2 & 4 & 1 & 3 & 18 & 18 \\
$10-20^{-}$ & 10 & 2 & 5 & 1 & 4 & 10 & 8 & 14 & 54 & 72 \\
$20-30^{-}$ & 17 & 7 & 10 & 9 & 6 & 18 & 22 & 21 & 110 & 182 \\
$30-40^{-}$ & 14 & 13 & 9 & 13 & 19 & 17 & 24 & 9 & 118 & 300 \\
$40-50^{-}$ & 14 & 9 & 14 & 17 & 12 & 12 & 14 & 15 & 107 & 407 \\
$50-60^{-}$ & 8 & 13 & 14 & 9 & 15 & 9 & 4 & 13 & 85 & 492 \\
$60-70^{-}$ & 5 & 18 & 10 & 19 & 6 & 8 & 4 & 3 & 73 & 565 \\
$70-80^{-}$ & 1 & 14 & 9 & 5 & 8 & 2 & 3 & 1 & 43 & 608 \\
$80-90^{-}$ & 1 & 2 & 7 & 6 & 4 & 0 & 0 & 1 & 21 & 629 \\
$90-100^{-}$ & 2 & 2 & 2 & 1 & 4 & 0 & 0 & 0 & 11 & 640 \\
Total & $80 \dagger$ & 80 & 80 & 80 & 80 & 80 & 80 & 80 & 640 & \\
\hline
\end{tabular}

*Holes numbered vertically down the drum - ten holes per vertical section.

fTen holes per vertical section occurring in eight frames around the drum equals 80 holes.

This reduction in the transmission of the collimating holes was most likely caused by misalignment of and curvature in the two rods making up each collimating hole arising from the following factors: (a) misalignment of the drilled holes in the three concentric shells, (b) deviations from straightness in the rods, and (c) improper matching of the eccentricities of the two rods. The holes were checked individually during the drilling operation and were measured to be aligned within 2 mils. The deviations from straightness in the rods is extremely difficult to measure, and the three concentric shells should constrain the rods to be straight. Therefore, if the hole within the rod was initially inherently straight, the installed hole should be straight. The eccentricities of the holes from the center were measured to vary from 0 to $7 \mathrm{mils}$, but the rods were installed in the drum in matched pairs with the same eccentricities (and supposedly lined up in the same direction). Therefore, the reduction in transmission by a factor of 2.5 might indicate that the hole is not inherently straight in the rod. 
Space Resolution

Measurements to check the spatial resolution were made for several holes. A micrometer was mounted on the edge of the drum and a rubber band under tension kept pressure on a screw drive so the drum could be advanced in small known increments. Figure 22 shows the signal above background plotted against displacement along the edge of the drum. The value of the full width at half maximum shown on the curve must be multiplied by 12.5 to transform to the dimensions of the source.

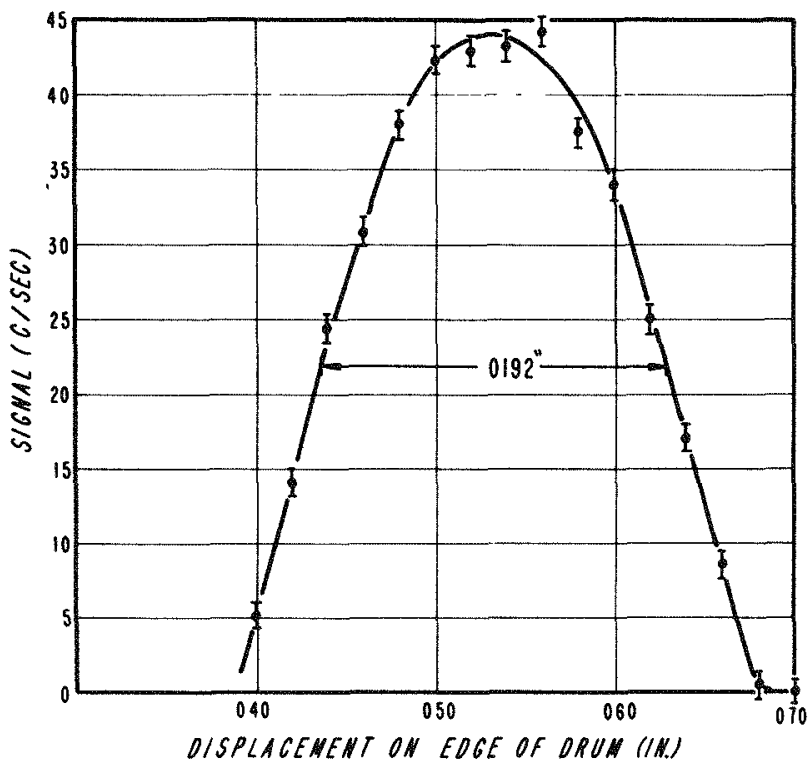

Fig. 22 - Typical spatial resolution curve for a particular hole

To interpret the data obtained by scanning across the slot source, theoretical resolution curves were computed and folded into the source function. A collimating hole of radius $r_{o}$ and length $\ell$ viewing a uniform source at a distance $d$ views a circular area of radius $r_{0}$ with the full solid angle of the hole while an additional source area out to a radius of $h_{\max }$ is viewed with a continuously diminishing solid angle because the near end of the hole eclipses the far end. The response function of a circular collimating hole is therefore a flattopped volcano-shaped figure. For a uniform source, the effective source area is approximately that of a circle of radius $\left(h_{\max } / 2\right)+r_{0}$.

For the resolution measurements at the NRL Reactor, $d=127$ in., $r_{o}=0.0075$ in., and $\ell=22.2 \mathrm{in}$. (which is the length of the steel rods reduced by one mean-free-path for gamma penetration of the rod edge). ${ }^{*}$ Consequently, for this geometry, $h_{\max }$ is $0.086 \mathrm{in}$. The theoretical response of such a collimating hole to a line source is shown in Fig. 23 with a full width at half-maximum of $0.094 \mathrm{in}$. If this response function to a line source is folded into a finite width source, a response is obtained for the collimating hole sweeping across a finite source as shown in Fig. 24.

The resolution of a system determines the width of its response to a narrow source but not to a wide source; however, it always determines the slope of the rise and fall of the response to a step function source. The width at half-maximum for a source width much less than the resolution width of the system will be approximated by the resolution width,

\footnotetext{
*A. S. Mathes, "Gamma Ray Collimator Penetration and Scattering Effects" USNDL-TR-174, May 20, 1957.
} 


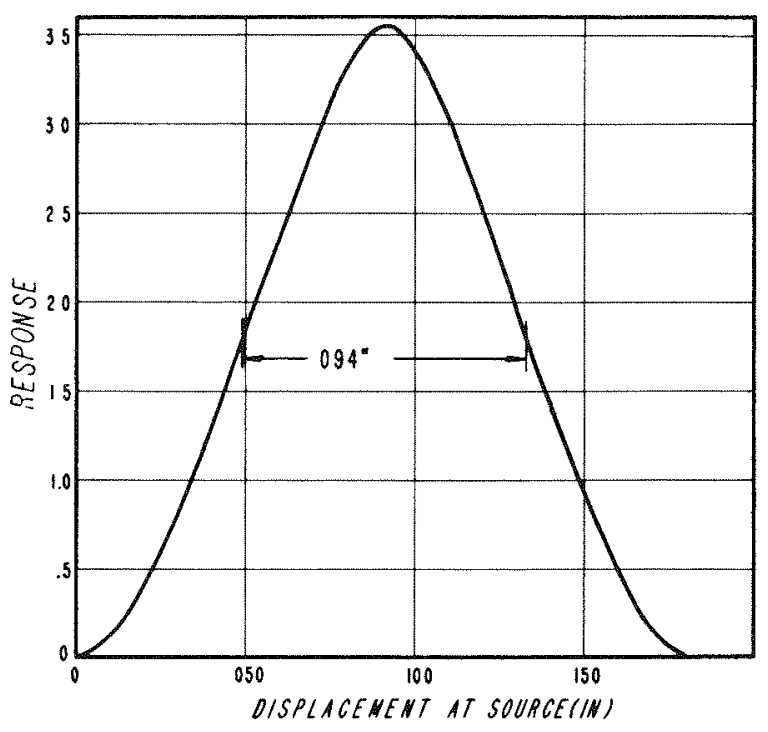

Fig. 23 - Theoretical response of a collimating hole to a line source in the geometry at the NRL Reactor

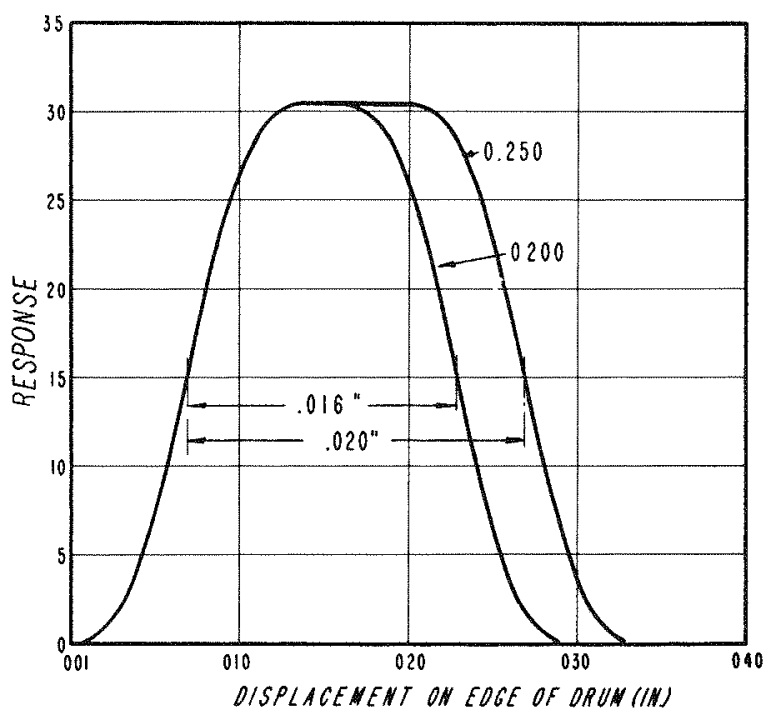

Fig. 24 - Theoretical response of a collimating hole to finite width sources in the geometry at the NRL Reactor 
but the width at half-maximum for a source at least twice the resolution width will be equal to the source width. Since the source width $(\approx 0.25$ in. $)$ in the NRL arrangement was wider than the theoretical resolution of $0.094 \mathrm{in}$., the experimental widths at half-maximum are a better measure of the source width than of resolution. The measured widths at halfmaximum in terms of displacement at the source were from 0.215 to $0.240 \mathrm{in}$., which is in good agreement, since the effective source width was probably less than $0.250 \mathrm{in}$, , being formed by a 1/4-in. slot in $4 \mathrm{in}$. of lead and $12 \mathrm{in.}$ of graphite. However, since the slopes of the experimental curves agreed with that of the theoretical curve, these measurements were consistent with the theoretical resolution.

Assuming the theoretical resolution was correct, data was computed for the expected performance of the collimating holes for the design geometry at the TREAT reactor. In this case, $d$ is decreased to $97 \mathrm{in}$. and $h_{\max }$ is therefore $0.0655 \mathrm{in}$. The response of a collimating hole to a line source at the center of the test section has a width at halfmaximum of $0.067 \mathrm{in}$. This indicated that the spatial resolution of the Mark I system would be slightly better than the desired 0.100 in.

\section{Horizontal Slits}

In the initial experimental arrangement at the NRL Reactor, a high background, probably caused by fast neutrons, obscured the signal from collimated radiation. To reduce the background below the average signal, a set of horizontal steel collimators made of eleven steel plates $0.093 \mathrm{in}$. thick, $18 \mathrm{in}$. long, and 6 in. wide were placed in front of the drum. This slit remained fixed in the beam emanating from the reactor, while the cart was moved up and down during the measurements. Steel was chosen for its structural rigidity and good neutron attenuation.

Therefore, a horizontal collimator of 81 steel plates approximately $0.135 \mathrm{in}$. thick (0.065-in. spacers) and 28 in. long was installed in the front vertical slit. The effect of this horizontal collimator is a reduction in the source area for uncollimated radiation striking a detector and attenuation of the general radiation striking the front face of the drum. A crude lower estimate of its effect is that it reduces the source area by a factor of eight, i.e., from the entire height of the drum, 16 in., to the crystal height, 2 in. An upper limit is obtained by assuming that steel is a perfect absorber of all radiation striking it except for penetration of edges which effectively reduce its length by one mean-freepath. Since this high estimate had a value of 200 to 250 , it was assumed that this horizontal collimator reduced the uncollimated radiation by a factor of 80 .

\section{MEASUREMENTS AT TREAT WITH \\ THE MARK I SYSTEM}

The radiation scanning device was installed in the north access hole of the TREAT reactor during August 1959, and the system was checked out independent of reactor operation. In September, unsuccessful attempts were made to view a fuel pin in a standard dummy element in transient operation of the reactor. The counting rates of all detectors were essentially constant during any scan across the test section but increased to saturation at powers of $100 \mathrm{Mw}$ or higher. Background counting rates at low-power steady-state operation were consistent with these peak values. A series of measurements coupled with step by step shielding modifications conducted during the fall led to the following conclusions:

1. The overall shielding was not adequate to protect the detectors from background rates from the entire main core when the system was located in the design position. 
2. The fast-neutron attenuation of the drum was low (200 to 500 ), particularly since the geometry was poor, whereas it had been assumed to be good in the design calculations.

3. The 2.1-degree opening ${ }^{*}$ of the front slit allowed radiation from core areas along the slot to illuminate directly the front of the drum through the vertical and horizontal slits. This radiation caused a high uncollimated counting rate in the detectors independent of drum rotation after penetrating through the drum and front wall of the detector cavity.

4. The low gamma transmission of the collimating holes was reducing the signal below predicted values.

5. There was possibly poor contrast between the signal from the pin and that from the relatively dense standard dummy element.

By mid-November, the following modifications had been made to the system without any success in viewing fuel pins. To increase general shielding, the cart had been retracted $40 \mathrm{in}$. from its design position. All voids in the niche ahead of the cart were filled with concrete blocks and lead bricks except for the extension of the viewing slot. In addition, $8 \mathrm{in}$. of concrete shielding had been added to all sides of the cart to minimize background from radiation escaping from the shield and subsequently scattering towards the detector cavity. Restrictions in the vertical slot reduced the viewed width and the uncollimated background. A slit formed by graphite blocks was installed in the gate and removable reflector so no fuel area could illuminate the front of the drum without at least one scattering. This reduced the viewed width at the test section to 2.5 to $2.67 \mathrm{in}$. Through the shield the viewing slot was reduced to $1-1 / 2$ in. $x 20$ in. by inserting sheets of Plexiglas. The detector cavity had been moved back 8 in. from the drum to allow an addition of 8 in. of shielding material, with the most optimum arrangement being alternate layers of iron and wax with boron-loaded plastic sheets. An aluminum water shutter $20 \mathrm{in}$. high and $30 \mathrm{in.}$ long was inserted into the reduced opening through the shield area. Since the counting rate was nearly a linear function of the water height in this water shutter, the majority of the remaining background was coming down the slot.

On transients 56 and 57 (mid-November) at peak power levels near $300 \mathrm{Mw}$, the vertical slit was limited to a 2-in. height by replacing the water shutter with wax so only one detector was viewing the pin. Although the background was still appreciable, it would not have obscured a strong pin signal. It was concluded within the poor statistics that the Mark I system could not observe a pin against the background under transient operation. In attempting to improve the statistics, low-level steady-state observations of a $3 \%$ pin were made in December without success.

To understand this inability to distinguish the fuel pin from the background, the design calculations were reviewed. At the time of conception of the radiation scanning device, it had been calculated that there was adequate signal strength to view the pin during a $5-\mathrm{ms}$ period. The peak signal from the pin viewed with a 0.015 -in.-diameter hole in a $22-$ in. drum $9 \mathrm{ft}$ from the test section was computed to be $50 \mathrm{Mev}$ of gammas per scan across the pin. This signal strength seemed adequate to view meltdown during these fast transients, as the signal would probably not drop more than a factor of 5 from the peak before meltdown. This assumed a space resolution of approximately $0.1 \mathrm{in}$. and a time

\footnotetext{
* The 2.1-degree opening had been chosen to allow the collimating holes to scan the full 4-in. width of the test section. The assumption had been that radiation from fuel beyond the test section would be attenuated by a high-density shield. As discussed previously, this high-density shield had been eliminated and compensated for by extending the viewing slot entirely through the reactor.
} 
resolution of $5 \mathrm{~ms}$. Lower intensity signals from slower transients were to be compensated for by fewer frames per second possible by reduction of drum rotation and camera speed. The dynamic range of the system was assumed to be limited by the ratio of signal to uncollimated radiation arising in the test section, coming through the slit and subsequently penetrating the drum. It had been assumed that collimated radiation arising in the test section other than in the pin would be negligible in comparison to the signal.

The previous calculation assumed a transient rising with a 5 -ms period, assumed perfect transmission of the collimating holes, and contained an error in the viewed source area. Since the control rod drives were driven by compressed air (not explosives) the fastest transients with TREAT are 50 to $80 \mathrm{~ms}$ and normal operation was in the range 100 to $200 \mathrm{~ms}$. Therefore, the peak rate used in the calculation was a factor of 20 too high for the slower transients. The measured average transmission of the circular collimating holes was approximately $40 \%$ and the source area used was high by a factor of 3.5 . Therefore, on the average less than $0.3 \mathrm{Mev}$ of gammas per view time would strike the crystal even at the peak. This signal level is obviously too low for an intelligible picture of the fuel pin even at the peak and neglecting background and lack of contrast.

Therefore, it was apparent that additional modifications were required to increase the collimated signal strength and reduce the background. The signal strength could be increased by an increase in size of the collimating holes with a loss in space resolution and/or by a decrease in drum rotation with a loss in time resolution. The background reduction would require an increase in fast-neutron attenuation of the drum and surrounding shielding volumes. It appeared feasible to achieve these objectives by fabricating a Mark II drum of the same diameter by stacking solid brass or steel plates with rectangular collimating holes milled in each plate. It was predicted that a 0.030 -in. square hole with perfect transmission would give an increase in signal radiation of 38 from the imperfect 0.015 -in. circular holes with a space resolution of $0.2 \mathrm{in}$. The fast-neutron attenuation of a solid brass drum should be at least a factor of 200 greater than the Mark I drum.

\section{TEST MEASUREMENTS, EARLY 1960}

Prior to construction of a Mark II drum, measurements were made at TREAT with rectangular collimating holes to check the following points: (a) determine feasibility of fabrication; (b) measure background through a solid brass drum; and (c) determine what size hole (space resolution) is required to get an intelligible signal.

For measurements in January 1960, the experimental arrangement in front of the drum was modified as shown in Fig. 25. The slit was reduced to $2 \mathrm{in}$. in height from the core to the drum with alternate layers of a hydrogenous material and lead (or shot) replacing the single-material shields wherever possible. With the modified shielding, the Mark I drum was able to distinguish a cadmium foil 22 mils thick and $1 \mathrm{in}$. wide viewed edge-on, a factor of 1 to 2 above background with correct space resolution and relative transmission values in agreement with the NRL data. But since the source strength of even a $6 \%$ pin would be a factor of 30 below the cadmium foil, the Mark I drum was removed.

A series of measurements were conducted viewing the cadmium foil and $6 \%$ enriched pin with various rectangular holes ranging in size from $0.030 \times 0.030 \mathrm{in}$. to $0.050 \times 0.060 \mathrm{in}$. milled into four brass plates 23 in. diameter in the arrangement shown in Fig. 25. Table 4 summarizes the results for the $0.050 \times 0.040$ in. hole and Fig. 26 shows the scan of the 6\% enriched fuel pin in a stainless steel capsule mounted in the standard test element.

Several conclusions were drawn from these results. The minimum rates given in Table 4 represent the background from radiation penetrating the brass plates when no collimating holes are in the front slit (with the vertical height of front slit limited to $5 / 8 \mathrm{in}$.). The width of the wing corresponds to the horizontal opening of the front slit. The radiation 


\section{-}

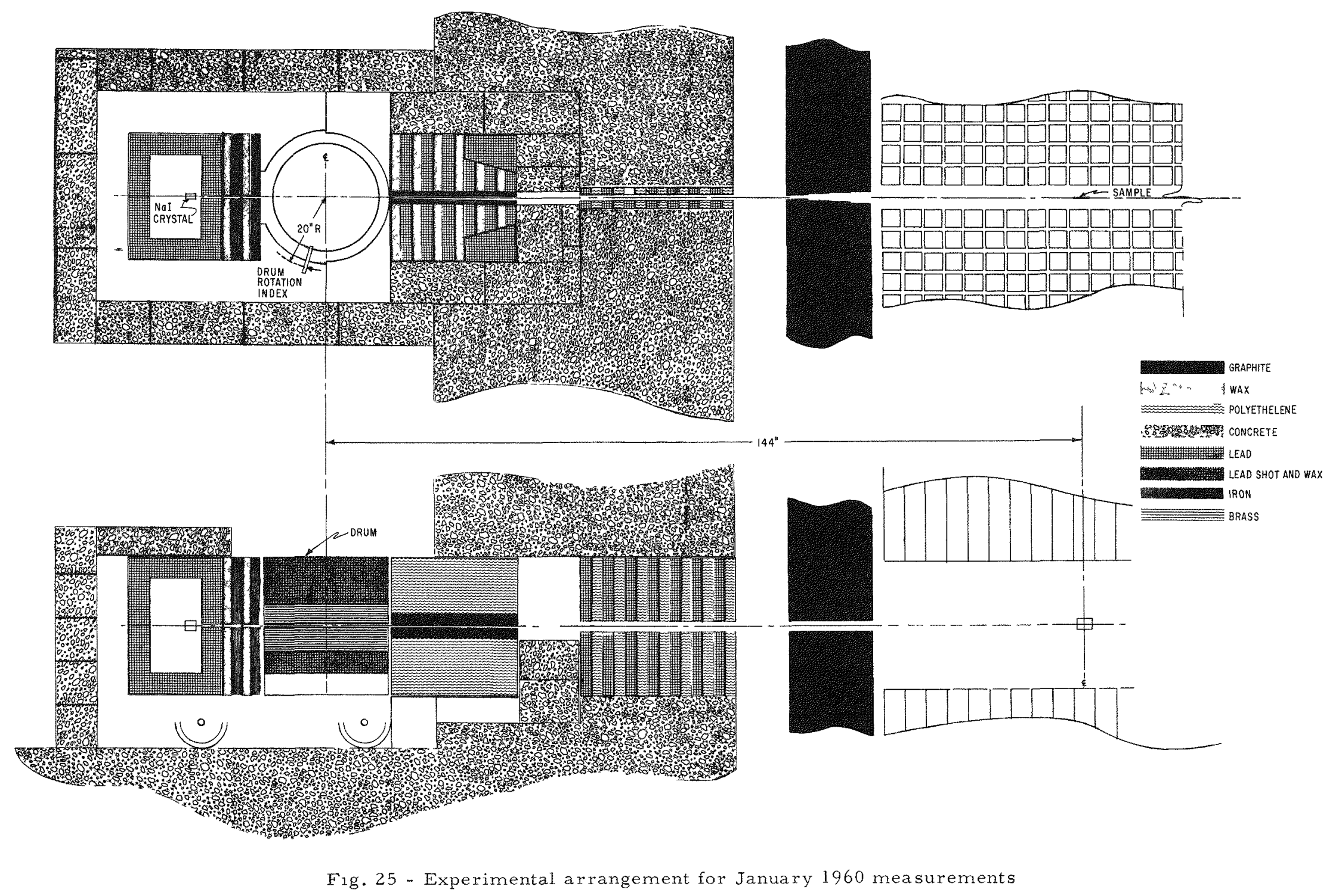


Table 4

Summary of January Measurements with $0.050 \times 0.040 \mathrm{in}$. Hole

\begin{tabular}{|l|r|r|c|}
\hline \multirow{2}{*}{ Source Description } & \multicolumn{3}{|c|}{ Counting Rate } \\
\cline { 2 - 4 } & Peak & Wing & Minimum \\
\hline \hline Cd foil mounted on 100-mil Al & 1750 & 50 & 15 \\
Cd foil viewed through 100-mil Zr & 1550 & 75 & 13 \\
Cd foil through graphite element & 1200 & 150 & 17 \\
$\begin{array}{l}\text { Cd foil through graphite element } \\
\text { with stainless steel tube }\end{array}$ & 1240 & 260 & 26 \\
$\begin{array}{l}\text { 6\% fuel pin graphite element } \\
\text { including stainless steel } \\
\text { capsule }\end{array}$ & 235 & 150 & 20 \\
\hline
\end{tabular}

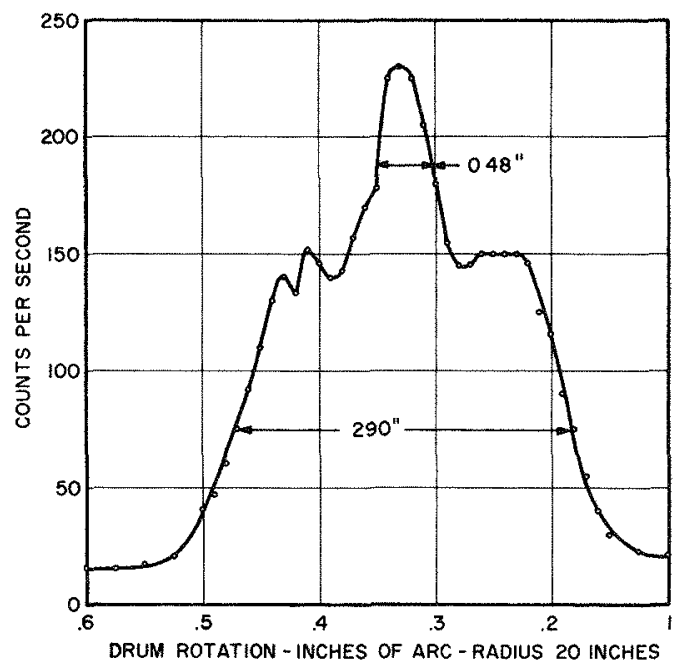

Fig. 26 - Scan with $0.050 \times 0.040$ in hole of $6 \% \mathrm{U}^{235}$ fuel pin in stainless steel capsule within test element

responsible for the wings arise or are scattered by the material being viewed (material in dummy element), and because of the multiple sources (several materials and processes) it was impossible to unscramble it into various components from these measurements. Space resolution was approximately correct but the ratios of different hole sizes didn't agree with predicted values, most likely due to errors in alignment of the plates.

In February 1960, after realignment of the plates (and stacking additional brass above and below), measurements were made with certain holes viewing $\mathrm{Cd}, \mathrm{Fe}, \mathrm{Al}$, zircaloy, and graphite plates mounted in a slotted element and a $6 \%$ enriched fuel pin mounted in a $1.5-$ in.-diameter zircaloy container $(1 / 8-$ in. wall) with a graphite liner $1 / 4 \mathrm{in}$. thick. Scans across the cadmium foil are given in Fig. 27 for two different holes. Comparison of measured values with predicted ratios indicated that the plates may have bowed by 8 mils in fabrication and installation. The results for the stainless steel and graphite plates are given in Fig. 28 with the high background between the peaks largely due to radiation originating in the far gate, which was down. Figure 29 shows results with zircaloy and aluminum plates (the far gate has been retracted for this scan). The $6 \%$ fuel pin is clearly defined against the background of the zircaloy container as shown in Fig. 30. 


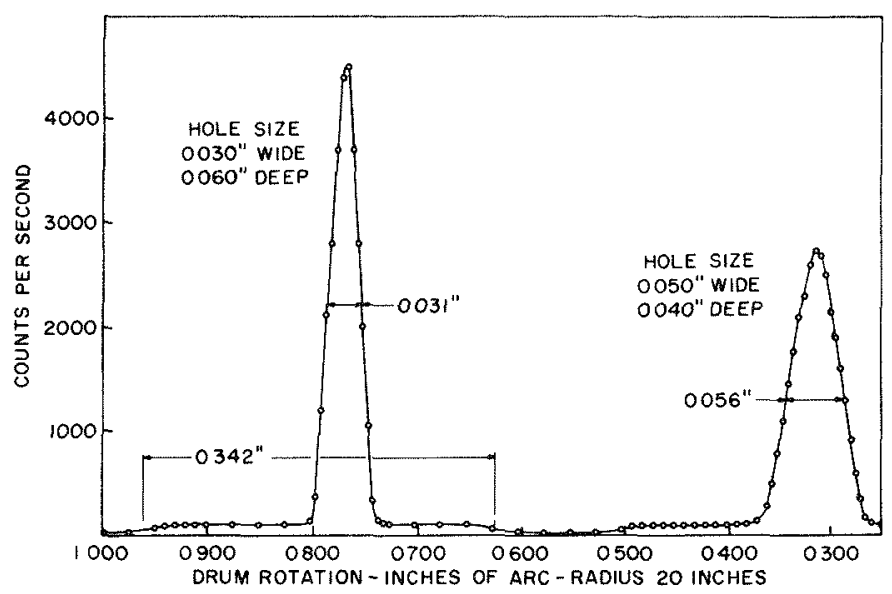

Fig. 27 - Scan of cadmium foil with rectangular holes

Fig. 28 - Scan of stainless steel and graphite plates with rectangular holes
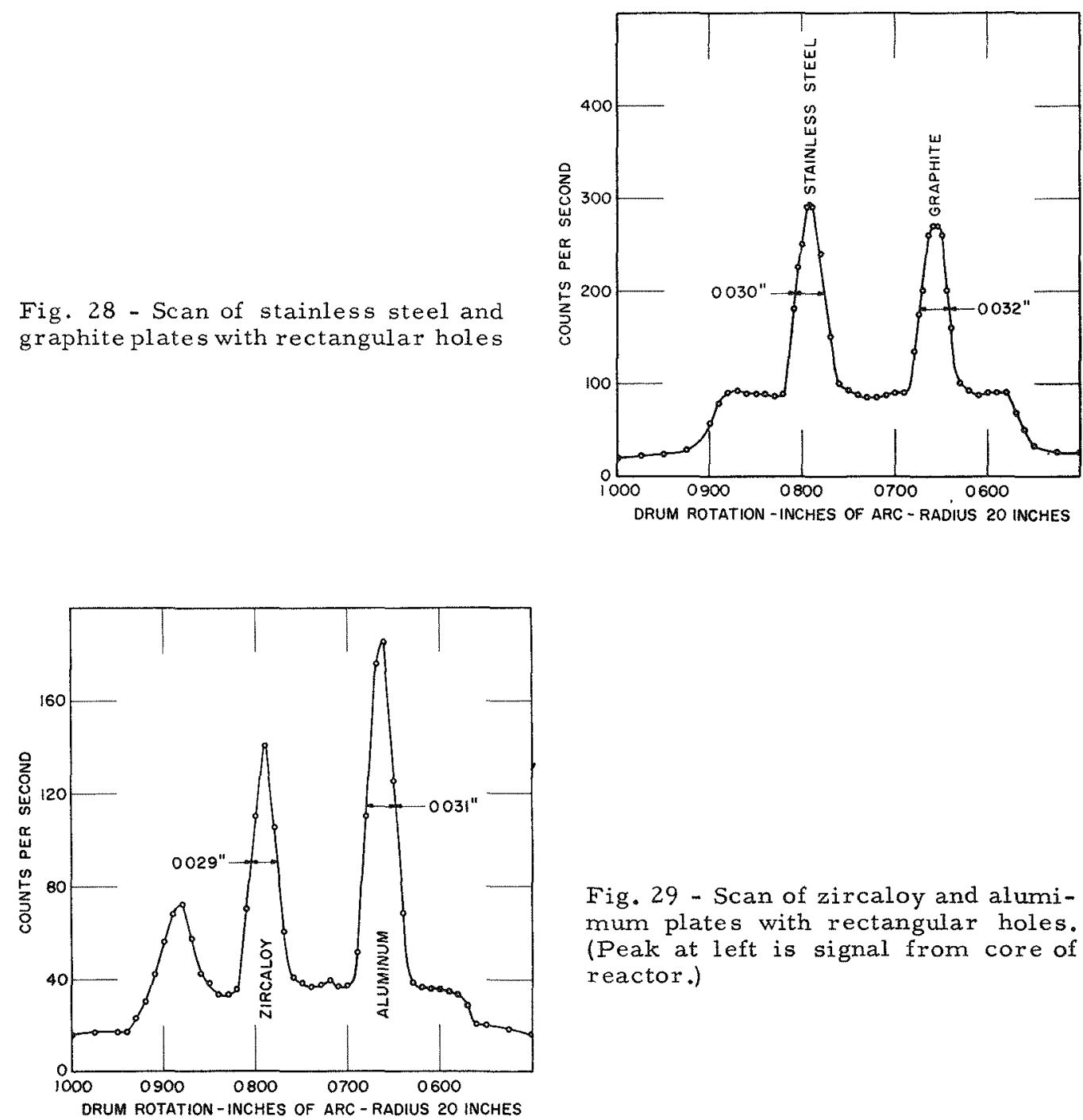

Fig. 29 - Scan of zircaloy and alumimum plates with rectangular holes. (Peak at left is signal from core of reactor.) 


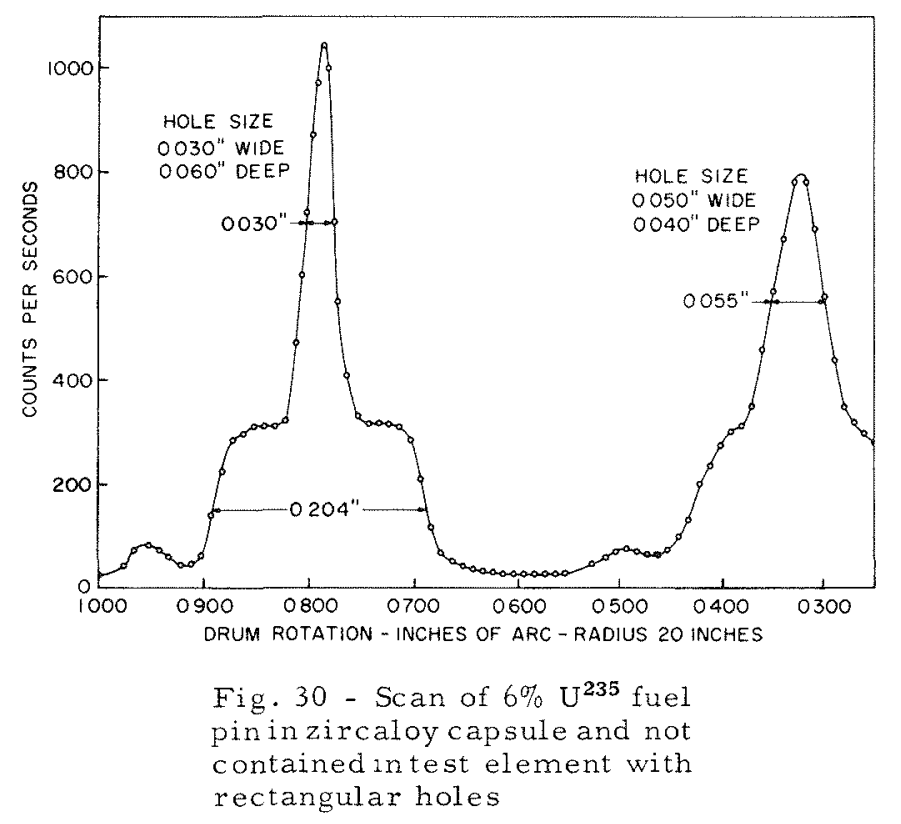

It had been believed that gamma rays from the capture of thermal neutrons would account for the greater part of the gamma brightness of any material placed in the reactor. How ever, except for the cadmium foil, inelastic scattering of fast neutron flux and Compton scattering of the reactor gamma-ray flux must be considered. Table 5 gives the predicted and measured counting rates for the various substances in the measured geometry. Similarly, the computed gamma rays from the $6 \% \mathrm{U}^{235}$ fuel pin are given in Table 6 . By a transformation of the basic data from the plates (from Table 5) to the zircaloy container, a predicted value of $301 \mathrm{c} / \mathrm{sec}$ is obtained in comparison with a measured value of $310 \mathrm{c} / \mathrm{sec}$ near the fuel pin as shown in Fig. 30. The predicted peak rate from the $6 \%$ pin attenuated by the zircaloy container was $858 \mathrm{c} / \mathrm{sec}$. The measured peak rate from the $6 \%$ pin plus zircaloy container was $1125 \mathrm{c} / \mathrm{sec}$. Subtracting the container signal, attenuating the contribution from the back side of the container by the fuel pin, i.e., reducing the $310 \mathrm{c} / \mathrm{sec}$ to $265 \mathrm{c} / \mathrm{sec}$, the measured rate from the pin is $860 \mathrm{c} / \mathrm{sec}$.

Integral pulse height spectra were measured to obtain differential energy spectra in order to calculate the expected statistical fluctuation* in signal to background ratios. Stainless steel, with a majority of the gamma radiation from thermal neutron capture, exhibited a very hard spectrum while zircaloy, aluminum, graphite, and the uranium pin were much softer. From this consideration, a capsule of zircaloy would be preferable to a stainless steel capsule.

\section{PREDICTIONS AND RECOMMENDATIONS FOR A MARK II SYSTEM}

To predict the capabilities of a Mark II system, the above data were used along with the best available data on transient shapes and peak powers. $\dagger$ The extrapolated rates for a natural uranium pin at the peak and 2 sec later (for a transient that should melt the pin) when viewed by a 0.030 in. x 0.030 in. square collimating hole at $108 \mathrm{in.} \mathrm{from} \mathrm{the} \mathrm{pin} \mathrm{are}$ given in Table 7. Also shown for comparison are the extrapolated values for a $1 / 8$-in. -wall

*Criteria for the statistical fluctuations at low counting rates are derived in Appendix C. $\dagger$ †. Okrent, D. F. Schoeberle, and L. Lois, Trans. Amer. Nuc. Soc. 2(No. 2):56, Nov. 1959, and private communication from C. E. Dickerman. 
Table 5

Predicted and Measured Counting Rates from Various Materials

\begin{tabular}{|c|c|c|c|c|c|c|c|}
\hline \multirow[b]{2}{*}{ Material } & \multirow[b]{2}{*}{$\begin{array}{l}\text { Atoms/cc } \\
\times 10^{-22}\end{array}$} & \multirow[b]{2}{*}{$\begin{array}{c}\text { Source } \\
\text { Width (in.) }\end{array}$} & \multicolumn{4}{|c|}{ Predicted Rates (c/sec) } & \multirow[b]{2}{*}{ Measured } \\
\hline & & & $\begin{array}{c}\text { Capture } \\
\text { Radiation }\end{array}$ & $\begin{array}{l}\text { Compton* } \\
\text { Scattering }\end{array}$ & $\begin{array}{l}\text { Inelastic }{ }^{-} \\
\text {Scattering }\end{array}$ & Total & \\
\hline $\begin{array}{l}\text { Stainless } \\
\text { Steel }\end{array}$ & 8.45 & 0.031 & 135 & 85 & 71 & 291 & 295 \\
\hline Graphite & 8.1 & 0.150 & - & 241 & 2 & 243 & 245 \\
\hline Zircaloy & 4.25 & 0.028 & 11 & 79 & 44 & 134 & 130 \\
\hline Aluminum & 6.00 & 0.050 & 30 & 93 & 40 & 163 & 165 \\
\hline Sodium & 2.53 & 0.025 & 5 & 18 & 20 & 43 & - \\
\hline
\end{tabular}

* The counting rate from graphite was assumed to arise from Compton scattering of the reactor gamma flux. Therefore the carbon data was used to calculate the gamma flux used to predict the Compton scattering for other materials. This flux was assumed to enter the sample from the side, scatter through 90 degrees, and be attenuated going out of the sample.

TIt was assumed all neutrons above $1.0 \mathrm{Mev}$ that were inelastically scattered lost most of their energy in approximately $1.0-\mathrm{Mev}$ gammas.

Table 6

Predicted Counting Rates for Uranium Fuel Pins at $70 \mathrm{kw}$ Steady-State Operation for a $0.030 \mathrm{in.} \times 0.060 \mathrm{in}$. Hole

\begin{tabular}{|c|c|c|c|c|}
\hline \multirow{3}{*}{ Source } & \multicolumn{4}{|c|}{ Counting Rate $(\mathrm{c} / \mathrm{sec})$} \\
\hline & \multirow{2}{*}{$\begin{array}{l}\text { Bare } \\
6 \% \text { Pin }\end{array}$} & \multicolumn{3}{|c|}{ Contained in Zircaloy Container } \\
\hline & & $6 \% \mathrm{Pin}$ & $3 \% \mathrm{Pin}$ & Natural Uranium \\
\hline Stainless Steel Cladding & 7 & 6 & 6 & 6 \\
\hline Gammas Scattering by $U$ & 19 & 16 & 16 & 16 \\
\hline Inelastic Scattering by $U$ & 55 & 47 & 47 & 47 \\
\hline Prompt Gammas from $\mathrm{U}^{235}$ & 525 & 445 & 223 & 59 \\
\hline Radiative Capture from $\mathrm{U}^{235}$ & 39 & 33 & 17 & 8 \\
\hline Radiative Capture from $\mathrm{U}^{238}$ & 16 & 14 & 15 & 16 \\
\hline Fast Fission & 6 & 5 & 5 & 5 \\
\hline Delay Gammas & 345 & 292 & 146 & 37 \\
\hline Total & 1012 & 858 & 475 & 194 \\
\hline
\end{tabular}

zircaloy container with a 1/4-in. graphite liner and for a 1/16-in. -wall stainless steel container. The lower half of Table 7 shows these same rates increased by a factor of 8 , which could be accomplished by doubling the height of the collimating hole and reducing the speed of drum rotation by 2 . The corresponding space resolution would be 0.15 in. $\mathrm{x} 0.30 \mathrm{in}$. Increasing the horizontal dimension of the collimating hole is undesirable because it favors the container signal more than the fuel pin signal. Since the vertical height viewed is doubled, the same fraction of the pin could be viewed as before by reducing the number of levels to 40 . Then by doubling the number of holes per level, the $5-\mathrm{ms}$ time resolution could be maintained. 
Table 7

Predicted Number of Pulses Above

$0.17 \mathrm{Mev}$ per Resolution Element Scanned Assuming an Integration Time Equal to the Time to Scan a Resolution Element

\begin{tabular}{|l|c|c|c|c|}
\hline \multirow{2}{*}{ Source } & \multicolumn{2}{|c|}{ Natural Uranium Pin } & \multicolumn{2}{c|}{$3 \%$ Enriched Pin } \\
\cline { 2 - 5 } & $\begin{array}{c}\text { Peak } \\
(\approx 615 \mathrm{Mw})\end{array}$ & $\begin{array}{c}2 \mathrm{sec} \\
\text { later }\end{array}$ & $\begin{array}{c}\text { Peak } \\
(\approx 300 \mathrm{Mw})\end{array}$ & $\begin{array}{c}1 \mathrm{sec} \\
\text { later }\end{array}$ \\
\hline \hline \multicolumn{5}{|c|}{0.030 in. x $0.030 \mathrm{in}$. Hole } \\
\hline Pin & 12.8 & 0.98 & 13.2 & 1.32 \\
Zircaloy Container & 16.4 & 1.1 & 8.0 & 0.8 \\
Stainless Steel Container & 13.7 & 0.9 & 6.7 & 0.7 \\
\hline \multicolumn{5}{|c|}{0.030 in. x 0.060 in. Hole and One-Half Rotation Speed } \\
\hline Pin & 102 & 7.8 & 106 & 10.6 \\
Zircaloy Container & 131 & 8.8 & 64 & 8.0 \\
Stainless Steel Container & 109 & 7.2 & 53 & 5.6 \\
\hline
\end{tabular}

To illustrate the importance of the fluctuations in pulse height and to show the larger effect in stainless steel, computations were made on the signal counting rates from a fuel pin required above the container signal for both the zircaloy (plus graphite liner) and stainless steel containers to meet the statistical criterion given by Eq. (1). Table 8 shows the signal values required to meet the criterion for the two containers when assuming $\mathrm{k}_{\mathrm{s}}=\mathrm{k}_{\mathrm{c}}=1$ (on approximately $90 \%$ of the scans the pin signal will be higher than the wing data). Comparison of these values with those predicted (shown in Table 7) indicate that for viewing a fuel pin with a $0.030 \mathrm{in} . x 0.030 \mathrm{in}$. hole, this criterion can be met at the peaks of the transients with the zircaloy container but not for any appreciable time after the peak. With the gain of 8 , this criterion could be met for some time after the peak with the zircaloy container but not for the stainless steel container.

The following conclusions and recommendations were forwarded to Argonne for their consideration:

1. It was feasible and practical to fabricate a Mark II drum from brass plates ground smooth, with rectangular slots milled in the surface for collimating holes. The 23 in. of solid brass and modification of other shielding to alternate layers of lead, iron, and plastic (plus boron) should reduce background satisfactorily.

2. Since all materials placed in the center of the reactor will scatter or emit gamma rays in serious quantities, the background from containers is a most important consideration; therefore, as much material as possible should be removed from the test section. Since the fluctuations in pulse height are important and become greater for materials with a high contribution from hard capture gamma radiation, such as stainless steel, it was recommended that stainless steel containers be replaced by zircaloy containers.

3. With 0.030 in. $\times 0.060$ in. rectangular holes (space resolution $0.15 \times 0.30$ in.), fuel pins could be viewed during transients long enough to 'see the meltdown if a zircaloy container were used. Therefore, under these conditions, a radiation scanning device would work reasonably well with a Mark II drum made from 40 brass plates, 0.4 in. thick with 24 rectangular holes per level (0.030 in. x 0.060 in.). 
Table 8

Minimum Values of $\overline{\mathrm{N}}_{\mathrm{s}}$ Required to Meet the Criterion of Eq. (1) When $k_{s}=k_{c}=1$

\begin{tabular}{|r|c|c|}
\hline \multirow{2}{*}{$\overline{\mathrm{N}}_{\mathrm{c}}$} & \multicolumn{2}{|c|}{$\mathrm{N}_{\mathrm{s}}$} \\
\cline { 2 - 3 } & Zircaloy & Stainless Steel \\
\hline 0 & 1.44 & 1.44 \\
1 & 3.44 & 7.36 \\
2 & 4.27 & 9.83 \\
3 & 4.91 & 11.71 \\
4 & 5.44 & 13.28 \\
5 & 5.90 & 14.65 \\
6 & 6.34 & 15.91 \\
7 & 6.84 & 17.14 \\
8 & 7.09 & 18.19 \\
9 & 7.44 & 19.20 \\
16 & 9.44 & 25.12 \\
25 & 11.44 & 31.04 \\
36 & 13.44 & 36.91 \\
49 & 15.44 & 42.83 \\
64 & 17.44 & 48.75 \\
81 & 19.44 & 54.67 \\
100 & 21.44 & 60.59 \\
\hline
\end{tabular}

\section{MEASUREMENTS, AUGUST 1960}

After consideration of the above conclusions and recommendations, ANL personnel made the following decisions:

1. To insure the safety of the TREAT reactor against contamination, meltdown experiments would have to be carried out in stainless steel capsules (distrust of zircaloy welds), and these capsules would be placed within the standard dummy element.

2. Since the above decision makes it impossible to distinguish any fuel pins (from natural to $6 \%$ enrichment) from this nearly solid test section with previously considered space and time resolutions, they asked for consideration of a Mark II drum with a horizontal space resolution of 0.15 in., a vertical resolution in the range 0.5 to $1.0 \mathrm{in}$., and a time resolution of $5 \mathrm{~ms}$.

NRL was instructed to prepare test plates with collimating holes corresponding to this space resolution, modify the shielding in front of the drum, and determine the capabilities of a radiation scanning device with these dimensions to view meltdown of enriched fuel pins.

\section{Shield Modifications}

For the previous measurements the cart was withdrawn from its designed-in-theniche position so that more shielding could be inserted ahead of the cart and thereby reduce the background counting rate. It became apparent from various measurements with different shielding arrangements that the neutron-generated gamma-ray sources near the detector cavity were the main contributors to the uncollimated background counting rate. By improving the neutron attenuation of the shield ahead of the drum, the cart 
could be moved back into the niche. If additional shielding were required, it should be added between the drum and detector cavity to preserve the best space resolution.

The new shield shown in Fig. 31, consisted of replacing the shield ahead of the drum with alternating 2-in.-thick layers of iron, polyethylene, and lead. A 1/4-in.-thick sheet of boron-loaded plastic was inserted behind each layer of polyethylene to absorb the thermalized neutrons. These layers wereplaced perpendicular to the beam of radiation from the reactor. The tapered slot in these layers of material was 1.3 degrees wide and 16 in. tall. In front of this combination shield and in the area of the permanent reflector was a graphite block which also had a slot 16 in. tall and tapered to match the slotted opening in the combination shield.

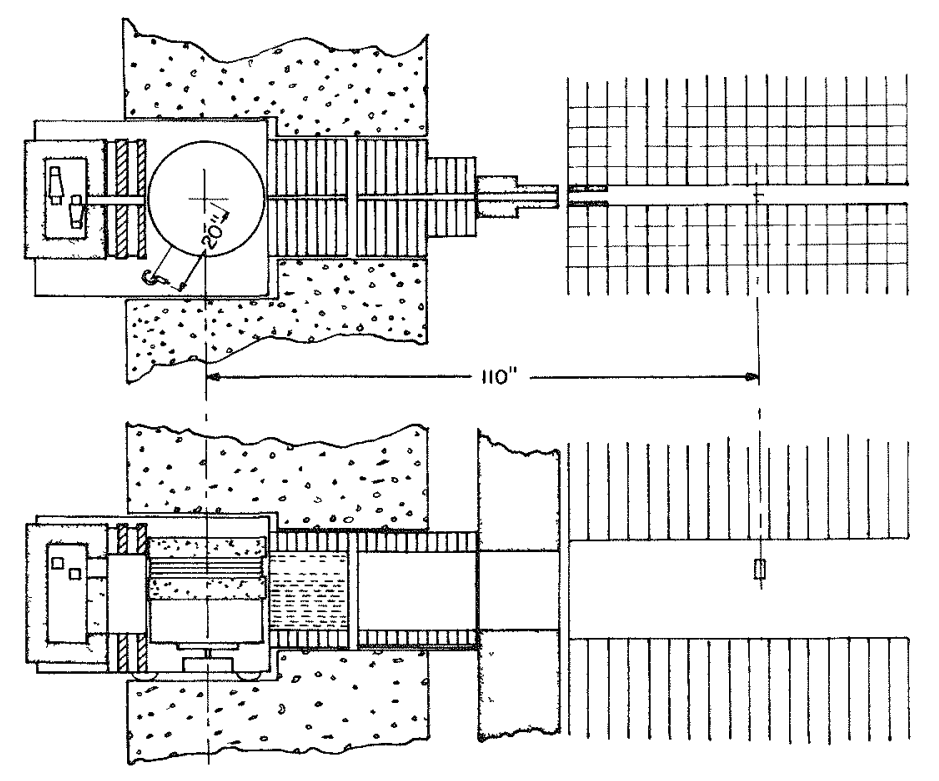

Fig. 31 - Shielding arrangement for August 1960 tests

For this series of tests, a partial drum of two plates was made of $7 / 8$-in.-thick brass. Both plates had three different depth radial slots cut in them with an angular separation of 3.0 degrees. Above and below these plates were 1 -in.-thick brass plates, and these in turn were sandwiched between two 4-in.-tall circular pans of lead shot potted with wax. This assembly was placed on a 6-in.-tall stack of circular plywood sheets which sat on the drum spindle. A radial arm was attached to this partial drum so that the drum could be turned with a micrometer. The micrometer pushed on the arm at a point 20 inches from center of the drum. It was also possible to rotate the upper plate with respect to the lower plate, thus making it possible with the use of individual detectors for each plate to obtain simultaneous measurements of the signal from the fuel pin and from the container during a transient.

The shielding between the drum and the detector housing was not changed. This 8-in. space was filled with alternate layers of steel and wax, with each wax layer followed by 1/4-in.-thick boron-loaded plastic. The vertical slot in the detector housing was restricted to a 4-in. opening because of the insufficient attenuation of radiation above and below the brass plates. Separate sodium iodide crystals were lined up with each layer of holes. 


\section{Static Tests}

The first series of tests was to check out the alignment of the modified shielding as well as to check out the electronics. For all these tests the cart was in the niche, with the center of the drum $110 \mathrm{in}$. from the center of the reactor. Since the lever arm on the drum was $20 \mathrm{in}$. long, the readings on the micrometer had to be multiplied by $110 / 20=5.5$ in order to arrive at the corresponding displacement at the center of the reactor, It was possible to scan the central 2.33 in. of the test section.

A 0.022 -in.-thick cadmium foil, 1 in. wide and 4 in. long, was mounted in a slotted fuel element located at the center of the reactor. This cadmium foil served as an intense source of gamma rays when the reactor was operating. When discriminating against pulses of less than $0.17 \mathrm{Mev}$, the measured cadmium pulse rate for the three different size holes with the reactor at $1.0 \mathrm{kw}$ power level is as given in Table 9 .

Table 9

Measured Counting Rates for Cadmium

\begin{tabular}{|c|c|c|c|c|}
\hline \multicolumn{2}{|c|}{ Hole Size (in.) } & \multirow{2}{*}{$\begin{array}{c}\text { Total } \\
\text { Signal } \\
(\mathrm{c} / \mathrm{sec})\end{array}$} & \multirow{2}{*}{$\begin{array}{l}\text { Background } \\
(\mathrm{c} / \mathrm{sec})\end{array}$} & \multirow{2}{*}{$\begin{array}{l}\text { Cadmium } \\
\text { Signal } \\
\text { (c/sec) }\end{array}$} \\
\hline Width & Depth & & & \\
\hline 0.025 & 0.200 & 1200 & 150 & 1050 \\
\hline 0.025 & 0.150 & 670 & 150 & 520 \\
\hline 0.025 & 0.100 & 400 & 150 & 250 \\
\hline
\end{tabular}

The cadmium signal is proportional to the square of the depth of the hole because the signal is not only proportional to the length of the source being viewed but also to the solid angle of radiation intercepted by the detector. Previously, the measured count rate from cadmium was $4400 \mathrm{c} / \mathrm{sec}$ with a $0.030 \mathrm{in}$. by $0.060 \mathrm{in}$. hole at a distance of $144 \mathrm{in}$. and a power level of $70 \mathrm{kw}$. Correcting for these various factors, the calculated counting rate for a 0.025 in. $x 0.200$ in. hole at a distance of $110 \mathrm{in}$. at $1.0 \mathrm{kw}$ reactor power is $1000 \mathrm{c} / \mathrm{sec}$.

The above measurements were made with the tapered slot ahead of the drum fully open. When the height of the slot was restricted to an opening slightly less than the thickness of the 4-in.-tall brass drum, the background counting rate was reduced by a factor of 2.25 , corresponding to an opening reduction factor of 4.85 . It must be remembered that the crystal detectors are 2 in. tall, whereas the partial brass drum is only 4 in. tall.

One objective of the August tests was to ascertain the effectiveness of gamma shields on each side of the test section which would reduce the flux of reactor gammas incident on the graphite. The February data indicated that $98 \%$ of the counting rate from graphite in the test section was due to reactor core gammas undergoing Compton scattering in the graphite. If the flux of gammas incident on the test section could be reduced without appreciable neutron flux depression, the contrast between fuel pin and the surrounding graphite test element could be improved. In order to measure the effectiveness of side shields, the gamma source strength of a plate of graphite as well as stainless steel and cadmium foil was measured for various shielding configurations.

Stainless steel was measured because it is another material used in the test element that has a high gamma source strength. The shields would not be expected to reduce the signal from stainless steel because $70 \%$ of this signal was due to neutron-induced radiations. Cadmium was included to monitor the thermal neutron flux levels. There was no measurable depression of the thermal neutron flux with these shields. 
The three materials were mounted in a slotted fuel element so that the plates were viewed edge-on and were separated by 0.625 in. The horizontal space resolution of the 0.025 -in. wide hole was 0.15 in. which was sufficiently narrow to resolve the three plates.

The shields were made of bismuth encased in aluminum cans ( $2 \mathrm{in}$. thick, 4 in. wide, and $20 \mathrm{in.} \mathrm{long).} \mathrm{They} \mathrm{were} \mathrm{fabricated} \mathrm{so} \mathrm{as} \mathrm{to} \mathrm{fit} \mathrm{into} \mathrm{a} \mathrm{slotted} \mathrm{fuel} \mathrm{element,} \mathrm{but} \mathrm{because}$ of reactor safety considerations they were mounted in zircaloy dummy elements. The zircaloy element was essentially another container to contain the bismuth if it became molten during a reactor excursion. Since there were only two empty dummy elements available, the tests had to be made sequentially; that is, the gamma intensities of the three materials were first measured without a shield, then with one shield on each side of the test section (side shields), and then with the same shielding elements at the right and left flanks of the test section (back shields).

The first series of tests was made with the slot through the reactor fully opened, so that the graphite reflector was viewed at the far side of the reactor. With this experimental setup, the total background counting rate was about twice the magnitude of the signal from the graphite and stainless steel. Figure 32(a) is a scan across the three materials with side shields. The stainless steel plate was $0.031 \mathrm{in}$. thick; the cadmium $0.022 \mathrm{in}$. thick and the graphite was $0.150 \mathrm{in}$. thick. The high background counting reduced the reliability of these measurements, so the measurements were repeated with the graph ite reflector retracted or in the up position. The total background counting rate was reduced by a factor of two, so that now the total background was the order of the signal. Figure 32(b) is a scan across the graphite and steel plates with the graphite gate retracted and clearly shows the reduction of the collimated background. Cadmium foil was removed in order to check its possible nuclear interaction with the other materials.

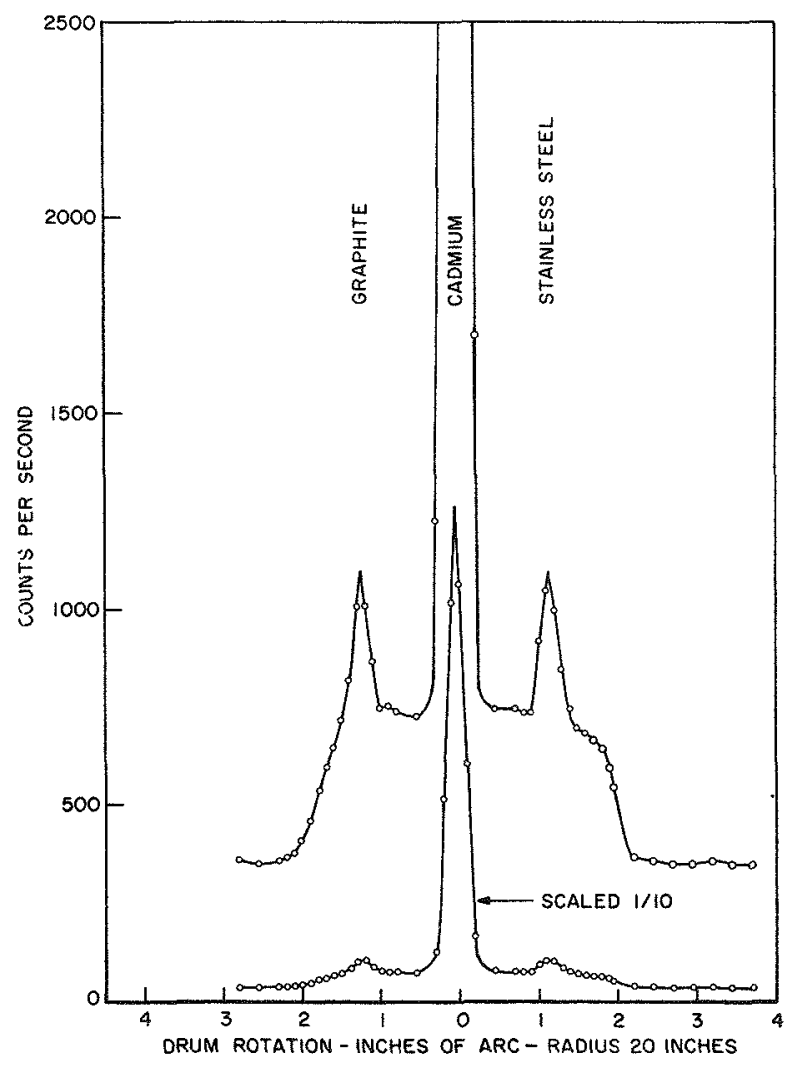

Fig. 32(a) - Scan of graphite, cadmium, and stainless steel plates 


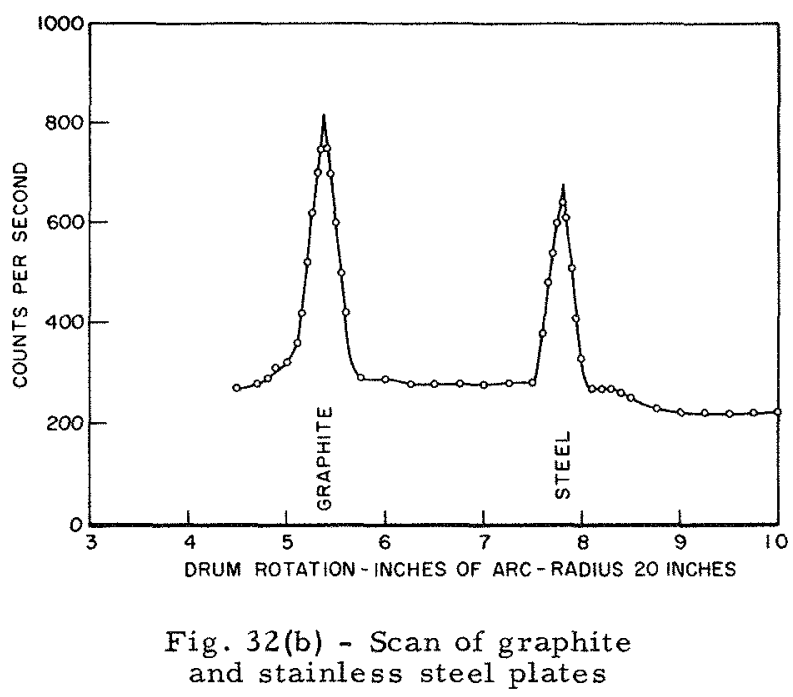

The background is made up of two parts; one part is the collimated gammas emitted from the backdrop, i.e., the graphite at the far side of the reactor, and the other is the uncollimated background from gammas which penetrate the drum or are neutron-produced in or near the detector cavity. These two components were of the same order of magnitude when the graphite gate was down, but the collimated or backdrop rate was only $20 \%$ of uncollimated background rate when the gate was retracted. Because the sample material attenuates that part of the backdrop signal which the sample hides, the correction of the raw data was complicated. Since this correction was large for the case with graphite gate down, the reliability of the data is reduced.

The corrected data for both cases is tabulated in Table 10. It can be seen that the data with the graphite gate up is more consistent and indicates that there is a slight increase in both the graphite and stainless steel signals with the addition of side or back shields. This result is not too unreasonable for the following reasons: Firstly, the shields are $2.0 \mathrm{in}$. thick and for good geometry this would reduce the 1 to $2 \mathrm{Mev}$ transmitted gamma flux to $13 \%$ of the incident flux. Secondly, the solid angle of reactor sources which a pair of shields will attenuate is roughly $30 \%$. So, $30 \%$ of the signal is reduced to $13 \%$, which is $4 \%$ of all the signal. The unattenuated $70 \%$ of the flux plus this $4 \%$ means that $74 \%$ is still incident on the sample. Thirdly, both fast and thermal neutrons produce gammas in the bismuth shields, so in effect their gamma attenuation is reduced; and fourthly, there was no shield above or below the sample.

The data in Table 10 with the graphite gate up and no shields is plotted in Fig. 33 along with the total background counting rate. These curves are the integral pulse height spectra as seen by the 1-in.-wide, 2-in.-tall, 2-in.-deep sodium iodide crystal detector. No correction was made for crystal efficiency at the various energies. The differential spectra of graphite and stainless steel were derived from these integral curves. Measurements of the spectrum were not carried to higher energies because of nonlinearity of the discriminator. Extrapolations were made to the higher energies such that the sum of the differential spectrum above $1.83 \mathrm{Mev}$ was equal to the value of the measured integral at $1.83 \mathrm{Mev}$.

It can be seen that the stainless steel spectrum is much harder than the graphite. The contribution of Compton-scattered gammas in graphite can be seen at low energies. The probability of these lower energy gammas emerging from the less dense graphite is much greater than for steel. The spectra using side and back shields are very similar in shape to these curves. The graphite spectrum was hardened somewhat by the addition of shields. 
Table 10

Summary of Corrected Steel and Graphite Counting Rates

August 1960 Data

\begin{tabular}{|c|c|c|c|c|c|c|c|c|c|}
\hline \multirow{2}{*}{\multicolumn{2}{|c|}{$\begin{array}{c}\text { Discriminator } \\
(\mathrm{Mev})\end{array}$}} & \multicolumn{3}{|c|}{ Gate Up } & \multicolumn{5}{|c|}{ Gate Down } \\
\hline & & $\begin{array}{c}\text { No } \\
\text { Shields }\end{array}$ & $\begin{array}{c}\text { Side } \\
\text { Shields }\end{array}$ & $\begin{array}{c}\text { Back } \\
\text { Shields }\end{array}$ & \multirow{2}{*}{$\begin{array}{c}\text { No } \\
\text { Shields } \\
\mathrm{el}\end{array}$} & \multirow[t]{2}{*}{$\begin{array}{c}\text { Side } \\
\text { Shields }\end{array}$} & \multicolumn{3}{|c|}{$\begin{array}{l}\text { Back } \\
\text { Shields }\end{array}$} \\
\hline \multicolumn{8}{|c|}{ Stainless Steel } & & \\
\hline \multicolumn{2}{|l|}{0.17} & 372 & 394 & 382 & 384 & 360 & 340 & 298 & 390 \\
\hline \multicolumn{2}{|l|}{0.50} & 288 & 260 & 270 & 202 & 222 & 168 & 151 & 278 \\
\hline \multicolumn{2}{|l|}{0.83} & 215 & 211 & 228 & 150 & 190 & 152 & 124 & 218 \\
\hline \multicolumn{2}{|l|}{1.17} & 167 & 175 & 180 & 123 & 140 & 104 & 111 & 194 \\
\hline \multicolumn{2}{|l|}{1.51} & 143 & 143 & 151 & 100 & 122 & 97 & 108 & 154 \\
\hline \multicolumn{2}{|l|}{1.83} & 102 & 122 & 110 & 63 & 94 & 74 & 82 & 116 \\
\hline \multirow{3}{*}{$\begin{array}{l}\text { Calc } \\
\text { Constants }\end{array}$} & $P_{1}$ & 1.24 & 1.27 & 1.30 & & & & & \\
\hline & $\mathrm{P}_{2}$ & 1.53 & 1.65 & 1.59 & & & & & \\
\hline & F & 1.23 & 1.30 & 1.22 & & & & & \\
\hline \multicolumn{10}{|c|}{ Graphite } \\
\hline \multicolumn{2}{|l|}{0.17} & 442 & 487 & 452 & 634 & 553 & 445 & 424 & 563 \\
\hline \multicolumn{2}{|l|}{0.50} & 221 & 247 & 257 & 290 & 276 & 190 & 207 & 291 \\
\hline \multicolumn{2}{|l|}{0.83} & 144 & 172 & 182 & 189 & 170 & 142 & 123 & 190 \\
\hline \multicolumn{2}{|l|}{1.17} & 108 & 124 & 128 & 94 & 97 & 80 & 75 & 131 \\
\hline \multicolumn{2}{|l|}{1.51} & 72 & 88 & 89 & 62 & 70 & 53 & 71 & 77 \\
\hline \multicolumn{2}{|l|}{1.81} & 29 & 56 & 45 & 24 & 39 & 33 & 34 & 42 \\
\hline \multirow{3}{*}{$\begin{array}{l}\text { Calc } \\
\text { Constants }\end{array}$} & $\mathrm{P}_{1}$ & 0.772 & 0.832 & 0.867 & & & & & \\
\hline & $\mathrm{P}_{2}$ & 0.964 & 1.06 & 1.07 & & & & & \\
\hline & $F$ & 1.25 & 1.27 & 1.23 & & & & & \\
\hline
\end{tabular}

Figure 34 shows a typical test element containing a uranium fuel pin capsule. The pin has to be viewed through 0.125 in. of stainless steel, 0.115 in. of zircaloy, and 1.15 in. of graphite; and in addition this same amount of material in back of the pin increases the backdrop counting rate. In other words, any material placed in front of or in back of the fuel pin will reduce the contrast between pin and surrounding area.

In an effort to assess the contribution from each of these containers a series of measurements were made, first with an empty test element and then repeated runs with the addition of successive and concentric containers. Figure 35 is a scan across the empty test element with side shields. On the upper part of the plot is a top view drawing of test element drawn to same scale and oriented horizontally to correspond with the scan plot. The field of view was restricted to about $2.0 \mathrm{in}$., which is just equal to the inside diam eter of the cylindrical hole in the test element. The field of view was restricted so that no reactor fuel lining the viewing slot would be seen by the scanning system. A measurement of the integral pulse height spectra from the middle of the test element showed that 
Fig. 33 - Integral pulse height spectra (see Table 10, no shields)
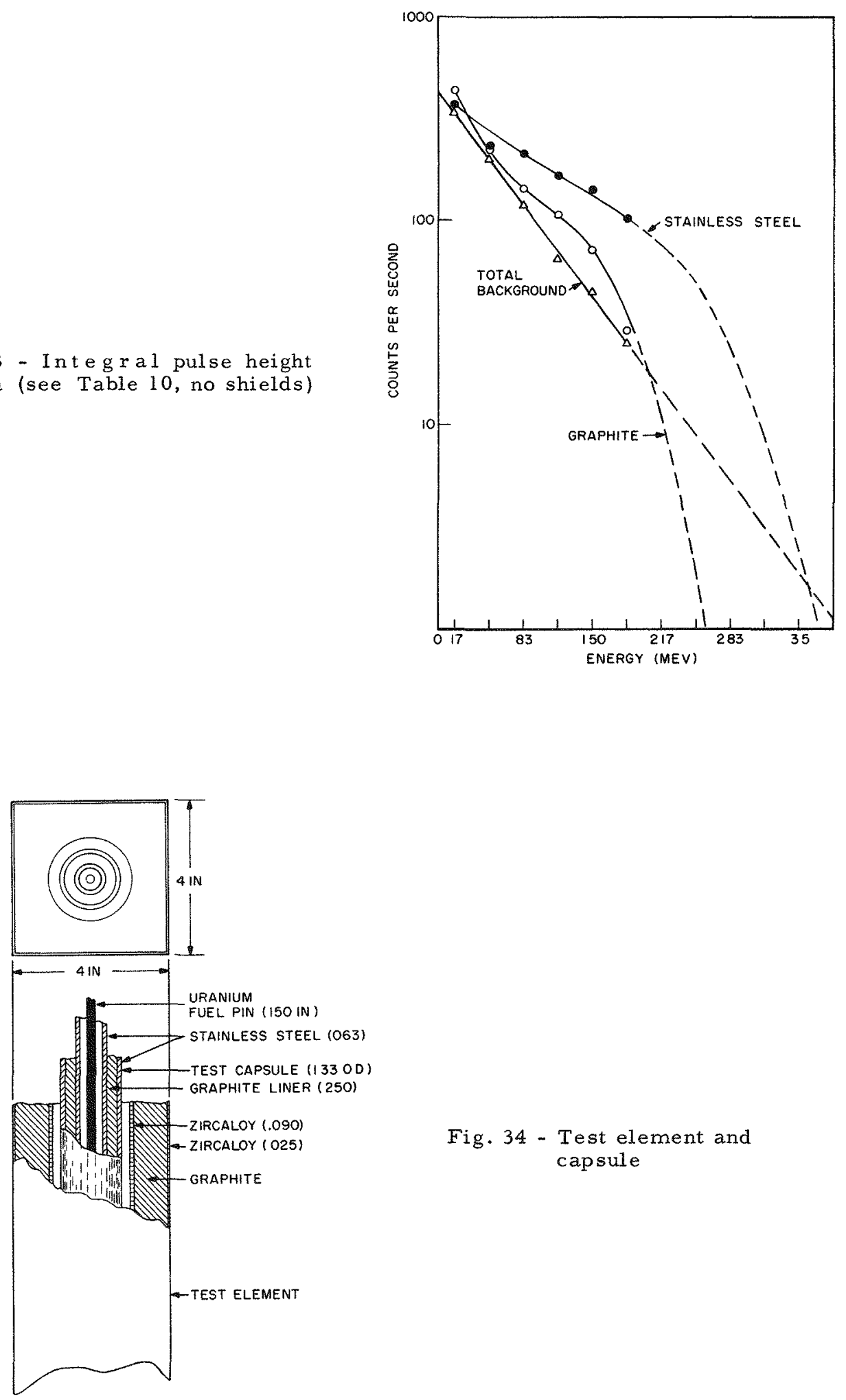

Fig. 34 - Test element and capsule 


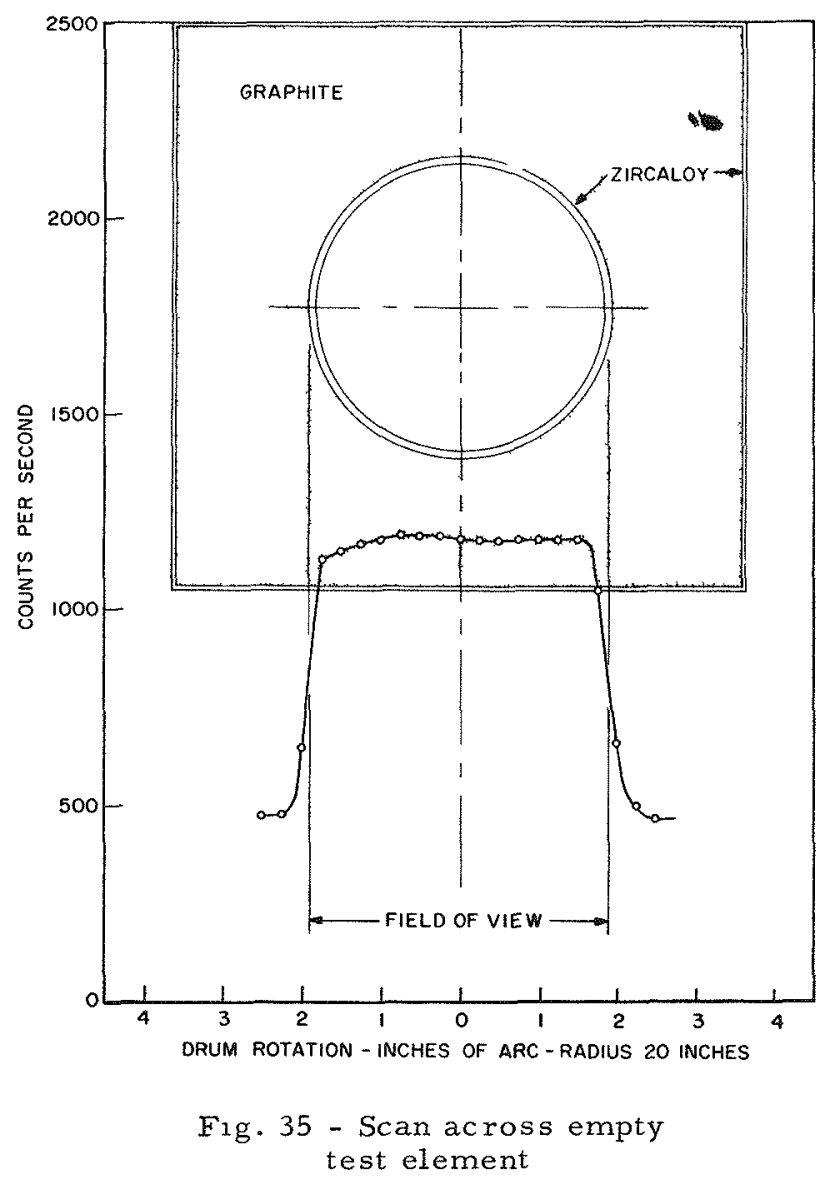

the spectra had a shape corresponding to the graphite curve in Fig. 33, except that above $1.83 \mathrm{Mev}$ the test element curve was higher. The values of three parameters (see Appendix C) were $P_{1}=0.918, P_{2}=1.15$, and $F=1.26$, whereas from Table 10 for graphite we have $P_{1}=0.832, P_{2}=1.06$, and $F=1.27$.

Figure 36 is a plot of the scan across the test element with a $1 / 16$-in.-thick stainless tube inserted. The counting rate at the midpoint of the test element did not increase, but the counting rate increased at edges of the tube because of the greater amount of stainless steel in the viewed area. The shape of the spectra at the midpoint and at the edge of the steel were both similar to graphite spectra. The harder stainless steel spectrum is filtered by the graphite so that it looks like graphite.

A test capsule as pictured in Fig. 34, except for the fuel pin, was inserted in the test element. A scan across this combination of containers is shown in Fig. 37. The inner stainless steel tube is just discernible in the center of the capsule.

This stainless steel tube would be much more prominent if it weren't for the edge effect as well as the filtering effect of the outer stainless steel tube. The resolution width of the hole is equal to about $1 / 3$ of the diameter of the inner steel tube. This is the composite background picture in which a uranium fuel pin must be seen with the exception that the signal from the material behind the dense fuel pin will be attenuated.

A sweep across a $6 \% \mathrm{U}^{235}$ fuel pin in a container as shown in Fig. 34 is plotted in Fig. 38. There were no shields for this run and the graphite gate in back of the test element was retracted. Retracting the gate reduced the container signal slightly. 
Fig. 36 - Scan across test element containing a stainless steel tube
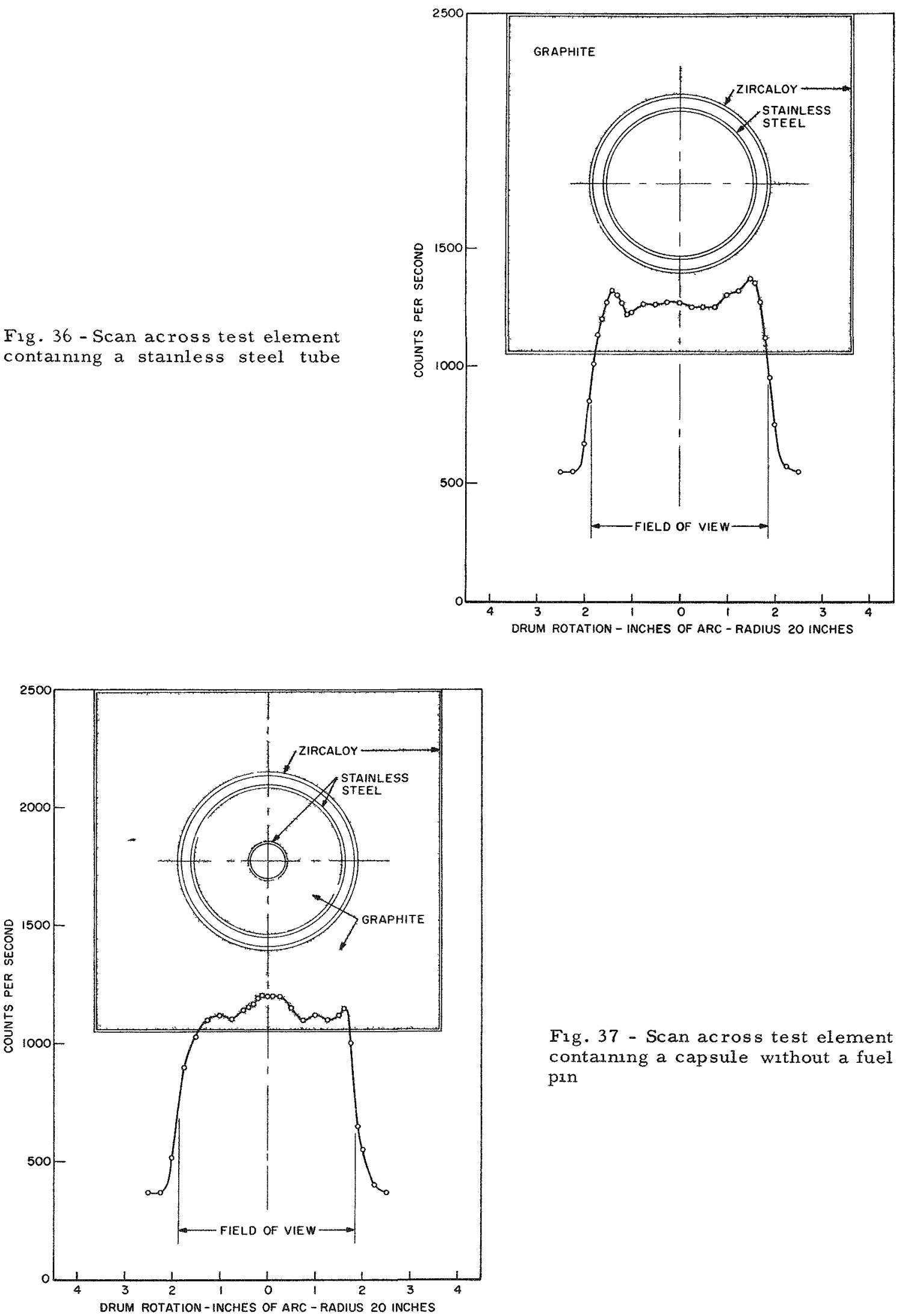

Fig. 37 - Scan across test element containing a capsule without a fuel pin 


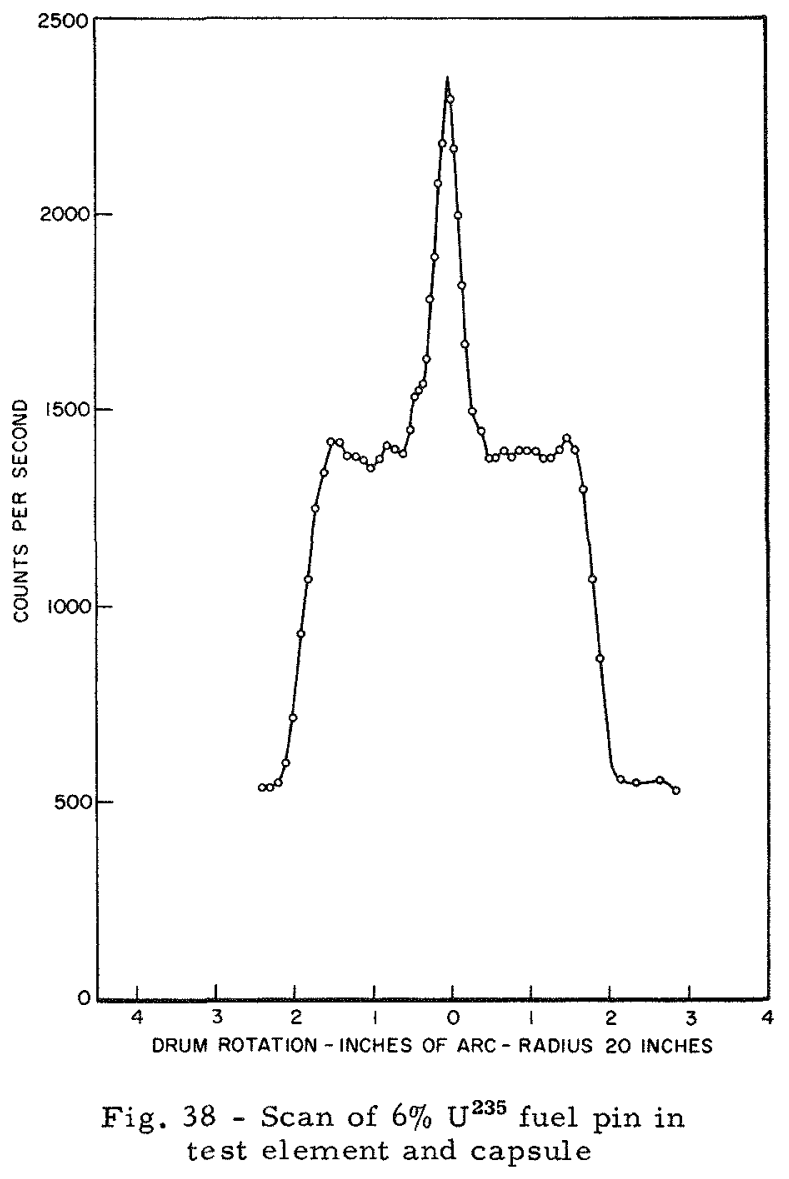

The inner stainless container can even be seen as a bulge at the base of the pin signal. The ratio of the pin plus total background to the total background is $2300 / 1400=1.64$, or what is more informative the pin signal to container signal ratio is $(2300-1400) /(1400$ $550)=900 / 850=1.06$. The $6 \% \mathrm{U}^{235}$ fuel pin is slightly brighter than this type of container for a horizontal spacial solution of $0.15 \mathrm{in}$. and a vertical resolution of $1.20 \mathrm{in}$.

The spectrum of the signal from the uranium fuel pin filtered by this combination of containers is plotted in Fig. 39. The container spectra is harder than the uranium spectra, and in fact the container is twice as bright as the uranium fuel pin with $1.83 \mathrm{Mev}$ energy cutoff.

A scan was made across the same $6 \% \mathrm{U}^{235}$ fuel pin in the test section with a side shield on each side of the test section. This scan is shown in Fig. 40. The side shields did seem to reduce the signal from the middle of the test element so that now the edges of the test capsule can be seen. The ratio of the pin to container signal is 1.04 , which essentially is the same as without the side shields.

A shield was placed on each side of the viewing slot just ahead of the test section and a scan was made across the same encapsulated $6 \% \mathrm{U}^{235}$ fuel pin. This scan is plotted in Fig. 41, which indicates that the front shields are slightly more effective than side shields.

The conclusion that can be drawn from these shielding tests, even assuming better shielding arrangements than those used for these tests, is that there is only a small 


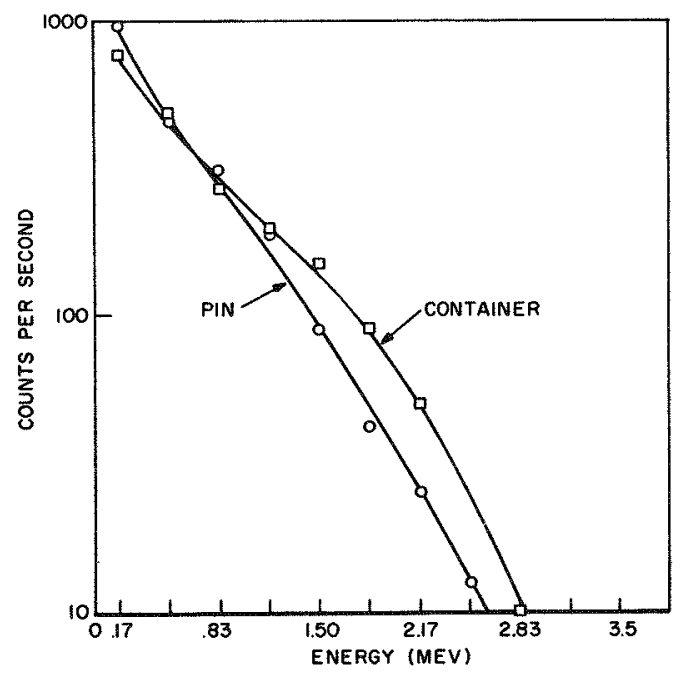

Fig. 39 - Integral pulse height spectra for $6 \%$ fuel pin and standard container

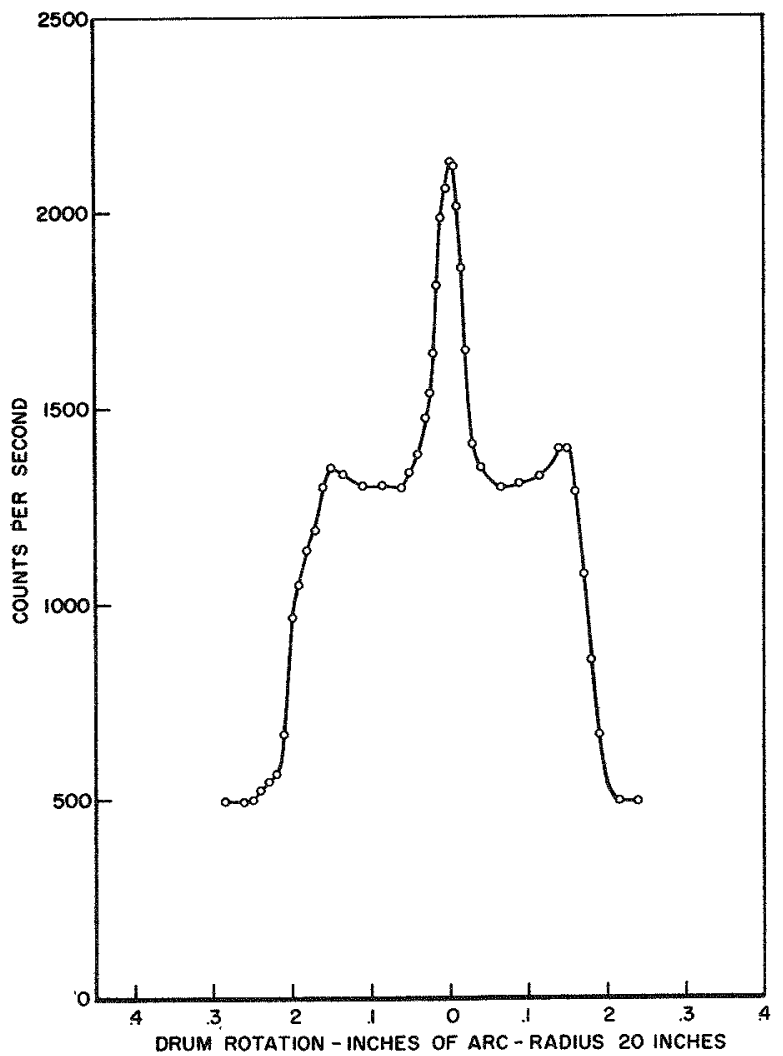

Fig. 40 - Scan of $6 \% \mathrm{U}^{235}$ fuel pin in test element with side shields 


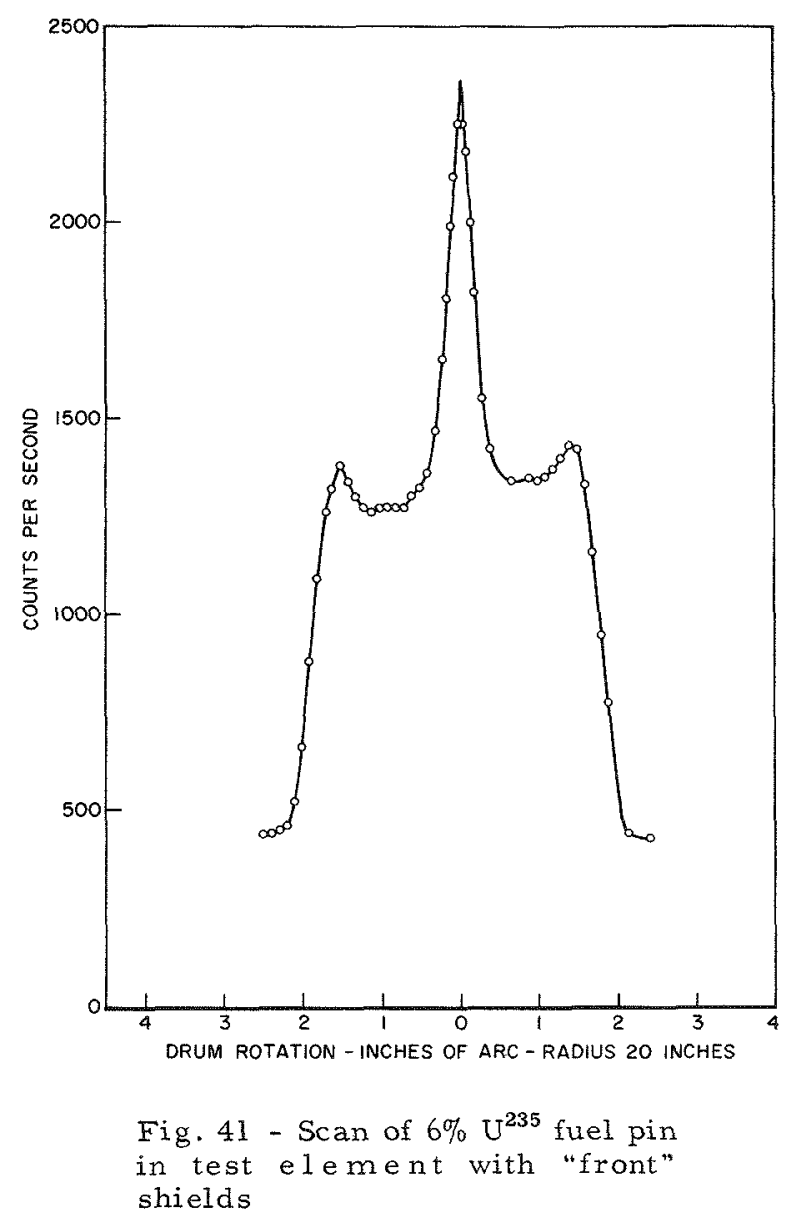

improvement in the contrast between fuel pin and the container. Any material placed in the reactor for shielding purposes becomes a source of radiation which roughly compensates for its attenuation properties.

\section{Transient Tests}

In order to confirm that the ratio of the fuel pin signal to container signal, measured under low-power steady-state conditions using a count rate meter, is equal to the ratio measured by an ammeter when fuel pin is subjected to a high peak power transient, a series of transient tests were made. At a steady-state power of $10 \mathrm{kw}$ the counting rate from the $6 \%$ fuel pin was $2500 \mathrm{c} / \mathrm{sec}$, which is easily measured by a count rate meter. Whereas a nominal peak power for a typical transient would be $100,000 \mathrm{kw}$, so that the expected counting rate would be $25,000,000 \mathrm{c} / \mathrm{sec}$, much too high to be measured by a count rate meter. Therefore, a measurement of the output current of the photomultipliers was made. This meant that there was no discrimination against low-energy pulses, which should not be significant since the amount of energy below $0.17 \mathrm{Mev}$ is small compared to the total energy above $0.17 \mathrm{Mev}$.

For these transient tests, a $6 \% \mathrm{U}^{235}$ fuel pin in a 1-3/4 in.-O.D. stainless steel capsule lined with graphite and placed inside a graphite test element was used. There was no inner stainless tube surrounding the fuel pin. This fuel pin was subjected to three nonmeltdown transients and one severe meltdown transient. 
For the first transient, a hole $(0.025 \mathrm{in}$. wide, $0.200 \mathrm{in}$. deep) in the top layer of the drum (Channel 2) was pointed at the container about $3 / 8$ in. to the right of the fuel pin. An identical hole in the bottom layer (Channel 3) was pointed at the fuel pin. Separate sodium iodide crystal-photomultiplier assemblies were placed behind each hole. The outputs of the photomultipliers were fed into two current amplifiers which were connected to different channels of a fast galvanometric recorder. The direct current output of both photomultipliers was measured with a sensitive micromicroammeter with the reactor at a power level of $70 \mathrm{kw}$. The output of Channel 3 was 1.5 times that of Channel 2 when viewing the same object. The amplifier and galvanometric recorder were calibrated with a current source just prior to each transient.

The first transient was No. 177. A peak power of $28 \mathrm{Mw}$ was reached, the integrated power was $7 \mathrm{Mw}-\mathrm{sec}$, and the period was $0.208 \mathrm{sec}$. The gains of the amplifier were set a little too high and the peak of the transient was clipped for about $70 \mathrm{~ms}$ on Channel 3. The ratio of the signal from Channel 3 to Channel 2 was 2.5. Since Channel 3 was 1.5 times more sensitive than Channel 2, the ratio of the fuel pin plus container plus background signal to the container plus background signal is $2.5 / 1.5=1.66$. This is in excellent agreement with the value of 1.64 measured under steady-state conditions. No measurement of the background counting rate was made under transient conditions. There was good agreement between the signal from the linear reactor power level circuit and our two data channels.

Transient 178 was run with Channel 2 looking at the pin and Channel 3 at the container, just the reverse of No. 177. A peak power of $24.4 \mathrm{Mw}$ was reached, and the integrated power was $6 \mathrm{Mw}-\mathrm{sec}$. The ratio of signal from the two channels was 1.22. Correcting for the difference in sensitivities of the detectors, the ratio of fuel pin plus container, plus background signal to the container, plus background is 1.83 , which is $11 \%$ larger than the ratio measured under steady-state conditions. There was very good agreement in the slopes of the linear power curves, and signals from Channels 2 and 3 when the power was increasing but on the down side of the peak signal from Channels 2 and 3 decayed more rapidly than the linear power curve. The linear power curve seemed to have a delay of about $8 \mathrm{~ms}$. The curves were parallel again after about $90 \mathrm{~ms}$.

Transient 179 was supposed to have been a meltdown transient, but the scram rods were driven in prematurely. The peak power was $97 \mathrm{Mw}$, and integrated power was $29 \mathrm{Mw}$ sec. Both channels were pointed at the pin in an attempt to see the pin break. The slopes of the curves on this transient were almost identical to the respective curves of the previous transient.

Transient 180 was a meltdown transient with a peak power of $164 \mathrm{Mw}$ and integrated power of $67.0 \mathrm{Mw}-\mathrm{sec}$. Figure 42 is the plotted output of Channel No. 3 (dashed curve) versus time in milliseconds after peak power. The solid curve is the linear power curve normalized to the same point at time of peak power. The linear power curve here has the same shape as Channel 3 in Transient 179 and, therefore, seems to be a fairly reliable reference. The record shows a definite break interpreted as removal of fuel at $50 \mathrm{~ms}$. The ratio of linear power to the Channel 3 signal varies from 1.38 at $50 \mathrm{~ms}$ to 1.85 at $90 \mathrm{~ms}$, which is in good agreement with the static value of 1.64 for the ratio of pin plus container (plus background) signal as shown in Fig. 40. Therefore, it is a reasonable interpretation that Channel 3 , which was viewing the $6 \%$ pin, was only seeing the container after the break at $50 \mathrm{~ms}$. The three points at the lower end of the dashed curve should be discounted because the signal was in the noise at this level.

Figure 43 is the plotted output of Channel 2 (dashed curve), and the same linear power level curve versus the time after peak power as in Fig. 42. The shape of this curve is certainly different than for Channel 3 , and one plausible explanation follows. 


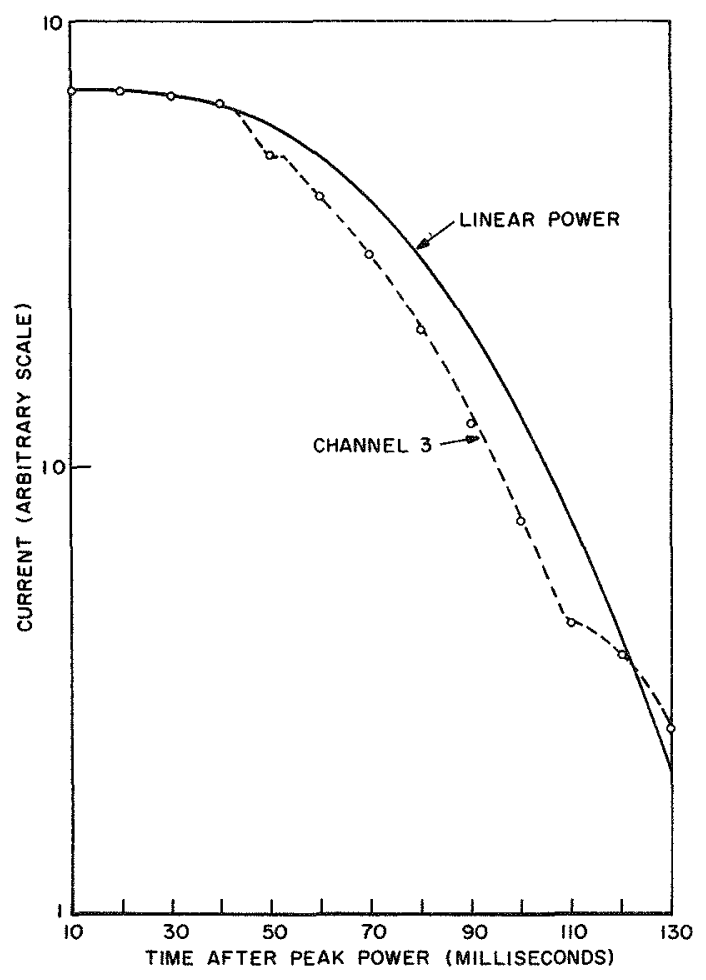

Fig. 42 - Comparison of pin signal from Channel 3 with linear power during Transient 180

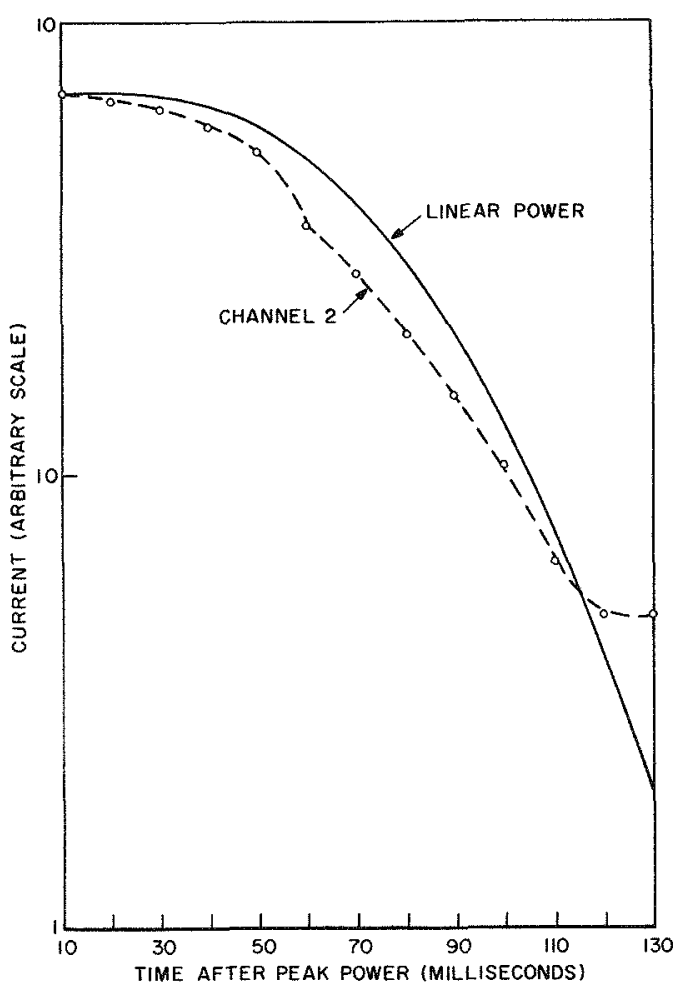

Fig. 43 - Comparison of pin signal from Channel 2 with linear power during Transient 180

The uranium melts at $70 \mathrm{~ms}$ before peak power and sags under the force of gravity to displace the sodium bond. The top of the uranium almost passes through the field of view of Channel 2 prior to the time of the catastrophic failure of the fuel pin clad. Initially, the top of the uranium pin is $1 \mathrm{in}$. above the top of the viewed area of Channel 2. If the 0.006 -in. sodium annulus is completely displaced by uranium, the level of the uranium can drop as much as 2.2 in. The level of the uranium will fall the first inch in $72 \mathrm{~ms}$, assuming free fall. At $75 \mathrm{~ms}$ before peak power, the lower thermocouple indicated a cladding temperature of $1040^{\circ} \mathrm{C}$. In an article on TREAT results ${ }^{*}$ it is reported that at a cladding temperature of $970^{\circ} \mathrm{C}$ some cladding failures occurred. Thus it appears that the uranium could be molten some $75 \mathrm{~ms}$ or more prior to peak power. The level of the uranium would, therefore, be just entering the field of view of Channel 2 at a time corresponding to peak power. The velocity of the uranium level at peak power would be $27 \mathrm{in} . / \mathrm{sec}$. The time for the uranium level to drop the next inch, which is the height of the field of view of Channel 2, is $30 \mathrm{~ms}$. This transit time is in very good agreement with the 35 to $40 \mathrm{~ms}$ derived from the signal level curves. The transit time is the difference between when Channel 2 was at full amplitude (10 ms after peak power) and when Channel 3 indicated the cladding failed ( 45 to $50 \mathrm{~ms}$ after peak power). Why the signal from Channel 2 did not remain parallel to the linear power curve is not clear, but the noise level on Channel 2 was much higher than on Channel 3.

$*$ E. S. Sowa, Nucleonics 18(No, 6):122, June 1960. 


\section{PREDICTIONS OF MARK II SYSTEM}

Based upon results of the above measurements, predictions about the Radiation Scanning Device with a Mark II drum can be made, including statistical effects for $3 \%$, $6 \%$, and $10 \%$ enriched pins mounted in a stainless steel capsule inserted into the usual graphite test element with collimating holes 0.025 in. wide and $0.100,0.150$, and 0.200 in. deep (vertical space resolutions are $1 / 2,3 / 4$, and 1 in.). With the 0.025 in. $\times 0.200$ in. hole, the counting rate of pulses above $0.17 \mathrm{Mev}$ from the $6 \%$ enriched pin was $800 \mathrm{c} / \mathrm{sec}$ above a container background of $750 \mathrm{c} / \mathrm{sec}$ at $10 \mathrm{kw}$ reactor power. If these results are converted to a transient scan by this hole across a $6 \%$ pin at $150 \mathrm{Mw}$ peak power, there would be 1920 counts per horizontal resolution element ( 0.16 in.) from the pin above 1800 counts per resolution element from the container. These values assume two lines per detector with a time resolution of $5 \mathrm{~ms}$. In Appendix $\mathrm{C}$, a formula is derived to consider statistical fluctuations in numbers of counts and pulse heights. This relation gives $\bar{N}_{s}$, the average number of pulses required from the pin in order to distinguish the pin from the background of the container in terms of $\vec{N}_{c}$, the average number of pulses from the container:

$$
\overline{\mathrm{N}}_{\mathrm{s}}=\mathrm{k}_{\mathrm{s}}^{2} \mathrm{~F}_{\mathrm{s}}^{2}+2 \mathrm{k}_{\mathrm{c}} \mathrm{F}_{\mathrm{c}} \frac{\mathrm{P}_{1 \mathrm{c}}}{\mathrm{P}_{1 \mathrm{~s}}} \sqrt{\overline{\mathrm{N}}_{\mathrm{c}}}
$$

where the $k$ 's are statistical parameters, the $F$ 's are dimensionless constants characteristic of the pulse height spectra and the p's are the average pulse heights. Pulse height data from the $6 \%$ pin in a stainless steel capsule inserted in the graphite dummy element gave the following values:

$$
\begin{array}{ll}
F_{s}=1.19 & P_{1 \mathrm{~s}}=0.8 \mathrm{Mev} \\
F_{c}=1.22 & P_{1 c}=0.91 \mathrm{Mev} .
\end{array}
$$

In the calculations that follow, we have assumed that $\mathrm{k}_{\mathrm{s}}=\mathrm{k}_{\mathrm{c}}=\mathrm{k}$ and have allowed $\mathrm{k}$ to take on the values of $2, \sqrt{2}$, and 1 , which approximately corresponds to $98 \%, 95 \%$, and $90 \%$ probability of each scan to distinguish the pin from the container.

Signal levels required from the pin to meet this statistical criteria are given in Tables 11-13 for the different hole depths. An examination of Table 11 indicates that a $0.025 \mathrm{in} . x 0.100 \mathrm{in}$. hole would give signal levels that would meet the $\mathrm{k}=2$ criterion down to $30 \%, 15 \%$, and $12 \%$ of peak power for the three enrichments, respectively. Table 12 shows that a 0.025 in. $x 0.150$ in. hole would meet the $\mathrm{k}=2$ criterion down to $10 \%, 5 \%$, and $<5 \%$ of peak powers (for typical meltdown transients) for the respective enrichments. Table 13 shows clearly that with a 0.025 in. $x 0.200$ in. hole, the data would meet the $k=2$ criterion down from the peak at least a factor of ten in all cases.

It would appear that the $0.025 \mathrm{in}$. $x 0.150 \mathrm{in}$. holes (vertical space resolution $\approx 3 / 4 \mathrm{in}$.) would be the best compromise for the Mark II drum. Such a drum would contain 24 solid brass plates, 23.5 in. in diameter and $2 / 3$ in. thick. Each plate would contain 45 through rectangular slots 0.025 in. wide and 0.150 in. deep. All plates would be the same but adjacent plates would be rotated by $1-1 / 3$ degrees. The speed of drum rotation would be approximately $150 \mathrm{rpm}$ for a time resolution of $5 \mathrm{~ms}$. Eight crystal detectors would be used, but each crystal would only view three different layers. Since the number of lines has been reduced from ten to three per detector, the previously designed television-type of display is not appropriate; so an amplitude versus time type of presentation is being proposed which eliminates the need for the complicated electronic sweeps. Each of the eight signal channels would be fed into appropriate amplifiers and then to the vertical 
Table 11

Signal Levels (counts/resolutions element)

Required to Meet the Statistical Criteria with a Slot 0.025 in. $x 0.100$ in., Four Lines per Crystal

\begin{tabular}{|c|c|c|c|c|c|}
\hline \multirow{2}{*}{$\begin{array}{c}\text { Power } \\
\text { (\% of peak) }\end{array}$} & \multirow{2}{*}{$\mathrm{N}_{\mathrm{c}}$} & \multirow{2}{*}{$\mathrm{N}_{\mathrm{s}}$} & \multicolumn{3}{|c|}{$\mathrm{N}_{\mathrm{s}}$ (required) } \\
\hline & & & $k=2$ & $\mathrm{k}=\sqrt{2}$ & $k=1$ \\
\hline \multicolumn{6}{|c|}{$3 \%$ Pin, Peak Power $=300 \mathrm{Mw}$} \\
\hline 100 & 450 & 240 & 124 & 86 & 61 \\
\hline 80 & 360 & 192 & 111 & 76 & 54 \\
\hline 60 & 270 & 144 & 97 & 67 & 47 \\
\hline 40 & 180 & 96 & 80 & 56 & 39 \\
\hline 20 & 90 & 48 & 58 & 40 & 28 \\
\hline 10 & 45 & 24 & 43 & 30 & 20 \\
\hline 5 & 23 & 12 & 32 & 22 & 15 \\
\hline \multicolumn{6}{|c|}{$6 \%$ Pin, Peak Power $=150 \mathrm{Mw}$} \\
\hline 100 & 225 & 240 & 89 & 62 & 43 \\
\hline 80 & 180 & 192 & 80 & 56 & 39 \\
\hline 60 & 135 & 144 & 71 & 48 & 33 \\
\hline 40 & 90 & 96 & 58 & 40 & 28 \\
\hline 20 & 45 & 48 & 43 & 30 & 20 \\
\hline 10 & 23 & 24 & 32 & 22 & 15 \\
\hline 5 & 11 & 12 & 24 & 16 & 11 \\
\hline \multicolumn{6}{|c|}{$10 \%$ Pin, Peak Power $=120 \mathrm{Mw}$} \\
\hline 100 & 144 & 240 & 73 & 50 & 35 \\
\hline 80 & 114 & 192 & 65 & 44 & 31 \\
\hline 60 & 86 & 144 & 57 & 39 & 27 \\
\hline 40 & 58 & 96 & 48 & 33 & 23 \\
\hline 20 & 27 & 48 & 35 & 23 & 15 \\
\hline 10 & 15 & 24 & 27 & 18 & 12 \\
\hline 5 & 8 & 12 & 22 & 14 & 9 \\
\hline
\end{tabular}


Table 12

Signal Levels Required to Meet the Statistical

Criteria with a Slot 0.025 in. $x 0.150$ in., Three

Lines per Crystal

\begin{tabular}{|c|c|c|c|c|c|}
\hline \multirow{2}{*}{$\begin{array}{c}\text { Power } \\
(\% \text { of peak })\end{array}$} & \multirow{2}{*}{$\mathbf{N}_{c}$} & \multirow{2}{*}{$\mathrm{N}_{\mathrm{s}}$} & \multicolumn{3}{|c|}{$\mathrm{N}_{\mathrm{s}}$ (required) } \\
\hline & & & $k=2$ & $\mathrm{k}=\sqrt{2}$ & $k=1$ \\
\hline \multicolumn{6}{|c|}{$3 \% \mathrm{Pin}$, Peak $=300 \mathrm{Mw}$} \\
\hline 100 & 1200 & 640 & 199 & 139 & 98 \\
\hline 80 & 960 & 510 & 178 & 125 & 88 \\
\hline 60 & 720 & 384 & 155 & 109 & 76 \\
\hline 40 & 480 & 256 & 128 & 89 & 63 \\
\hline 20 & 240 & 128 & 92 & 64 & 45 \\
\hline 10 & 120 & 64 & 67 & 46 & 32 \\
\hline 5 & 60 & 32 & 48 & 34 & 23 \\
\hline \multicolumn{6}{|c|}{$6 \%$ Pin, Peak $=150 \mathrm{Mw}$} \\
\hline 100 & 600 & 640 & 142 & 99 & 70 \\
\hline 80 & 480 & 512 & 128 & 89 & 63 \\
\hline 60 & 360 & 384 & 111 & 76 & 54 \\
\hline 40 & 240 & 256 & 92 & 64 & 45 \\
\hline 20 & 120 & 128 & 67 & 46 & 32 \\
\hline 10 & 60 & 64 & 48 & 34 & 23 \\
\hline 5 & 30 & 32 & 36 & 24 & 17 \\
\hline \multicolumn{6}{|c|}{$10 \%$ Pin, Peak Power $=120 \mathrm{Mw}$} \\
\hline 100 & 384 & 640 & 115 & 79 & 56 \\
\hline 80 & 306 & 512 & 103 & 71 & 50 \\
\hline 60 & 231 & 384 & 90 & 62 & 44 \\
\hline 40 & 153 & 256 & 75 & 52 & 35 \\
\hline 20 & 78 & 128 & 54 & 37 & 26 \\
\hline 10 & 38 & 64 & 40 & 38 & 18 \\
\hline 5 & 19 & 32 & 30 & 20 & 14 \\
\hline
\end{tabular}


Table 13

Signal Levels Required to Meet the Statistical Criteria with a Slot 0.025 in. $x 0.200$ in., Two

Lines per Crystal

\begin{tabular}{|c|c|c|c|c|c|}
\hline \multirow{2}{*}{$\begin{array}{c}\text { Power } \\
\text { (\% of peak) }\end{array}$} & \multirow{2}{*}{$\mathrm{N}_{\mathrm{c}}$} & \multirow{2}{*}{$\mathrm{N}_{\mathrm{s}}$} & \multicolumn{3}{|c|}{$\mathrm{N}_{\mathrm{s}}$ (required) } \\
\hline & & & $k=2$ & $\mathrm{k}=\sqrt{2}$ & $k=1$ \\
\hline \multicolumn{6}{|c|}{$3 \%$ Pin, Peak $=300 \mathrm{Mw}$} \\
\hline 100 & 3600 & 1920 & 339 & 240 & 168 \\
\hline 80 & 2880 & 1535 & 304 & 214 & 151 \\
\hline 60 & 2160 & 1150 & 264 & 184 & 129 \\
\hline 40 & 1440 & 768 & 216 & 151 & 107 \\
\hline 20 & 720 & 384 & 155 & 109 & 76 \\
\hline 10 & 360 & 192 & 111 & 76 & 54 \\
\hline 5 & 180 & 96 & 80 & 56 & 39 \\
\hline \multicolumn{6}{|c|}{$6 \%$ Pin, Peak Power $=150 \mathrm{Mw}$} \\
\hline 100 & 1800 & 1920 & 241 & 169 & 120 \\
\hline 80 & 1440 & 1535 & 216 & 151 & 107 \\
\hline 60 & 1080 & 1150 & 188 & 132 & 93 \\
\hline 40 & 720 & 768 & 155 & 109 & 76 \\
\hline 20 & 360 & 384 & 111 & 76 & 54 \\
\hline 10 & 180 & 192 & 80 & 56 & 39 \\
\hline 5 & 90 & 96 & 58 & 40 & 28 \\
\hline \multicolumn{6}{|c|}{$10 \%$ Pin, Peak Power $\approx 120 \mathrm{Mw}$} \\
\hline 100 & 1150 & 1920 & 194 & 136 & 96 \\
\hline 80 & 922 & 1535 & 174 & 122 & 85 \\
\hline 60 & 691 & 1150 & 152 & 106 & 75 \\
\hline 40 & 461 & 768 & 125 & 87 & 62 \\
\hline 20 & 230 & 384 & 90 & 62 & 44 \\
\hline 10 & 115 & 192 & 65 & 44 & 31 \\
\hline 5 & 58 & 96 & 48 & 33 & 23 \\
\hline
\end{tabular}


deflection plates of the two four-gun oscilloscopes. The strip film technique of recording would be used. The maximum film speed of the cameras is $500 \mathrm{~cm} / \mathrm{sec}$, and since there are three sweeps per framing time of $5 \mathrm{~ms}$, each sweep would be $8 \mathrm{~mm}$ long on the film. It can be shown that with obtainable scope spot sizes and photo-reduction factor, that the method of recording will not affect the space resolution of the system.

The magnitude of general background from uncollimated radiation cannot be accurately predicted for a Mark II system from the results of the August measurements. However, it appears reasonable that with the installation of the complete drum and suitable Buckey slits, this general background should be of the order of 20 to $40 \%$ of the container signal. Even with the inclusion of this amount of uncollimated background, the power level which just satisfies the criterion is only, increased slightly.

\section{VALUE OF DATA OBTAINED WITH THE MARK II SYSTEM}

In considering the value of data obtained with the Radiation Scanning Device, it is well to consider the mechanism of failure of fuel pins under transient studies in TREAT. In the dry pin tests, apparently, after the uranium melts and comes in contact with the stainless steel clad, the formation of eutectic mixture of $U$ and $F e$ weakens the clad sufficiently to cause failure. The high pressure, presumably from the boiling sodium bond at this high temperature, now expels the molten uranium from the entire pin with enough force that it deposits in one or more annuli on the colder surface of the graphite liner. It appears reasonable that pressures could be high enough to expel the uranium in times of the order of 10 to $15 \mathrm{~ms}$.

If this meltdown and expulsion occurs soon enough in the transient, the Radiation Scanning Device could give a reasonable picture of this type failure of a dry meltdown. If it is assumed that the entire pin is deposited within one vertical resolution element on the surface of a graphite liner, which is 1 in. I.D., the weight of uranium per viewed area on the surface would be approximately the same as per viewed area in the pin prior to meltdown. Since two surfaces of the liner would be viewed, the signal from the hole scanning this annulus would be twice that when scanning the intact pin at the same power level. It the uranium were deposited over the surface scanned by two levels of holes, the signal would be the same order of magnitude as from the pin. Therefore, from Table 12, a good picture of this failure for any of the tabulated pin enrichments could be obtained if the deposition on the liner were completed before power level had decreased by a factor of 10 below the peak. The holes scanning the sections above and below this fuel deposition would clearly show the absence of fuel.

The signal levels in the stagnant sodium case are similar to the above dry pin case, but the failure mechanism could vary because of different constraints. The static measurements with a sodium capsule indicated that the sodium makes a negligible contribution above that from' the container; however, the sodium will provide a viscous dampening to the flow of molten uranium from the ruptured pin. The second constraint is the much smaller volume into which the molten uranium can be expelled because of the $0.3-\mathrm{in}$. -I.D. stainless steel crucible. The volume expelled into for the dry pin case is fifteen times that of the stagnant sodium case. In fact, the region between the clad and crucible will be filled to a height of $4 \mathrm{in}$. with complete expulsion of uranium from the fuel pin. For the flowing sodium case, the densities of accumulation will be less but otherwise the mechanism of pin failure is similar. It can be stated that if densities of accumulation per viewed area occur of the order of magnitude of pin densities or greater, the scanning device should easily show this, provided it occurs before the power level drops by a factor of 10 to 20 , even for the $3 \%$ pin. If the failure of a $6 \%$ pin occurred when the power level had dropped by a factor of 5 , accumulations per viewed area of $50 \%$ of pin densities would meet the $k=2$ criterion (or $35 \%$ for $k=\sqrt{2}$, or $25 \%$ for $k=1$ ). However, for the same pin, if the 
failure does not occur until the power level has dropped by a factor of 10 , it will take accumulations per viewed area of $75 \%$ of pin densities to meet the $\mathrm{k}=2$ criterion (or $50 \%$ for $\mathrm{k}=\sqrt{2}$, or $35 \%$ for $\mathrm{k}=1$ ).

The scanning device is less effective when viewing clusters of closely packed pins than for single pins or widely separated pins. If all the pins of the cluster melted and the material was expelled from the pins, the system could probably see this as for single pins. For a large cluster of pins if only the inner pins fail, these would be shielded by the remaining intact pins, so any movement of uranium could not be seen. The possibility of viewing the propagation of pin failures is not very great because this propagation time is probably too long to be covered by the dynamic range of the system.

\section{CONCLUSIONS}

It can be concluded that the construction of a gamma-ray pinhole camera, ${ }^{*}$ Radiation Scanning Device, or similar system to view a pure gamma source is reasonably straightforward, with the obtainable space and time resolution primarily limited by the source strength. However, the design becomes more complex when the gamma source to be viewed is under strong gamma and neutron irradiation from external sources. In particular, the container required in the TREAT meltdown experiments for safety reasons became in the combined gamma and neutron flux at the time of interest a source of comparable strength to that of the pin to be viewed. It can be stated that natural uranium pins viewed through this container exhibit negligible contrast regardless of the radiation viewing system. A Radiation Scanning Device could be constructed to view pins enriched to 3 to $6 \%$ of $\mathrm{U}^{235}$ with a space resolution of $0.15 \mathrm{in}$. horizontally and $0.75 \mathrm{in}$. vertically with a time resolution of $5 \mathrm{~ms}$. This system could follow the molten fuel if meltdown occurs before the power drops below the peak by more than a factor of 5 and the viewed density of fuel remains within an order of magnitude of the original density.

\section{ACKNOWLEDGMENTS}

The authors acknowledge with thanks and appreciation the assistance of many Laboratory personnel in this project. Mr. J. M. Frame made many contributions on the mechanical feasibility of the system and suggested possible materials to fabricate components. Mr. R. S. Rovinski designed the mechanical parts of the system and supervised its construction and assembly by the machine shop. Messrs. G. F. Wall, M. N. Fischer, R. L. Grant, and J. J. Brotzman assisted in the design, construction, and checkout of the electronics system. Mr. C. E. Thompson modified the automatic film developer and checked out the development technique. The authors are deeply indebted to Mr. R. L. Borkey for assistance during the construction and assembly of the system, the measurements at the NRL Reactor, the balancing of the drum, and the preparations for shipment. We gratefully acknowledge the assistance of Dr. J. O. Elliot and Mr. E. I. Nowstrup and their staff for the use of the NRL Reactor. We are indebted to the assistance and cooperation of Mr. J. F. Boland and the TREAT operating staff during the measurements with the TREAT reactor. Many helpful discussions were held with Drs. C. V. Strain, W. R. Faust, V. J. Linnenbom, and Mr. D. C. Cook. In addition, Dr. C. V. Strain derived the statistical criteria discussed in Appendix C.

\footnotetext{
*D. E. Copeland and E. W. Benjamin, Nucleonics 5(No. 2):44, Aug. 1949;

W. V. Mayneord, C. Turner, S. P. Newbery, and H. J. Hodt, Nature 168:762 (1951);

H. O. Anger, Rev. Sci. Instr. 29:27 (1958);

A. Cohen, Rev. Sci. Instr. 31:29 (1960).
} 


\section{APPENDIX A}

\section{DESIGN AND FABRICATION OF MARK I DRUM}

The design of the drum must (a) maintain a proper balance between signal intensity and space resolution and (b) provide adequate attenuation for uncollimated radiation. Although the signal intensity is a strong function of the radius of the collimating hole, large radii are eliminated because of the requirement of good space resolution. Space resolution favors smaller radii of collimating holes and/or longer holes (i.e., larger diameter of a drum). The drum diameter was taken as 22 in., which is near the maximum allowable under criterian $1(p .8)$. It is desirable to keep the distance between the drums and test chamber small, but to meet criterian (1) and provide necessary shielding requires a distance of at least $108 \mathrm{in.} \mathrm{Actually} \mathrm{the} \mathrm{signal} \mathrm{strength} \mathrm{through} \mathrm{a} \mathrm{collimating} \mathrm{hole} \mathrm{from}$ a uniform plane source does not vary with a change in the separation between drum and source because a decrease in solid angle is compensated by an increase in the area viewed (with decreased resolution) and vice versa.

Originally, it was conceived that the rotating drum would be solid and fabricated from a heavy material such as lead or a tungsten alloy to provide the radiation attenuation. A tungsten alloy would provide the best attenuation (even including neutron effects) but its high cost and difficult machinability ruled it out of consideration. It seemed impossible to drill long straight holes in a solid block of lead but straight holes can be obtained by casting lead around stretched piano wires and later extracting the wires. This technique was not favorable for the entire drum because of the contraction of lead upon solidification and the possibility of the flow of lead at high speeds of rotation. Therefore, it was decided to attempt some method of confining the heavy material.

It was decided to fabricate the drum by drilling holes in two concentric brass shells (22 in. and $7 \mathrm{in}$. in diameter), insert straight steel rods with 15 -mil holes down the center, and then pot the drum with a heavy material to provide the attenuation. A lead-bismuth alloy with negligible expansion or contraction on solidification seemed ideal for this potting but closer investigation disclosed an expansion starting several hours after solidification, which eliminated this material. Mercury seemed a good possibility but the difficulty in sealing all the holes seemed formidable. However, since at this time it seemed that there would be sufficient bowing of the rods over the space between the two concentric shells an intermediate shell was added. It was decided to fill the outer region with lead shot potted with an apoxy resin. The apoxy was loaded with boron to provide thermal neutron absorption. Since it appeared that the apoxy resin of the outer region extending over greater than three inches along the rod should be an effective seal, an attempt was made to fill the inner region with mercury to get additional mass in the drum. However, despite careful insertion of the rods, sealing each one with apoxy and the potted lead cylindrical shell, during rotation the mercury leaked over into the potted material and was expelled out along many rods, creating a health hazard and resulting in a shifting balance of the drum. The mercury was later replaced by a fine lead shot. The Mark I drum apparently had a staisfactory gamma and thermal neutron attenuation but was quite inadequate in fast neutron attenuation. 


\section{APPENDIX B}

\section{OPTIMUM DRUM DESIGN}

To obtain the optimum drum parameters for fixed space resolution, without the restriction that the entire assembly fit the access hole, the following arguments were developed. A circular collimating hole with radius $r$ in a drum of diameter $d$ views a source plane at distance $\mathrm{D}$ from the close edge of the drum (see Fig. B1).

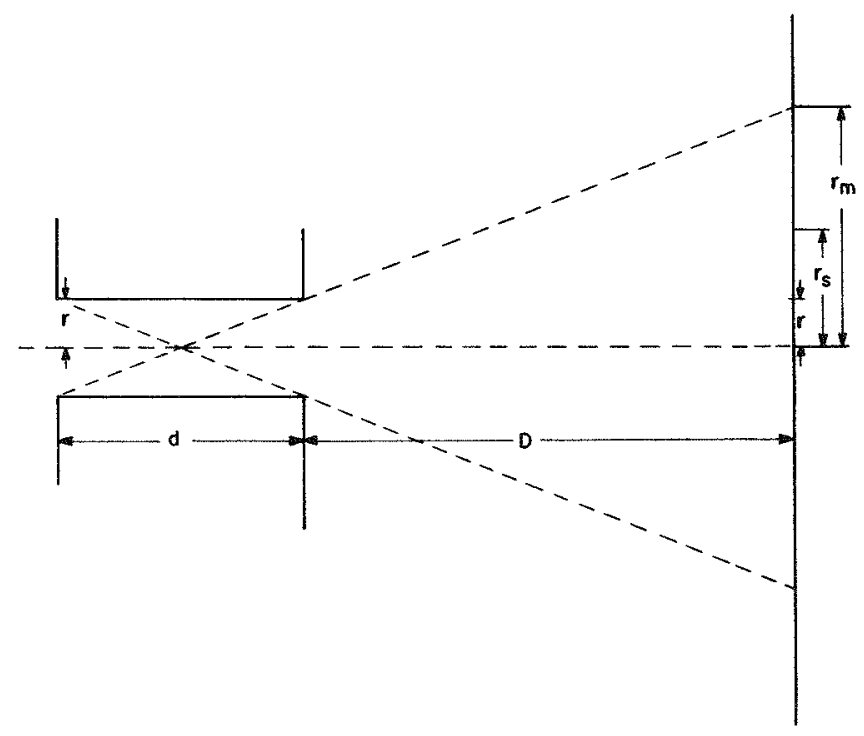

Fig. Bl - Geometry for a cylindrical collimating hole viewing a uniform source

Points on the source plane within a radius $\mathbf{r}$ transmit through the hole with a solid angle given by the area of the hole divided by the distance squared from the source to the far edge of the drum. Points beyond a radius $r$, transmit through the hole with constantly decreasing solid angle until it reaches zero at $r=r_{m}$. The resolution (width at halfmaximum $\left.=2 r_{s}\right)$ and the effective source area $\left(\pi r_{s}^{2}\right)$ are approximately defined by $r_{s} \approx 1 / 2 r_{m}$. For the same resolution, the collimator radius $r$, and consequently the signal transmitted, can be increased if the drum diameter is also increased.

The signal radiation passing through the collimating hole is given by

$$
\mathrm{S}=\frac{\mathrm{BA}_{\mathrm{s}} \pi \mathrm{r}^{2}}{4 \pi(\mathrm{d}+\mathrm{D})^{2}}
$$


where

$$
\begin{aligned}
B & =\text { source intensity per unit area } \\
A_{s} & =\text { effective source area }=\pi r_{s}^{2} \approx \pi r_{m}^{2} / 4
\end{aligned}
$$

Therefore

$$
S=\frac{B_{s}^{2} r^{2}}{4(d+D)^{2}}
$$

From similar triangles

$$
\begin{aligned}
& \frac{2 r}{d}=\frac{r_{m}}{D+\frac{d}{2}} \approx \frac{2 r_{s}}{D+\frac{d}{2}} \\
& r=\frac{r_{s} d}{D+\frac{d}{2}}
\end{aligned}
$$

Therefore

$$
S=\frac{B r_{s}^{4}}{4} \cdot \frac{d^{2}}{\left(D+\frac{d}{2}\right)^{2}(D+d)^{2}}
$$

To maximize $\mathrm{s}$ with respect to $\mathrm{d}$,

$$
\begin{gathered}
\frac{d S}{d d} a \frac{2 d}{\left(D+\frac{d}{2}\right)^{2}(D+d)^{2}}-\frac{d^{2}}{\left(D+\frac{d}{2}\right)^{3}(D+d)^{2}}-\frac{2 d^{2}}{\left(D+\frac{d}{2}\right)^{2}(D+d)^{3}}=0 \\
2-\frac{d}{D+\frac{d}{2}}-\frac{2 d}{D+d}=0 \\
2 D^{2}-d^{2}=0 \\
d=\sqrt{2 D} .
\end{gathered}
$$

To allow for any sizable increase in the drum diameter in the TREAT geometry, the minimum $D$ is 126 in. Therefore, an optimum $d$ would be 178 in., with a ratio of maximum signal to present signal of 7.1 . Of course such a drum is quite impractical and it is to be noted that the gain is not large. 
Next the question was asked if any gain could be obtained by replacing the cylindrical hole by a section of a truncated conic section as shown in Fig. B2. If $r_{2}$ is larger than $r_{1}$, the solid angle is increased to give a higher signal strength. It is assumed that

$$
\frac{r_{1}}{D}=\frac{r_{2}}{D+d}
$$

From similar triangles

$$
\frac{r_{m}+r_{2}}{D+d}=\frac{r_{1}+r_{2}}{d} \text {. }
$$

From these two relations

$$
\begin{aligned}
& r_{1}=\frac{r_{m} d}{2(D+d)} \approx \frac{r_{s} d}{D+d} \\
& r_{2}=\frac{r_{m} d}{2 D}=\frac{r_{s} d}{D} .
\end{aligned}
$$

Considering $r_{1}$ as limiting the solid angle

$$
\mathrm{S}_{\mathrm{free}}<\frac{\mathrm{Br} \mathrm{s}^{2}}{4} \frac{\pi \mathrm{r}_{2}^{2}}{(\mathrm{D}+\mathrm{d})^{2}}=\frac{\mathrm{B} \mathrm{r}_{\mathrm{s}}^{4} \mathrm{~d}^{2}}{(\mathrm{D}+\mathrm{d})^{2} \mathrm{D}^{2}}
$$

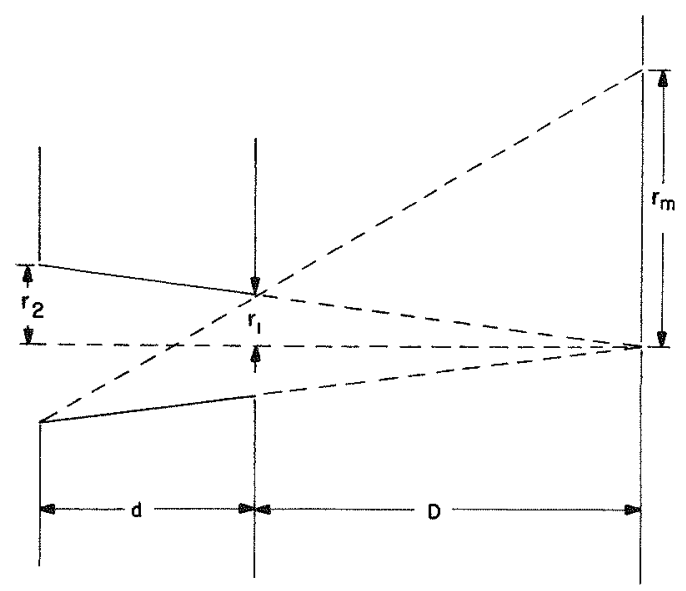

Fig. B2 - Geometry for a conic collimating hole viewing a uniform source 
Therefore

$$
\frac{S_{\text {free }}}{S_{\text {drum }}}<\frac{\left(D+\frac{d}{2}\right)^{2}(D+d)^{2}}{(D+d)^{2} D^{2}}=\left(1+\frac{d}{2 D}\right)^{2} .
$$

For the optimum drum $d=\sqrt{2} D$, the additional gain is less than 2.9. Here again the engineering difficulties would be tremendous with almost negligible gains. 


\section{APPENDIX C}

STATISTICAL CRITERIA

In order to establish criteria for the signal level required to distinguish a fuel pin in poor contrast with background, statistical fluctuations must be considered. The "video" signal level obtained during a scan across a fuel pin in a container will be a function of many things of which some of the more important are:

1. Gamma-ray brightness of the pin-both number of events and gamma-ray energy associated with each event are important.

2. Gamma-ray brightness of the container through which the pin is viewed-both number and energy are again important.

3. Uncollimated gamma-ray background-both number and energy are again important.

4. Geometry of the scanning collimator.

5. Scanning speed.

6. Many instrumentation factors of which the following appear most important:

a. Pulse height, that is, the amount of energy delivered to the detecting crystal as a function of gamma-ray energy.

b. Electrical integration time employed between the sodium iodide crystal and the display and associated effects.

c. The quality of the recorded display.

The measurements taken at the TREAT reactor show the counting rate and the pulse height spectra obtained through a particular collimator when viewing fuel pins and various other substances at a given steady-state power level. These furnish data on the combination of each of the first two quantities mentioned above (1 and 2) combined with the corresponding pulse height spectra (6a).

To attack the problem of estimating whether a given experimental arrangement will give a useful record, it seems appropriate to first analyze the statistical variations which are present both in the number of counts expected in the detector in a given interval of time and the statistical effects associated with the pulse height distributions. After this the other effects, which unfortunately will always degrade the final record, can be taken into account at least in an approximate way.

Considering first the statistical fluctuation in the number of counts expected within a given period, it is convenient to write

$$
\Delta \mathrm{N}=\mathrm{k}(\overline{\mathrm{N}})^{1 / 2}
$$

in which $\overline{\mathrm{N}}$ is the average number of counts expected and $\Delta \mathrm{N}$ is a deviation from $\overline{\mathrm{N}}$ exceeded on the average a percentage of times depending on the choice of $\mathrm{k}$. For example, if $\mathrm{k}=1$, the deviation is greater than $\Delta \mathrm{N}$ in $31.7 \%$ of the measurements, and if $\mathrm{k}=2$, in only $4.55 \%$. 
In this experiment we will observe a total signal $\mathrm{E}$, which is the sum of the pulse heights associated with each individual event of the $\mathrm{N}$ events which have taken place in the time period over which the equipment will integrate. If measured in terms of the energy deposited in the $\mathrm{NaI}(\mathrm{Tl})$ crystal, $\mathrm{E}$ is the total energy in Mev deposited by interaction of gamma rays. Thus, it depends on the energy of each gamma impinging on the detector, the efficiency of transfer of energy to the crystal (these two effects make up the pulse height spectrum), and the number of gammas incident in the time involved. This total signal, $\mathrm{E}$, for $\mathrm{N}$ gamma rays interacting in the crystal can be written as

$$
E=\sum_{i=1}^{N} p_{i}
$$

in which $p_{i}$ is the energy deposited in the crystal by the $i$ th gamma ray.

When considering the general case where the pulse heights are defined by a distribution, it is convenient to define $\eta \mathrm{dp}$ as the probability of the occurrence of a pulse height of magnitude between $p$ and $p+d p$ subject to the normalization

$$
\int_{0}^{\infty} \eta \mathrm{dp}=1
$$

A more general analysis than the illustrative one given above leads to the results

$$
\overline{\mathrm{E}}=\overline{\mathrm{N}} \int_{0}^{\infty} \eta p \mathrm{dp}
$$

and

$$
\Delta E=k\left(\bar{N} \int_{0}^{g} \eta p^{2} d p\right)^{1 / 2}
$$

For convenience, the integrals will be signified by

$$
\mathrm{p}_{1}=\int_{0}^{\infty} \eta \mathrm{pdp}
$$

and

$$
\mathrm{p}_{2}=\int_{0}^{\infty} \eta \mathrm{p}^{2} \mathrm{dp}
$$

Considerable attention has been given to the question of how large the values of count ing rates must be before the considerations used in deriving the expression for the combined number and pulse height variations would be valid. Equations (C4) and (C5) indicate that 
the statistical variation in $\mathrm{E}$ is predominately due to the variation in $\mathrm{N}$, with the variation of pulse height playing a secondary role. Thus one would expect the validity for small values of $N$ to correspond to that for the more usual relation $\Delta N=k(\bar{N})^{1 / 2}$, a result verified by calculations not reported here.

In the proposed measurement, the radiation from the test section will be scanned by the rotation of a collimator. It is planned to integrate (i.e., add) all of the pulses received while the collimator scans across approximately one resolution width of the source. From the collimator geometry, scanning speed, and other parameters of the experiment, the average number of counts obtained and added while scanning the container can be predicted. Similarly, the number of counts while scanning across a pin in its container can be predicted. These will be designated as $\overline{\mathrm{N}}_{\mathrm{c}}$ and $\overline{\mathrm{N}}_{\mathrm{t}}$, respectively.

The total signal, $\mathrm{E}_{\mathrm{t}}$, is the sum of two components, namely, a signal from the container and a signal from the fuel pin. These components have been separated by assuming the container component equal to that observed immediately to either side of the total pin plus container signal, and the pin signal, designated below as $\mathrm{E}_{\mathrm{s}}$, as the remainder of $\mathrm{E}_{\mathrm{t}}$. In addition to the observed counting rates, pulse height spectra are available from the data referred to previously.

Since the purpose of the experiment is to determine whether a fuel pin is intact and, if not intact, to follow the movement of the fuel, a minimum requirement is to know that the pin is still intact at the time associated with a given scan. From a single scan, a comparison of essentially one measurement of $\mathbf{E}_{t}$ can be made with a neighboring (or perhaps a few neighboring) values of $E_{c}$. It is necessary that in a large fraction of the scans that the measured value of $\mathrm{E}_{\mathrm{t}}$ be larger than a neighboring value of $\mathrm{E}_{\mathrm{c}}$.

Groundwork required to arrive at the necessary conditions will be developed before formulating a criterion for the minimum values of $\mathbf{E}_{t}$ which can be permitted in the presence of a given value of $\mathrm{E}_{\mathrm{c}}$. In this process, it is useful to set

$$
\overline{\mathrm{E}}_{\mathrm{t}}-\Delta \mathrm{E}_{\mathrm{t}}=\overline{\mathrm{E}}_{\mathrm{c}}+\Delta \mathrm{E}_{\mathrm{c}} \text {. }
$$

The quantity on the left is a low value of the total signal chosen such that a lower value will be obtained only in a small fraction of individual scans; the exact fraction depends, of course, on the value of $\mathrm{k}$ used in computing the $\Delta \mathrm{E}_{\mathrm{t}}$. Correspondingly, the right member is a high value of container signal which will be exceeded in a percentage of cases determined by the value of $\mathrm{k}$ used in computing $\Delta \mathrm{E}_{\mathrm{c}}$.

Expressed in terms of its two components, $E_{t}$ can be written as

$$
\overline{\mathrm{E}}_{\mathrm{t}}=\overline{\mathrm{N}}_{\mathrm{c}} \mathrm{P}_{1 \mathrm{c}}+\overline{\mathrm{N}}_{\mathrm{s}} \mathrm{P}_{1 \mathrm{~s}}
$$

and $\Delta E_{\varepsilon}$, using an rms sum of its components, as

$$
\Delta E_{t}=\left(k_{c}^{2} \bar{N}_{c} P_{2 c}+k_{s}^{2} \bar{N}_{s} P_{2 s}\right)^{1 / 2}
$$

Using these relations, and the corresponding ones for $\overline{\mathrm{E}}_{\mathrm{c}}$ and $\Delta \mathrm{E}_{\mathrm{c}}$, Eq. (C8) becomes

$$
\begin{gathered}
\overline{\mathrm{N}}_{\mathrm{c}} \mathrm{P}_{1 \mathrm{c}}+\overline{\mathrm{N}}_{\mathrm{s}} \mathrm{P}_{1 \mathrm{~s}}-\left(\mathrm{k}_{\mathrm{c}}^{2} \overline{\mathrm{N}}_{\mathrm{c}} \mathrm{P}_{2 \mathrm{c}}+\mathrm{k}_{\mathrm{s}}^{2} \overline{\mathrm{N}}_{\mathrm{s}} \mathrm{P}_{2 \mathrm{~s}}\right)^{1 / 2} \\
=\overline{\mathrm{N}}_{\mathrm{c}} \mathrm{P}_{1 \mathrm{c}}+\mathrm{k}_{\mathrm{c}}\left(\mathrm{P}_{2 \mathrm{c}} \overline{\mathrm{N}}_{\mathrm{c}}\right)^{1 / 2}
\end{gathered}
$$


By simplifying and solving for $\overline{\mathrm{N}}_{\mathrm{s}}, \mathrm{Eq} .(\mathrm{C} 11)$ becomes

$$
\overrightarrow{\mathrm{N}}_{\mathrm{s}}=\mathrm{k}_{\mathrm{s}}^{2} \frac{\mathrm{P}_{2 \mathrm{~s}}}{\mathrm{P}_{1 \mathrm{~s}}^{2}}+2 \mathrm{k}_{\mathrm{c}} \frac{\left(\mathrm{P}_{2 \mathrm{c}}\right)^{1 / 2}}{\mathrm{P}_{1 \mathrm{~s}}}\left(\overline{\mathrm{N}}_{\mathrm{c}}\right)^{1 / 2}
$$

It is convenient to define dimensionless constants characteristic of the pulse height spectra, namely,

$$
F_{s} \equiv \frac{\left(P_{2 s}\right)^{1 / 2}}{P_{1 c}} \text { and } F_{c}=\frac{\left(P_{2 c}\right)^{1 / 2}}{P_{1 c}}
$$

thus permitting the expression

$$
\overline{\mathrm{N}}_{\mathrm{s}}=\mathrm{k}_{\mathrm{s}}^{2} \mathrm{~F}_{\mathrm{s}}^{2}+2 \mathrm{k}_{\mathrm{c}} \mathrm{F}_{\mathrm{c}} \frac{\mathrm{P}_{1 \mathrm{c}}}{\mathrm{P}_{1 \mathrm{~s}}}\left(\overline{\mathrm{N}}_{\mathrm{c}}\right)^{1 / 2}
$$

This equation can be simplified for the values of the k's even as large as 2 because the values of the spectra parameters for the materials used in the test section are

$$
\begin{aligned}
& 1.2 \leq \mathrm{F} \leq 1.4 \\
& 1.0 \leq \frac{\mathrm{P}_{1 \mathrm{c}}}{\mathrm{P}_{1 \mathrm{~s}}} \leq 2.0
\end{aligned}
$$

which will make

$$
\mathrm{k}_{\mathrm{s}}^{2} \mathrm{~F}_{\mathrm{s}}^{2} \ll 2 \mathrm{k}_{\mathrm{c}} \mathrm{F}_{\mathrm{c}} \frac{\mathrm{P}_{1 \mathrm{c}}}{\mathrm{P} 1 \mathrm{~s}}\left(\overrightarrow{\mathrm{N}}_{\mathrm{c}}\right)^{1 / 2}
$$

unless $\overline{\mathrm{N}}_{\mathrm{c}}$ is very small. Therefore, for the situations imposed for which $\overline{\mathrm{N}}_{c} \gg 1$,

$$
\overline{\mathrm{N}}_{\mathrm{s}} \geq 2 \mathrm{k}_{\mathrm{c}} \mathrm{F}_{\mathrm{c}} \frac{\mathrm{P}_{1 \mathrm{c}}}{\mathrm{P}_{1 \mathrm{~s}}}\left(\overline{\mathrm{N}}_{\mathrm{c}}\right)^{1 / 2}
$$

and

$$
\left[\left(\frac{\bar{N}_{s}}{\bar{N}_{c}}\right) \bar{N}_{s}\right]^{1 / 2} \geq k U
$$

where $U=$ constant $=2 F_{c} \frac{P_{1 c}}{P_{1 s}}$. 
This equation shows that the magnitude of the signal $\mathrm{N}_{\mathrm{s}}$ must be large if the pin signal to container signal ratio is small.

Formulation of a criterion is difficult and, of course, depends on what minimumamount of information will be acceptable. If one accepts the rather minimal objective of knowing whether a fuel pin is in place and, further, is willing to rely, if necessary, on more than one scan (or possibly more than one frame), then perhaps the criterion $\mathrm{k}_{\mathrm{s}}=\mathrm{k}_{\mathrm{c}}=1$ is acceptable. If, however, one would like to know in more than $95 \%$ of the individual scans whether a pin were present or not, then $\mathrm{k}_{\mathrm{s}}$ and $\mathrm{k}_{\mathrm{c}}$ should be set equal to about $\sqrt{2}$. Larger values of the k's would, of course, increase reliability.

The question of criterion can be viewed in a different light according to the following argument. It would be desirable to be able to detect the presence (or absence) of some fraction of a fuel pin within a given spatial resolution element. In this case, the criterion could be formulated by asking that the signal, $\mathrm{N}_{\mathrm{s}}$, be a multiple of that obtained from the criterion discussed above, and this multiple, of course, would be the reciprocal of the fraction of a fuel pin which one desired to see. 


\section{APPENDIX D}

\section{SIGNAL INTENSITY CALCULATION}

If the collimator is made of rectangular holes of height $h$ and width $w$, the signal radiation passing through the hole is given by (see Appendix B)

$$
S=\frac{B h w\left(r_{h} r_{v}\right)^{2}}{4 \pi(d+D)^{2}}
$$

where $r_{h}$ and $r$ are the horizontal and vertical space resolutions which are fundamental parameters in the drum design. We can express $h$ and $w$ in terms of the respective space resolutions since

$$
\begin{aligned}
& \frac{\mathrm{h}}{\mathrm{d}} \approx \frac{\mathrm{r}_{\mathrm{h}}}{\mathrm{D}+\frac{\mathrm{d}}{2}} \\
& \frac{\mathrm{w}}{\mathrm{d}}=\frac{\mathrm{r}_{\mathrm{v}}}{\mathrm{D}+\frac{\mathrm{d}}{2}} .
\end{aligned}
$$

Therefore

$$
S=\frac{B\left(r_{h} r_{v}\right)^{2} d^{2}}{4 \pi\left(D+\frac{d}{2}\right)^{2}(d+D)^{2}} .
$$

The true pin signal is proportional to the above signal factor as well as factors which can be expressed as

$$
\mathrm{N}_{\mathrm{s}}=\mathrm{S}_{\mathrm{s}} \in \mathrm{T}_{\mathrm{e}}
$$

where $\epsilon$ is the detector efficiency, which will be considered constant for any detector but is a function of gamma-ray energy and crystal size. $T_{e}$ is the time to scan across a horizontal space resolution element. For a system with $M$ detectors, the time to scan a horizontal resolution element is

$$
T_{e}=\frac{T_{f} M}{R}
$$

where $R=$ total number of resolution elements in the picture and $T_{f}$ is the framing time. 
The equation

$$
\mathrm{R}=\frac{\gamma \mathrm{A}}{\mathrm{r}_{\mathrm{h}} \mathrm{r}_{\mathrm{v}}},
$$

where $\mathrm{A}=$ total area viewed at the source and $\gamma$ defines the degree of vertical overlap or of vertical gap, combines with the preceding equation to give

$$
\mathrm{T}_{\mathrm{e}}=\frac{\mathrm{T}_{\mathrm{f}} \mathrm{M} \mathrm{r}_{\mathrm{h}} \mathrm{r}_{\mathrm{v}}}{\gamma \mathrm{A}} .
$$

Therefore

$$
\begin{aligned}
& N_{s}=\frac{S_{s} \in T_{f} M r_{h} r_{v}}{\gamma A} \\
& N_{s}=\frac{B_{s} \in T_{f} M}{\gamma A} \frac{\left(r_{h} r_{v}\right)^{3} d^{2}}{4 \pi\left(D+\frac{d}{2}\right)^{2}(D+d)^{2}} .
\end{aligned}
$$

Except for the brightness factor, the container signal is equal to an identical expression, because the same detectors view both the container and pin.

Obviously the pin signal could be increased by increasing any of the factors in the numerator and or decreasing either $\gamma, \mathbf{A}$, or $\mathbf{D}$, but because of practical considerations this is not possible. The brightness factor is very significant because an increase in the pin brightness will not result in an increase in container brightness. It is estimated that there is no gain beyond a 10\% enrichment because the pin is then very black to thermal neutrons. The limitations on $d$ and $D$ have been previously discussed in Appendix B. An increase of the framing time directly reduces the time resolution, which is undesirable. Theoretically, the number of detectors can be increased without any other losses, but a practical design, besides the difficulties of calibrating and equalizing a large number of detectors, will require smaller crystals and thereby reduce the crystal detector efficiency. An increase in $\mathrm{r}_{\mathrm{h}}$ beyond the diameter of the fuel pin $\left(0.15 \mathrm{in}\right.$.) will favor $\mathrm{N}_{c}$ more than $\mathrm{N}_{\mathrm{s}}$. Therefore, a substantial gain can be had by an increase in the vertical space resolution $\left(r_{v}\right)$ because of the cubic dependence. 


\section{APPENDIX E}

\section{CALCULATION OF THE RATIO OF THE PIN-IN-CONTAINER \\ SIGNAL TO THE CONTAINER SIGNAL}

The signal obtained from a gamma-ray scanning system viewing a test chamber containing a fuel pin will have several components. In order to distinguish the pin signal from the container signal and other background effects, it should stand in strong contrast with these terms, i.e.,

$$
N_{t}-N_{c} \gg N_{c}
$$

where

$$
\begin{aligned}
\mathrm{N}_{\mathrm{t}}= & \text { the total number of counts per integration time, which should be equal to the } \\
& \text { time to scan a horizontal resolution element when scanning directly across } \\
\text { the fuel pin within its container } & \\
\mathrm{N}_{\mathrm{c}}= & \text { the number of counts per integration time when scanning across the container. }
\end{aligned}
$$

Both $\mathrm{N}_{\mathrm{t}}$ and $\mathrm{N}_{\mathrm{c}}$ contain an uncollimated background, but for this discussion, it will be considered negligible or just as part of $N_{c}$. The pin-in-container signal $N_{s}^{\prime}$ will be defined as

$$
\mathrm{N}_{\mathrm{s}}^{\prime}=\mathrm{N}_{\mathrm{t}}-\mathrm{N}_{\mathrm{c}} \text {. }
$$

$\mathrm{N}_{\mathrm{s}}^{\prime}$ is less than the true pin signal $\mathrm{N}_{\mathrm{s}}$ for two reasons. Firstly, the true pin signal is attenuated by a factor of 1.77 by the standard container shown in Fig. 34 . Secondly, the pin attenuates the radiation from the container in back of the pin by a factor of 1.5 so that in effect the pin signal does not ride on top of the container signal but sits in a depression.

The first effect is rather straightforward, but the second effect profoundly influences the magnitude of $\mathrm{N}_{\mathrm{s}}^{\prime}$. This will be illustrated in what follows. The container signal without fuel pin is made up of the radiation from the front of the container plus the radiation from the back of the container, i.e.,

$$
N_{c}=F+B .
$$

But $\mathrm{F}$ and $\mathrm{B}$ are equal except for the attenuation of $\mathrm{B}$ by the front part of the container:

$$
F=a B
$$

where $\alpha$ is equal to container attenuation factor. Therefore

$$
N_{c}=F\left(1+\frac{1}{a}\right)
$$

and

$$
N_{s}^{\prime}=N_{t}-F\left(1+\frac{1}{a}\right)
$$


But $N_{t}$ is equal to the sum of front container signal, the true pin signal attenuated by the container, and the back container signal attenuated by the pin:

$$
\begin{aligned}
& N_{t}=F+\frac{N_{s}}{\alpha}+\frac{B}{\beta} \\
& N_{t}=F+\frac{N_{s}}{\alpha}+\frac{F}{a \beta} \\
& N_{t}=\frac{N_{s}}{a}+F\left(1+\frac{1}{\alpha \beta}\right)
\end{aligned}
$$

where $\beta=$ pin attenuation factor. Substituting this in the definition of $\mathrm{N}_{\mathrm{s}}^{\prime}$ we have

$$
N_{s}^{\prime}=\frac{1}{a}\left[\frac{N_{s}}{a}-\frac{F}{\alpha}\left(1-\frac{1}{\beta}\right)\right] .
$$

Eliminating $\mathrm{F}$ we have

$$
\mathrm{N}_{\mathrm{s}}^{\prime}=\frac{1}{\alpha} \mathrm{N}_{\mathrm{s}}-\frac{(\beta-1)}{\beta(1+\alpha)} \mathrm{N}_{\mathrm{c}}
$$

Or in terms of signal to container ratios, we have

$$
\left(\frac{N_{s}^{\prime}}{N_{c}}\right)=\frac{1}{\alpha}\left(\frac{N_{s}}{N_{c}}\right)-\frac{(\beta-1)}{\beta(1+a)} .
$$

For the standard container $a$ is equal to 1.77 and $\beta$ is equal to 1.5 :

$$
\frac{N_{s}^{\prime}}{N_{c}}=56 \% \frac{N_{s}}{N_{c}}-12 \% .
$$

That is, the depression the pin signal sits in is $12 \%$ of the container signal. Therefore, if the container signal is large compared to the true pin signal, the pin-in-container signal can be completely obscured. If the pin signal to container ratio is $12 / 56$ or $21 \%, \mathrm{~N}_{\mathrm{s}}^{\prime}=0$. A smaller ratio will result in a negative $\mathrm{N}_{s}$ or a depression will be visible. The maximum value of the depression will be $12 \% \mathrm{~N}_{c}$.

For a $6 \% \mathrm{U}^{235}$ fuel pin in the standard container

$$
\frac{\mathrm{N}_{\mathrm{s}}}{\mathrm{N}_{\mathrm{c}}}=2.1
$$


and therefore

$$
\frac{N_{s}^{\prime}}{N_{c}}=1.05
$$

But for a natural uranium pin

$$
\frac{\mathrm{N}_{\mathrm{s}}}{\mathrm{N}_{\mathrm{c}}}=\frac{2.1}{4}=0.505
$$

and

$$
\frac{\mathrm{N}_{\mathrm{s}}^{\prime}}{\mathrm{N}_{\mathrm{c}}}=0.16
$$

The true pin signal to container dropped a factor of 4 , but the pin-in-container signal to container ratio dropped a factor of 6.5. The serious effect that the container has on the signal to background ratio can be further illustrated in the following manner. A $6 \% \mathrm{U}^{235}$ pin in a zircaloy capsule but not in the standard container was measured in February 1960 and the measured true pin signal to container ratio was 2.78 ; the attenuation factor was 1.16 vs 1.77 for the standard container. The pin-in-container signal to container ratio was therefore 2.24, more than double the ratio for the standard container even though the ratio is better by a factor of only 1.32. The apparent signal to container for a natural uranium pin is 0.43 , which is 2.7 times better than for the standard container. 